\title{
Cytomegalovirus and vascular pathology
}

Citation for published version (APA):

Persoons, M. C. J. S. (1998). Cytomegalovirus and vascular pathology. [Doctoral Thesis, Maastricht University]. Universiteit Maastricht. https://doi.org/10.26481/dis.19981030mp

Document status and date:

Published: 01/01/1998

DOI:

10.26481/dis. $19981030 \mathrm{mp}$

Document Version:

Publisher's PDF, also known as Version of record

\section{Please check the document version of this publication:}

- A submitted manuscript is the version of the article upon submission and before peer-review. There can be important differences between the submitted version and the official published version of record.

People interested in the research are advised to contact the author for the final version of the publication, or visit the DOI to the publisher's website.

- The final author version and the galley proof are versions of the publication after peer review.

- The final published version features the final layout of the paper including the volume, issue and page numbers.

Link to publication

\footnotetext{
General rights rights.

- You may freely distribute the URL identifying the publication in the public portal. please follow below link for the End User Agreement:

www.umlib.nl/taverne-license

Take down policy

If you believe that this document breaches copyright please contact us at:

repository@maastrichtuniversity.nl

providing details and we will investigate your claim.
}

Copyright and moral rights for the publications made accessible in the public portal are retained by the authors and/or other copyright owners and it is a condition of accessing publications that users recognise and abide by the legal requirements associated with these

- Users may download and print one copy of any publication from the public portal for the purpose of private study or research.

- You may not further distribute the material or use it for any profit-making activity or commercial gain

If the publication is distributed under the terms of Article $25 \mathrm{fa}$ of the Dutch Copyright Act, indicated by the "Taverne" license above, 
Cytomegalovirus and vascular pathology 
1998, MCJ Stuart Persoons, Maustricht, The Netherlands ISBN 90-9012094-?

Druk Datawyse/ Universitaire pers Maastricht

The publication of this thesis was financially supported by Wyeth - Lederle 


\title{
Cytomegalovirus and vascular pathology
}

\author{
Proefschrift
}

ter verkrijging van de graad van doctor

aan de Universiteit Maastricht

op gezag van de Rector Magnificus,

Prof. dr. A.C. Nieuwenhuijzen Kruseman,

volgens het besluit van het College van Decanen

in het openbaar te verdedigen op

vrijdag 30 oktober 1998 om 10.00 uur

door

Maria Cornelia Johanna Stuart Persoons 
Promotores

Prof. dr. CA Bruggeman

Prof. dr. MJAP Daemen

Beoordelingscommissie

Prof. dr. JGR de Mey (voorzitter)

Dr. FWAM Bär

Prof. dr. CPA van Boven (em. hoogleraar Rijksuniversiteit Leiden)

Prof. dr. CME van Dam Mieras (Open Universiteit)

Prof. dr. MP van Dieijen Visser 
Aan mijn ouders

Voor mijn mannen, onze jongste 



\section{Contents}

\section{Chapter 1}

General discussion

1.1. Preface

1.2. Atherosclerosis; chronic inflammatory responses cumulating in notorious disease

1.3. A role for infectious agents in atherogenesis? 13

1.4. Cytomegalovirus and vascular pathology 16

1.4.1. General aspects of cytomegalovirus infection $\quad 16$

1.4.2. Cytomegalovirus and atherosclerosis 19

1.4.3. Cytomegalovirus and arterial restenosis 20

1.4.4. Cytomegalovirus and transplant arteriosclerosis 21

1.4.5. Cytomegalovirus and vasculitis 23

1.5. Hypotheses and aims of this thesis 25

$\begin{array}{lll}1.6 \text { References } & 26\end{array}$

\section{Chapter 2}

Multiple organ involvement during experimental cytomegalovirus infection is associated with disseminated vascular pathology

\section{Chapter 3}

Enhancement of transplantation associated atherosclerosis by cytomegalovirus, which can be prevented by prophylaxis with HPMPC

\section{Chapter 4}

Active cytomegalovirus infection of arterial smooth muscle cells in immunocompromised rats. A clue to herpesvirus associated atherogenesis?

\section{Chapter 5}

Neointimal smooth muscle cell phenotype is important in its susceptibility to cytomegalovirus infection; a study in rat

\section{Chapter 6}

Rat medial smootl muscle cells in vivo are not susceptible to active cytomegalovirus infection

\section{Chapter 7}

General discussion 
Summary

Samenvatting

Nawoord

Curriculum vitae 135

List of publications 
Chapter I

General introduction 


\section{1 Preface}

In developed countries cardiovascular disease remains the prime cause of mortality. Responsible for the majority of these deaths is atherosclerosis, a slowly progressive disease of medium sized and larger arteries with multiple factors contributing to its pathogenesis.

Whereas a great deal of information has become available at the cellular and molecular level, which has resulted in more knowledge of the composition and genesis of atherosclerotic lesions, much remains to be elucidated. In the light of prevention or maybe even treatment of atherosclerosis, it is of great importance to gain more knowledge of all potential risk factors and of their exact role in the process.

In this chapter, some general aspects of atherosclerotic lesions and atherogenesis are mentioned, before the possibility of infectious agents playing a role in atherosclerosis will be discussed. In particular the associations that exist between cytomegalovirus and atherosclerosis and other vascular pathologies will be reviewed. At the end of this chapter preexistent hypotheses and aims of this thesis will be stated. 


\subsection{Atherosclerosis; chronic inflammatory responses cumulating in notorious disease}

The earliest atherosclerotic lesion is the fatty streak, a flat intimal cell aggregation of mainly lipid filled macrophages, T-lymphocytes and some lipid containing smooth muscle cells (SMCs). The fatty streak is ubiquitous already in children (Mc Gill jr. 1984, Stary 1989). Stary described that fatty streak-like lesions are found in coronary arteries of $45 \%$ of infants as young as 8 months (Stary 1989). The anatomical sites of fatty streaks in early life are often the same as the locations were advanced atherosclerotic lesions are found at older ages, being mainly branches and bifurcations of arteries where alterations in theological forces of the blood flow and in wall shear stress may disturb the endothelium. This supports the thought that the fatty streak represents early atherosclerosis and precedes advanced lesions (Fagiotto and Ross 1984a and b, Masuda and Ross 1990a and b, Rosenfield et al. 1987).

Proliferating SMCs and macrophages together with T-cells produce variable amounts of connective tissue, forming an intermediate fibro-fatty lesion that is characterized by the presence of a covering fibrous cap. This lesion increases by further cell replication, lipid accumulation, connective tissue formation and necrosis and progresses to finally become a fibrous or atherosclerotic plaque, which is the characteristic form of atherosclerosis. It has been suggested that cracks or tears in the outer thinner parts of the fibrous cap, that contain relative low amounts of connective tissue, may result in instability of the plaque and the occurrence of acute vascular events. Haemorrhaging into the lesion and thrombus formation may result in a peracute occlusion of the artery (Davies and Thomas 1984).

Atherosclerosis, in essence, may be viewed as an inflammatory fibroproliferative response to various possible forms of injury to the artery wall, that in its redundancy has become a chronic arterial disease. This hypothesis forms the basis of the 'responseto-injury' theory that has been postulated and modified by Ross (Ross and Glomset $1976,1986,1993 \mathrm{a}$ and b) and has gained general acceptance.

Whatever the nature of the insult, endothelial damage or (subtle) dysfunctional alteration of the endothelium is thought to be the first consequence. Endothelial expression of adhesion molecules and leakage of plasma constituents into the artery wall then result in the adherence of peripheral blood monocytes and T lymphocytes to the endothelium and their subsequent invasion into the subendothelial space.

In the inflammatory process that follows, endothelial cells, monocyte derived macrophages, T lymphocytes, SMCs and platelets take part, mediating their effects by the release of several cytokines and growth factors.

Immunological reactions are at least part of this inflammatory disease, as is indicated by the presence of substantial numbers of (activated)T-lymphocytes in early and late atherosclerotic lesions (Jonasson et al. 1986, Hansson et al. 1988 and 1989, Stemme et al. 1991 and 1992) and local and circulating autoantibodies to plaque components (Yokota and Hansson 1995, Hansson et al. 1994, Libby and Hansson 1991). This is further supported by the expression of lymphokine induced class II major 
histocompatibility complex (MHC-M) molecules by vascular cells in the atheroscerotic plaque (Jonasson et al. 1985 and 1988, Hansson et al. 1986).

Immunohistochemical studies have shown that CD4+ and CD8 + T-cells are present in the atherosclerotic plaque in approximately equal amounts (Jonasson et al. 1986, Stemme et al. 1992). CD4+ T-cells recognize immunogenic complexes on the surface of antigen-presenting cells. These complexes are formed by the binding of portions of exogenous proteins that have been internalized and subsequently processed in these cells, with MHC-II molecules. CD8+ T-cells on the other hand, recognize endogenously synthesized proteins, such as for instance viral antigens, that are processed and associated with MHC-I molecules.

There is evidence for specific immune responses against products of $\mathrm{LDL}$ oxidation (Steinberg et al. 1989, Palinski et al. 1989) and a correlation has been found between serum titres of such antibodies and progression of carotid atherosclerosis (Salonen et al. 1992). Among other interesting candidate antigens, present in the atherosclerotic artery wall, that may trigger specific $\mathrm{T}$-cell responses, are the heat shock proteins (HSPs) (Berberian et al. 1990, Xu et al. 1992 and 1993). The presence of carotid atherosclerotic plaques in human individuals has been correlated with higher serum titres of anti-HSP antibodies (Xu et al.1993). Moreover, immunization of rabbits with HSP- containing preparations has been shown to induce large atherosclerotic lesions, in contrast to a great variety of other antigen preparations, including preparations of human or rabbit atherosclerotic lesion proteins, or high cholesterol (Xu et al. 1992). Immunohistopathologic examination revealed that $20 \%$ of the cells in such lesions were T-cells and peripheral blood analysis of T-lymphocyte proliferative responses learned that lesions positively correlated with the presence of HSP65-reactive cells (Xu et al. 1992). Since not all T-cells that are present at atherosclerotic sites do express the same antigen specificities, it is thought that specific immunogenic responses do occur early in the atherosclerotic process and initiate (aspecific) inflammatory reactions (Yokota et all 1995).

The association of elevated levels of serum C-reactive protein (CRP) with symptomatic atherosclerosis (Ridker et al. 1998, Mendall et al. 1996, Haverkate et al. 1997, Thompson et al. 1995, Schulte et al. 1995, Mori et al. 1995) are at least in accordance with the inflammatory nature of this vascular disease. Recent data indicate pathogenetic roles of endothelial cell injury, impaired fibrinolysis and inflammatory activity in the progress of atherosclerotic disease, by finding positive correlations between increased serum levels of certain haemostatic factors and increased risks of acute coronary events (Thompson et al. 1997, Mendall et al. 1996, Haverkate et al. 1997, Becker et al. 1996).

These findings are compatible with the idea that an infection may possibly be important in atherogenesis. Through the years several associations have been made between persistent viral or bacterial infection and the presence of atherosclerotic lesions (Matilla et al. 1998, Danesh et al. 1997). However, only few infectious agents have been specifically mentioned with respect to atherosclerotic disease. 


\subsection{A role for infectious agents in atherogenesis?}

Since the finding, in the 1970s, that experimental infection of chickens with an avian herpesvirus can produce an arterial disease that remarkably resembles atherosclerosis (Fabrikant et al.1978) several infectious agents have been associated with atherosclerotic processes. However the nature of such associations is unclear. The key, but yet unresolved question, is whether infections can cause or contribute to atherosclerotic disease. Infectious causality in atherosclerosis would fit in the responseto-injury model of atherogenesis and is compatible with the importance of inflammatory mediators, like the cytokines, and with the inportance of the monocytemacrophage system in atherogenesis. The importance of an infectious etiology of atherosclerosis, lays primarily in the possibility of intervention and prevention. Over the years herpesviruses, more specifically cytomegalovirus (CMV), have remained important candidates to play a role in atherogenesis, but recently other agents have been mentioned in association with atherosclerotic disease such as Helicobacter pylori and Chlamydia pneumoniae.

Before considering the possible role of CMV in vascular disease in more detail, the associations that have been made for these other agents, including non-CMV herpesviruses, with atherosclerosis are shortly discussed here.

Since 1994, several epidemiological studies have been reported on an association of Helicobacter pylori antibody titers and coronary heart disease or stroke. Since Helicobacer pylori contain HSP60-like subunits, one suggestion under investigation is the possibility that autoimmune reactions against HSP60, an endothelial antigen, could induce atherogenesis (Birnie et al. 1996). Moreover, it has also been reported that an association exists between Helicobacter pylori and hypertension (Barnes et al.1991), which itself is a known risk factor for atherosclerosis. One study on the presence of Helicobacter pylori in the wall of atheromatous arteries has reported negative results (Blasi et al. 1996). In summary, there is only little evidence for the existence of a relation between Helicobacter pylori and atherosclerosis. The studies that have been reported were rather small and in general were not able to appropriately adjust for potential confounding factors (Danesh et al. 1997).

Chlamydia pneumoniae has emerged as one of the most serious candidates to play a role in atherosclerosis. Hence, at present considerable research is focussed on this microorganism. C pneumoniae is an obligate intracellular gram negative bacterium, which may survive for many years within human macrophages. It was first isolated from young adults with respiratory infections in Seattle in 1986 (Grayston et al. 1986) and it is now known to be one of the most prevalent infectious agents: prevalence of antibodies to $\mathrm{C}$ pneumonia in adults may be as high as $40-50 \%$ in developed countries and even $60-70 \%$ in tropical countries (Cook et al. 1995).

In $1988 \mathrm{C}$ pneumoniae was associated for the first time with vascular disease. Saikku et al. found that high titres of Chlamydial IgG and IgA correlated with chronic arterial 
disease and myocardial infarction (Saikku et al. 1988). Since that time several serological studies have been reported that do support the existence of an association between $\mathrm{C}$ pneumoniae and atherosclerotic disease (Danesh et al.1997).

Moreover, in contrast to Helicobacter pylori, $\mathrm{C}$ pneumoniae DNA, antigens and/or elementary bodies were shown to be present in human atherosclerotic tissues (Kuo et al. 1993 and 1995, Campbell et al. 1995, Grayston et al. 1995, Ong et al. 1996). Danesh et al, have calculated that infection was present in $52 \%$ of human atheromatous lesions, compared with only $5 \%$ of control samples (Danesh et al. 1997). Such an extreme difference does indeed strongly suggest a real association between $\mathrm{C}$ pneumoniae and atheroma, but these studies do not give a clue about the nature of this relation. Two studies in which anti-chlamydial therapy was shown to decrease the risk of adverse cardiovascular events in atherosclerotic patients, suggest that $C$ pneumoniae may at least play a contributing role in atherosclerotic disease (Gupta et al. 1997, Gurfinkel et al. 1997).

It has been reported that individuals who were seropositive for $\mathrm{C}$ pneumoniae have high plasma concentrations of fibrinogen (Patel et al. 1995) or C-reactive protein (Mendall et al. 1996), which is compatible with chronic (vascular) inflammation. In transgenic mice that spontaneously develop atherosclerosis, $\mathrm{C}$ pneumoniae can be detected for 20 weeks in the aorta within atherosclerotic lesions after intranasal inoculation of the bacterium (Moazed et al.1997). However, in mice, that only develop atherosclerosis on an atherogenic diet, when not given such a diet, $\mathrm{C}$ pneumonia is only present in few animals and at 2 weeks after inoculation only, suggesting a tropism of C pneumoniae for atherosclerotic lesions (Mozaed et al. 1997). Similar findings were done in rabbits, where intranasal inoculation of $\mathrm{C}$ pneumoniae accelerated intimal thickening of the thoracic aorta and azithromycin was found to prevent this effect (Muhlstein et all. 1998).

In vitro studies have shown that $\mathrm{C}$ pneumoniae can infect and replicate in human SMCs, endothelial cells and macrophages (Gaydos et al. 1996). Moreover, in transgenic mice it has been found that respiratory inoculation of $\mathrm{C}$ pneumoniae can induce vascular infection and dissemination of infection via macrophages (Campbell et al. 1996). This suggests a possible way of transport and infection in the human situation. However, it may be questioned if infected macrophages adhere to intact or slightly- injured endothelium and initiate atherogenetic changes or adhere to preexistent atheromatous lesions. It can be hypothesized that, even if the latter may be the case, $\mathrm{C}$ pneumoniae in arteries promotes local injury via inflanmatory mediators. Alternatively, $C$ pneumoniae may initiate an autoimmune inflammatory response (Leinonen et al. 1993, Gaydos et al. 1996), since, like H pylori, C pneumoniae contains HSP60-like subunits.

In conclusion, the evidence for an association between $\mathrm{C}$ pneumoniae and atherosclerosis is strong. Whether the agent may play a causal role, which could implicate a place for antibiotic therapy and probably vaccination, has not been revealed yet.

Before considering in more detail, in the next paragraph, the possible role of CMV in atherogenesis, associations that have been made for other herpesviruses with 
atherosclerotic disease are shortly mentioned here.

Fabricant et al. described in the late seventies that infection of chickens with Mareks disease herpesvirus (MDV) induced lesions in large coronary arteries, aortas, and major aortic branches, that closely resembled chronic atherosclerosis in humans (Fabricant et al. 1978, 1981 $\mathrm{a}$ and $\mathrm{b}$ and 1983). While these occlusive fibromuscular intimal thickenings were consistently induced by MDV, they never developed in chickens that had not been infected, regardless of blood cholesterol levels.

Viral antigens and nucleic acids were shown to be present in the atherosclerotic plaques (Fabrikant et al.1981 a) and the development of such plaques could be prevented by prior immunization with a related herpesvirus of turkeys (Fabricant et al. 1983).

Moreover, DNA sequences related to the avian herpesvirus were extracted from arteries of Japanese quails that had been selected on their susceptibility to cholesteroldiet induced atherosclerosis, while such sequences could not be detected in Japanese quails that were resistant to cholesterol induced atherosclerosis (Shih et al. 1983). MDV alters cellular cholesterol metabolism and accumulation as shown in infected chicken arterial SMCs in culture and in MDV infected chickens by a significant increase in total aortic lipid accumulation (cholesterol, cholesteryl-ester, triacylglycerol and phospholipid) and increased serum cholesterol levels (Hajjar et all. 1986 and 1985, Fabricant et al. 1981, Njenga and Dangler 1996). This may be one explanation for the MDV induced atherosclerotic lesions and may at least partly explain that it even occurs in chickens that had been fed a normocholesterolemic diet.

Moreover, two weeks after virus inoculation in chickens, MDV induces expression of class II major histocompatibility complex (Ia) by vascular endothelium, which is followed by intimal thickening and infiltration of mononuclear cells including CD3+, $\mathrm{CD} 4+, \mathrm{CD} 8+\mathrm{T}$-cells. This suggests an immunopathologic mechanism in the early pathogenesis of MDV induced atherosclerosis (Njenga and Dangler 1995).

The finding of MDV inducing atherosclerosis in chickens has been the basis for further research, focussing on possible associations that may exist between herpesviruses and atherosclerosis (Nicholson and Haijar 1998) and has remained of great importance in the discussion on a possible viral causality of atherogenesis.

Benditt et al. found evidence for the presence of HSV-mRNA in arterial specimens that had been retrieved from patients undergoing coronary bypass surgery (Benditt et al. 1983). They have also shown that HSV can infect human fetal SMCs in culture (Benditt et al. 1983).

Also, in one study $45 \%$ of the biopsies, taken from human coronary arteries during coronary bypass surgery, were found to be positive for HSV -2 antigens while only $1 \%$ were positive for HSV-l antigens (Raza-Ahmad et al. 1995). Significant positive correlations were detected between the presence of an inflammatory infiltrate and a history of colld sores and between the presence of such an inflammatory infiltrate and HSV-2 antigen positivity (Raza-Ahmad et al. 1995).

Fragments of HSV-1 and HSV-2, injected in temporarily isolated arterial segments in heritable hyperlipemic rabbits, have been found to induce highly localized, segmental, proliferative intimal tumours (Robertson et al. 1995). The largest intimal lesions, 
containing abundant amounts of lipid-laden macrophages and SMCs, developed at the injected loci in homozygous hyperlipemic animals, even before typical fatty streaks did develop elsewhere. In placebo infected animals such lesions were never found (Robertson et al. 1995).

In search for possible mechanisms of HSV induced arterial pathology, it has been found that HSV infection of endothelial cells induces endothelial expression of adhesion molecule GMP140 and that this requires cell surface expression of HSV glycoprotein C and local thrombin generation (Etingin and Haijar 1991). This is compatible with the findings of Span et al. (Span et al. 1991), who have described that HSV induction of increased adhesion of monocytes and polymorphonuclear leucocytes to endothelial cells in culture is blocked by tunamycin, indicating the mediation by glycoproteins (Span et al. 1991).

As with MDV, HSV infected arterial SMCs have increased cholesteryl ester accumulation and it has been shown that this can be prevented by TNF $\alpha$ and IL-1 (Etingin et al. 1990).

Recently, a murine model has been described in which a $\gamma$-herpesvirus (murine herpesvirus 68) is shown to cause severe large-vessel arteritis in mice lacking IFN- $\gamma$ receptors, suggesting that IFN- $\gamma$ may be important in the control of chronic vascular pathology, induced by this herpesvirus (Weck et al.1998)

It may be concluded that, although HSV 1 and/or 2 have been associated with atherosclerotic lesions in humans and appear to share some 'atherogenetic' features with MDV, the evidence for such a relation in humans is scarce. HSV may be a potential, but not a common contributor to atherogenesis.

The association, on the other hand, of CMV with vascular pathology in humans seems to be much stronger, which makes this virus an important topic in studies of atherogenesis, coronary restenosis and transplant atherosclerosis.

\subsection{Cytomegalovirus and vascular pathology}

\subsubsection{General charactertistics of CMV infection}

As other herpesviruses CMV is characterized by the presence of linear, double stranded DNA and an envelope. The virus is classified in the subfamily of the $\beta$ herpesviridae, based on its restriction to specific hosts, a long reproduction cycle, slow infection of cell cultures and characteristic enlargement of infected cells.

CMV (again as other herpesviruses) has the unique capacity to persist latently after recovery of the host from an acute primary infection. Under certain - especially immunocompromising - conditions the virus can reactivate from this latent state, resulting in endogenous infection. Worldwide, $\mathrm{CMV}$ is a common cause of infection: the prevalence of antibodies against CMV in the general population is as high as 50$80 \%$. In HIV-seropositive adults the prevalence of CMV infection is allmost $100 \%$. In immunocompetent individuals by far the majority of infections remains asymptomatic and only occasionally a mononucleosis-like illness develops. However, in immunocompromised patients such as transplant recipients receiving immunosuppressive therapy and HIV-seropositive individuals, CMV may cause severe and 
life-threatening disseminated infections. Pneumonia, hepatitis, colitis and retinitis are often seen in these patients. In HIV-seropositive individwals CMV infection accelerates the progression to AIDS and in transplant recipients infection frequently results in impaired graft function.

CMV is the primary cause of congenital infections. Cytomegalic inclusion disease in neonates has a low incidence but high morbidity and mortality rates and is almost exclusively a result of primary infection of the mother during pregnancy and transplacental transmission of CMV. Intrauterine CMV infection occurs in 0.4-2.3\% of all infants born alive (Stagno et al. 1982, Doerr et al. 1987, Hirota et al. 1992) but less than $10 \%$ of the congenitally CMV infected children develop acute symptoms such as petechia, jaundice, hepatosplenomegaly and microcephaly. In neonates - especially preterm infants-, being immunologic immature hosts, primary CMV infection may result in a severe disseminated disease with a high mortality rate.

CMV has a tropism for the salivary glands, which results in a persistent infection with recurrent shedding into the saliva. Saliva is believed to be the main mode of spreading of the virus in the population (Ho 1991): transmission generally requires close contact with persons excreting CMV as shown by studies in day-care centres (Pass et al. 1982,1984 and 1986, Adler 1986). After puberty transmission of CMV primarily occurs by sexual contact, as has been evidenced by epidemiologic studies (Jordan et al.1973, Chandler et al. 1987, Collier et al.1990). The virus can be isolated from semen and cervix. Other important routes of transmission are bone marrow and solid organ transplantation and blood transfusion.

Among the target cells for acute CMV infection are monocytes/macrophages, epithelial, parenchymal and endothelial cells. Moreover, especially fibroblasts are well known preferential cells for CMV infection and replication, which makes them the most appropriate cells for $\mathrm{CMV}$ isolation and propagation in culture.

During active CMV infection, the virus has been detected in different organs such as spleen, liver, kidney, salivary glands, lungs, brain, esophagus and colon.

As shown in animal models, CMV is detectable in almost every organ during the very acute phase of infection (Bruggeman et al. 1983 and 1985, Stals et all. 1989, Mercer and Spector 1986, Shanley et al. 1993). The virus load in these organs, however, as measured by virus cultivation, is low and cytomegalic cells are hardly present. In immunocompromised rats it had been shown that spleen and liver contain the highest levels of infectious virus during acute disseminated infection with rat- specific CMV (RCMV) (Stals et al. 1989).

During such acute disseminated CMV infection viral genome and antigens are also detectable in peripheral blood leucocytes, especially in polymorphonuclear leucocytes and monocytes (Jiwa et al. 1989a and b, Percivalle et al. 1993, Grefte et al. 1993, Dankner et al.1990). It could be that this is the result of phagocytosis by these cells and not of infection. It is thought that CMV containing leucocytes may play a role in dissemination of CMV infection, which is supported by in vitro findings of monocytes transmitting the virus to vascular cellss (Guetta et al.. 1996, Waldman et al. 1995). As shown by immunohistochemical and DNA techniques, most infected cells do not show a cytomegalic appearance. It is thought that the presence of cytopathic cells correlates with the presence of clinical symptoms (Borisch et al. 1988, Shibata et al. 


\section{9).}

T-cells are mainly responsible for the immunological control of herpesvirus infections, including CMV infection. CD8 + T-cells have cytolytic activity in CMV infected cells after recognition of viral antigens presented by $\mathrm{MHC}-\mathrm{I}$ molecules on the surface of the host cell. CD 4+ cells have regulatory functions and recognize viral antigens that are presented by MHC-II molecules. The importance of cellular immunity in the control of CMV infection, is clearly evidenced by the high prevalence of disseminated CMV infections and severe disease in patients with impaired T-cell immunity, such as transplant recipients and AIDS patients. Antibody responses to CMV play only a supportive role, but may be of increasing importance during conditions of impaired Tcell immunity. CMV specific antibodies can neutralize free virus particles and/or corroborate with the cellular response. Also natural killer cells are thought to act supportive in the immunologic control of CMV disease.

However the immune system, even when fully intact, appears not to be able to eliminate CMV completely. The virus, like all herpesviruses, has ways to escape the immunological control. In immunocompetent individuals immunologic responses prevent symptomatic disease, predominantly by termination of acute virus replication and spreading of the virus, but there is no complete clearance of the viral genome. Thus after acute infection, CMV persists in a non-replicating state or at an undetectable level of replication, called latency, most probably for the lifetime of the host. It has become clear that there is not one preferential cell type for CMV latency. This seems to be comparable with the behaviour of Epstein Barr virus, but is in contrast with other herpesviruses as HSV and Varicella Zoster that appear to latently infect onlly neurons. Studies in animals and of tissues retrieved post mortem from healthy individuals, indicate that during latency CMV DNA is present throughout the body. This has been shown for instance for salivary glands, liver, spleen, kidneys, pancreas, heart, bone marrow and abdominal aorta with use of sensitive molecular techniques such as polymerase chain reaction (PCR)(Hendrix 1997). It has furthermore been evidenced that the virus can be transferred by renal and cardiac allografts from latently infected donors to seronegative recipients (Shanley et al. 1983, Rubin et al. 1984, Bruning et al. 1986). With in situ DNA hybridisation it has been demonstrated that a great variety of cells may harbor latent CMV, such as hepatocytes, tubular and glomerular kidney cells, splenic red pulp cells, pancreatic acinar cells and arterial smooth muscle cells (Hendrix et al.1997, Mercer et al. 1988, Klotman et al. 1990, Pomeroy et al. 1991). CMV has been found to latently infect granulocyte-macrophage progenitors (Kundo et al. 1994, 1995 and 1996) and CMV DNA has been observed in peripheral blood cells, particularly mononuclear cells, of healthy individuals (Cassol et al. 1989, Stanier et al. 1989, Bevan et al. 1991). It appears that CMV-DNA may even be detectable in blood cells of seronegative individuals (Bevan et al. 1991, Hendrix et al. 1997). It thus seems plausible to suggest that bone marrow-derived myeloid progenitors and leucocytes are important natural sites of viral latency.

However, more data are necessary on the site(s) of CMV latency, the physical state of the latent viral DNA and its transcription and translation products as well as the mechanisms and conditions of reactivation. A detailed understanding may be of essential importance for prevention and therapy of CMV infections, especially in 
immunocompromised individuals where CMV frequently causes life-threatening disease.

\subsubsection{CMV and atherosclerosis}

Of all herpesviruses CMV has been most frequently and suggestively been associated with atherosclerotic disease in epidemiological, experimental and clinical studies and the virus has remained a hot item in the study after atherogenesis.

In the early eighties Melnick et al. reported that arterial SMCs, derived from patients that were known to suffer from severe atherosclerotic disease, did contain CMV DNA and expressed CMV antigens when brought into culture (Melnick et al. 1983, Petrie et al. 1987) CMV nucleic acids have repeatedly been detected in arteries that were derived from human individuals. Hendrix et al. demonstrated the presence of CMV DNA in high percentages of abdominal aortas and femoral arteries that had been obtained from atherosclerotic and non-atherosclerotic patients (Hendrix et al. 1989). However, using the highly sensitive polymerase chain reaction (PCR) technique, they have shown that CMV nucleic acids were more frequently present in artery walls of patients suffering from severe (at least grade III) atherosclerosis than in patients without, or with only little, evidence (maximally grade I) for atherosclerotic changes ( $90 \%$ vs $50 \%$, Hendrix et al. 1990). Since immediate-early (IE) mRNA but not late mRNA has been detected, it was stated that CMV is latently present in the artery wall. Comparable high percentages of CMV DNA have been found in arterial specimens from patients who underwent vascular surgery for symptomatic atherosclerotic disease (Melnick et al. 1994). However, in that study the presence of CMV DNA in atherosclerotic plaque tissue did not significantly differ from its presence in non atherosclerotic regions within the same patients (Melnick et al. 1994). Also in endarterectomy specimens from patients with coronary artery stenosis it has been found that atherosclerotic plaques with thrombosis are more likely to contain CMV than plaques without thrombosis ( $58 \%$ vs 17\%) (Chiu et al. 1997). No correlation did exist in this study between the presence of CMV in the vascular wall and the presence of CMV specific antibodies in the serum.

Several studies have reported higher prevalences and higher titres of CMV antibodies in patients with atherosclerosis (Adam et al. 1987, Musiani et al. 1990, Visseren et al. 1997). Elevated CMV antibodies have been associated with intimal thickening of carotid arteries as determined by ultrasonography (Sorlie et al. 1994), suggesting an association between CMV and early atherosclerotic, but asymptomatic vascular changes. Moreover from 150 sera of these individuals with increased intimal thickness, and of their matched controls with low intimal thickness values, that had been collected 17 years before ultrasonography of carotid arteries was performed, it was evidenced that a graded relation existed between intimal thickening and the levels of CMV antibodies at that time. This relation remained significant even after adjustment for the main cardiovascular risk factors and support the hypothesis that CMV may play a causal role in atherosclerosis (Nieto et al. 1996).

On the other hand, Adler et al. recently reported that in about 900 patients undergoing coronary angiography they failed to find a significant association with CMV 
seropositivity or antibody titres against specific CMV antigens (Adler et al. 1998). Support for a possible role in early atherogenetic changes has also been derived as well from rat studies, where RCMV induced endothelial cell damage, characterized by endothelial ballooning and loosening, lipid accumulation and increased adherence and migration of leucocytes (Span et al. 1993)

\subsubsection{CMV and arterial restenosis}

Coronary balloon angioplasty in patients suffering from severe symptomatic coronary artery disease results in restenosis in $25-50 \%$ of the cases. Although an excessive proliferative response of SMCs, culminating in an increased intimal mass, has long been considered to be the cause, coronary restenosis most probably is a multifactorial phenomenon. Recently several studies have shown that prominent proliferation responses may even be lacking in restenotic lesions and that defective remodelling may be more important (Post et al. 1994, Kimura et al. 1997, Mintz et al. 1997a and b, Lafont et al. 1995, O'Brien et al. 1993.).

Speir et al. have reported a potential role of $\mathrm{CMV}$ in coronary restenosis after angioplasty (Speir et al.1994, Epstein et al. 1996). HCMV DNA was found in 14 of 24 atherectomy tissue specimens that had been obtained from patients suffering from coronary restenosis, 1-6 months after they had undergone balloon angioplasty (Speir et al. 1994). None of 11 atherectomy specimens of primary atherosclerotic lesions contained HCMV DNA. SMCs from 4 of 9 of the restenotic CMV positive specimens, were shown to express the major immediate-early protein IE84 of the virus, when brought into culture (Speir et al. 1994).

The authors, who define coronary restenosis primarily as the result of an excessive proliferative response to angioplasty, suggest that the role of CMV may be mediated at least in part- by an inactivating effect on $p 53$, a tumour suppressor protein that inhibits cell cycle progression. Only when $\mathrm{p} 53$ has lost its inhibitory function, the protein is detectable by immunostaining, which is the result of an enhanced stability. Speir et al. have described that $\mathrm{p} 53$ could be detected in about $40 \%$ of restenotic atherectomy specimens, compared with $0 \%$ of specimens derived from primary atherosclerotic lesions. Moreover, in $80 \%$ of the specimens that were HCMV positive, p 53 could be detected with immunostaining.

HCMV infection of SMCs in culture enhanced the accumulation of $\mathrm{p} 53$, which correlated with the expression of IE84. Furthermore, it was shown that IE84 could bind to $\mathrm{p} 53$, abolishing its function to transcriptionally activate a reporter gene (Speir et al. 1994). These data are compatible with the hypothesis of the authors that injury to the coronary artery wall at the time of angioplasty, activates latent HCMV that is preexistently present in cells of this artery wall. This results in expression of HCMV IE 84 , which binds to and inactivates $\mathrm{p} 53$.

Studies from Zhou et al. have supported the existence of an association between CMV and arterial restenosis. They have described that patients that were seropositive for HCMV had significantly higher rates of restenosis at 6 months after coronary atherectomy than patients that were HCMV seronegative (43 vs $8 \%$ ) (Zhou et al. 1996b). HCMV seropositivity and HCMV titers proved to be independent predictors of the risk for restenosis. There was no evidence, however, of acute CMV infection, since 
anti-CMV IgG titers did not increase over time and anti-CMV IgM was never found in these patients.

In a small study, Pauletto et al. could not find support for a role of CMV in restenosis of the internal carotid artery. They could not find HCMV DNA in endarterectomy specimens from 5 internal carotid artery restenosis specimen (Pauletto et al. 1996). In conclusion, CMV has been associated with cases of coronary artery restenosis and thus may be an important factor in the post-angioplasty course. However, evidence for causality has remained indirect so far and the number of patients involved in these studies have been rather small.

\subsubsection{CMV and transplant arteriosclerosis}

Allograft vasculopathy, or transplant arteriosclerosis, was first described in cardiac transplant recipients, but occurs in most kinds of allografts. It is generally agreed to be the prime histological manifestation of chronic allograft rejection (Billingham et al. 1987) and a major factor affecting cardiac allograft survival in the long run (Kaye 1993).

Transplant vasculopathy differs from classic atherosclerosis in some characteristic aspects; it affects the entire length of vessels, including small penetrating intra-organ branches (Russell et al. 1993) and is associated with a persistent perivascular inflammation. Furthermore, allograft neointimal thickening is diffuse and concentric (Gao et al. 1988, Olivari et al. 1989, Billingham et al.1987 and 1992) and develops rapidly (months to years). The internal elastic lamina usually remains intact (Billingham et al. 1987) and intimal calcium deposits are seldomly present. Classic atherosclerosis, on the contrary, is a long, slowly progressing (over many years) disease, characterized by focal eccentric lesions in which the internal elastic lamina is often broken, calcium deposits are frequently seen and perivascular inflammation is absent (Ross et al. 1986, Billingham et al. 1987).

The pathophysiology of transplant arteriosclerosis is complex and both immunological and non-immunological factors are thought to have their parts in it (Tilney 1995, Tullius et al. 1995, Hruban et al.1990). Immunological factors that have been associated are recurrent major rejection episodes (Narrod et al. 1989, Young et al. 1992, Uretsky et al.1987, Radovancevic et al. 1989) and HLA incompatibility (Uretsky et al. 1987, Olivari et al..1989, Stovin et al. 1991). However, several clinical studies contradict the existence of a relationship between acute rejection episodes (Gao et al. 1987, Sharples et al. 1991, McDonald et al. 1991) or histo-incompatibility (Narrod et al. 1989, Radovancevic et al.1991) with allograft vasculopathy.

Non-immunological factors that have been correlated with the development of cardiac allograft vasculopathy are hyperlipemia (Winters et al. 1990, Eich et al. 1991, Gao et al. 1988), pretransplant ischaemia (Sharples et al. 1991, Gao et al. 1987), recipient high or low age and female sex (Sharples et al. 1991 , Eich et al. 1991) and donor high age and femalle sex (Bieber et al. 1981, Gao et al. 1987). Etiological factors for classic atherosclerosis such as diabetes, hypertension, smoking and family history, appear not to play important roles in the development of chronic graft rejection (Hosenpud et al. 1992, Johnson et al. 1992). 
Several studies indicate the potential importance of CMV in transplant atherosclerosis. Grattan et al. found, in a study of 301 cardiac transplant recipients, that allograft vasculopathy occurred more frequently and earlier in patients with $\mathrm{CMV}$ infection than in non-infected patients (Grattan et al. 1989). The rate of graft loss was significantly greater among patients that were CMV infected. No differences were found in the rate of occurrence of allograft vasculopathy between patients with symptomatic or asymptomatic CMV infection, nor did it make any difference whether patients were seropositive or negative for CMV before transplantation (Grattan et al. 1989). Similarly, Mc Donald et al. found higher incidences of cardiac allograft vasculopathy in CMV infected patients, compared to non-infected patients (Mc Donald et al. 1989). Loebe et al. also described that CMV infection after heart transplantation, as shown by serology, is a risk factor for cardiac allograft vasculopathy (Loebe et al. 1990), while Everett et al. showed that prolonged CMV infection with viraemia is associated with vasculopathy in cardiac recipients (Everett et al. 1992). Wu et al. detected CMV nucleic acids in coronary arteries of three out of five cardiac transplant recipients with severe allograft vasculopathy, but not in patients in which allograft vasculopathy was absent (Wu et al. 1992). Comparable results were found by Koskinen et al. in endomyocardial biopsies and using angiography (Koskinen et all. 1993a,b,c and 1994). Moreover these authors have shown that CMV antigenemia in human heart allograft recipients was assiociated with the induction of vascular adhesion molecules in the graft (Koskinen 1993d).

An association of CMV with transplant arteriosclerosis has also been observed in other kinds of human allografts. Pouteil-Noble, for instance, described a strong correlation of CMV infection and the development of rejection and arteriosclerosis in renal allografts (Poteil-Noble et al. 1993).

The rat aortic-allograft model has been used and proven to be of great value in the study after the pathogenesis of transplant associated arteriosclerosis (Hayry et al. 1991, Mennander 1991, Plissonier et al. 1991). It renders the opportunity to study allograft histological features in the absence of immunosuppressive therapy. Using this model, it has, for instance, been shown that the adherence of monocytes/macrophages to the endothelium occurs at about one week after transplantation. Moreover, from that time monocytes/macrophages and CD8 positive T cells appear in the adwentitia (Plissonier et al. 1995, Isik et al.1992, Mennander et al. 1991).

Endothelial cells and SMCs are considered to be clue cells in the pathogenesis of allograft vasculopathy (Plissonier et al. 1995, Salomon et al. 1991). Endothelial cells have a high level of antigenicity in the acute transplant rejection process as well as in chronic vascular lesions. Medial SMCs migrate to the intima and proliferate here, resulting in intimal thickening, while necrosis of medial SMCs has been correllated with adventitial inflammation (Lemstróm et al. 1993, Plissonier et al. 1995). In these aortic allograft rat models RCMV has been shown to induce enhanced allograft arteriosclerosis. Early RCMV infection of allograft recipients induced an increased inflammatory response in the adventitia (perivasculitis) and in the subendothelial space (endothelialitis) as well as increased SMC proliferation and intimal thickness (Li et al. 1996 a and b, Lemstróm et al. 1993, Koskinen et al. 1993d). Increased expression of antigens such as MHC class II, IL 2 receptor and ICAM-1 
molecules and of several growt factors and cytokines have been described (Lemstrom et al. 1994a). The RCMV accelerating effects on allograft arteriosclerosis have been confirmed in cardiac and lung rat transplants (Lemstrom et al. 1995, Steinhof et al. 1995 and 1996. Stals et al. 1996).

The mechanism(s) by which CMV exerts its effects may be direct or indirect.

However, the fact that enhanced allograft arteriosclerosis by RCMV has never been found in syngeneic graft recipients, indicates that RCMV acts via the acute alloimmune response in these grafts. This is further supported by the finding that immunosuppresive therapy significantly diminishes the enhancing effect of RCMV on rat aortic allograft arteriosclenosis (Lemstrom et al. 1994 b and d).

In conclusion, the evidence for stimulating effects of CMV on allograft arteriosclerosis is strong. Although the exact mechanisms are not clear, immune responses to alloantigens, involving $T$ cells, play a critical role in this.

\subsubsection{CMV and vasculitis}

Besides the evidence that suggest an association between CMV and pathology of (predominantly medium- and large-sized) arteries, the virus has also been shown to cause local vasculitis, which is defined as an inflammatory disease of both the venous and arterial intra- organ microvasculature.

Literature of such CMV-associated vasculitis concerns primarily case reports. Although CMV associated vasculitis is usually confined to one organ, disseminated disease can occur in which multiple organs are involved. The three most commonly affected organ systems turn out to be the gastrointestinal tract, the central nervous system and the skin.

Common findings are CMV infection of endothelial cells, inflammatory infiltration of the vessel, disturbance of vessel integrity and tissue necrosis. However, there is not always evidence for the local presence of CMV and it ihas been hypothesized that either endothelial cells may be productively infected by CMV, causing local vasculitis and tissue ischaemia, or vasculitis may be an immune mediated process. CMV infection may involve any segment of the gastrointestinal ract, including esophagus (Wilcox et al.1990, Freedman et a. 1985) and stomach (Campoell et al. 1977), however, by far the most frequently affected part is the colon. As is seen with CMV disease in general, CMV infection of the gastrointestinal tract occurs almost exclusively in immunocompromised hosts. Most cases concern transplant recipients (Foucar et al.1981, Goodman 1973, Hinnant et al. 1986, Campbell et al.1977, Muldoon et al.1996) and especially patients suffering from AIDS (Golden at al. 1994, Niedt et al. 1985, Francis et al. 1989, Levinson and Bennets 1985 , Roberts et al. 1989). Nevertheless, there are reports of CMV vasculitis of the gastrointestinal tract in apparently healthy hosts (Goodgame 1993, Diepersloot et al.1990). Pathology in CMV associated vasculitis of the gastrointestinal tract ranges from the presence of CMV specific inclusion bodies without any tissue response, to mucosal ulceration, toxic megacolon (Orloff et al. 1989), necrosis and perforation (Burke et al. 1987, Frank and Reight 1984, Tatum et al.1989, Yasunuga et al. 1995). Moreover, CMV pathology ranges from local involvement to widespread CMV gastroenterocolitis (Knapp et al. 1989). 
Athough CMV may be a primary pathogen that causes vasculitis in previously normal tissues, the virus may also have a predilection for areas of preexisting inflammation. This may contribute to the enhanced susceptibility of the gastrointestinal tract in patients with ulcerative colitis to CMV infection (Cooper et al.1977, Keren et al. 1976, Powel et al. 1961 , Sidi et al..1979, Tamura et al.1973).

Vasculitis in the central nervous system due to CMV has been well documented in AIDS patients, but has a low overall incidence, ranging from $2-13 \%$ in these patients (Golden et al. 1994, Guarda et al. 1984, Kalayjian et al. 1993, Klatt et al. 1988, Morgello et al. 1987, Tucker et al. 1985, Vinters et al. 1989). It may cause a variety of neurologic defects. CMV associated vasculitis of meningeal (Guarda et al. 1984) as well as extra-durall vessels of the brain and spinal cord (Morgallo et al. 1987) have been described. In a patient with an underlying lymphoma, a widespread CMV infection of the brain and the spinal cord was described, manifested by occlusive arteritis that involved the white and the grey matter (Koeppen et al. 1981) . Clinical manifestations of CMV infection of the central nervous system in general and CMV vasculitis in particular, are often non-specific and neuro-imaging techniques have not been very helpful in identifying active CMV disease of the central nervous system. Even the cerebrospinal (CSF) fluid profiles may reveal no or aspecific abnormalities and CSF cultures appeared to be positive for CMV only in low percentages of cases (Golden et al. 1994, Morgello et al. 1987, Vinters et al. 1989), with the highest rate of recovery found in patients with CMV radiculomyelitis (Morgello et al. 1987). Thus in case of aspecific symptomatology in the immunocompromised patient, high suspicion of CMV infection of the nerwous system may be justified even in the presence of normal imaging studies, normal CSF profiles and negative cultures.

Cutaneous vasculitis by CMV is unusual and has a large scala of possible manifestations without a predictable distribution, such as petechiae, purpura, papules, ulcera, diffuse maculopapular eruption or desquamation (Lin et al. 1981, MullerStameau et al. 1974). Overall the prognosis is poor; cutaneous CMV involvement seems to represent fulminant disease. In contrast to other CMV-alssociated vasculitis, cutaneous CMV vasculitis is relatively uncommon in patients with AIDS, compared with patients that are severely immunocompomised as a result of underlying malignancy and aggressive cytotoxic chemotherapy (Golden et al.1994). However, cutaneous vascullitis have also been reported in two otherwise healthy children suffering a CMV nucleosis like syndrome (Sandler 1987, Weigand, 1982). Moreover, CMV has been linked with systemic vasculitis in some cases (Bamji and Salisbury 1978, Doherty 1981), suggesting that CMV like HBV may be able to initiate polyvasculitis. Skin lesions as a result of CMV vasculitis do not occur in any predictable distribution and may involve face, digits, mucous membranes and genitalia (Bhawan et al. 1984, Bulpitt et al. 1989, Feldman et al. 1982, Curtis et al. 1982, Lin et al. 1981, Minare et al. 1977, Sandler et al. 1987, Walker et al. 1982, Weigand et al. 1980, Williams et al. 1960).

In summary, $\mathrm{CMV}$ associated vasculitis may occur in different organs and may be manifested in different ways. While the pathogenesis is not clear it probably concerns an important aspect of CMV disease. 


\subsection{Hypotheses and aims of this thesis}

Thus, as has been reviewed above, CMV can initiate an accelerated arteriosclerosis in transplanted organs and may cause local vasculitis. Moreover, CMV is associated with 'spontaneous' atherosclerosis of large and medium sized arteries and with restenosis of coronary arteries that have undergone angioplasty because of atherosclerotic stenosis. Whether and through which pathway(s) CMV may play a causal or contributing role in the pathogenesis of these vascular pathologies, may be different for each of the above mentioned examples and has remained largely unknown.

We hypothesized that vascular involvement is of basic importance in all CMV induced pathology. Moreover, we expected that large or medium sized arteries and intra-organ microvasculature differ in their susceptibility and response to CMV infection and that, with respect to this susceptibility, vascular cells within one artery (endothelial cells, intimal and medial SMCs) differ from each other, as well. Finally, we hypothesized that host immunological factors influence vascular susceptibility to CMV infection.

The main aim of this thesis was to either confirm or dismiss these hypotheses. Hereto, we have made use of rat models and a rat-specific CMV (RCMV) that had been isolated in our laboratory (Bruggeman et al. 1983) and, as evidenced by DNA characterisation (Meijer et al. 1986, Beissner et al. 1998, Vink et al. 1996 and 1997) and in vivo behaviour (Bruggeman et al. 1985, Stals et al. 1990), shows great analogy with human CMV.

To elicit the sequence of local events after CMV infection, a model of localized RCMV infection has been established, as is described in chapter 2. This model is of value in the study on the pathogenesis of CMV induced local vascular damage and vasculitis. Moreover, in chapter 2 the results of this model are compared with the findings during disseminated RCMV infection.

Chapter 3 describes the use of a rat allogenic abdominal aorta transplantation model in a study on the effects of acute RCMV infection on transplantation associated atherogenesis. This model was used as well to study the result of prophylaxis with the acyclic nucleoside analogue (S)-1-(3-hydroxy-2-phosphonylmethoxypropyl)cytosine (HPMPC), a potent inhibitor of CMV infection, on these atherogenetic effects. Chapters 4-6 describe the effects of RCMV in a rat balloon artery injury model. This model was used to study

1. the susceptibility of arterial SMCs in vivo to active CMV infection (Chapter 4)

2. the preconditions for and characteristics of active CMV infection of arterial SMCs (Chapter 4-6)

3. potential differences in susceptibility to $\mathrm{CMV}$ infection between medial and intimal SMCs (Chapter 6). 


\subsection{References}

Adarn E, Melnick NL, Probtsfield JL, Petrie BL, Burek J, Bailey KR, Mc Collum CH, DeBakey ME. High levels of cytomegalovirus antibody inpatients requiring vascular surgery for atherosclerosis. Lancet 1987;2:291-293.

Adler $\mathrm{SP}$, Hur $\sqrt{\mathrm{K}}$, Wang $\mathrm{JB}$, Vetrovec $\mathrm{GW}$. Prior infection with cytomegalovirus is not a major risk factor for angiographically demonstrated coronary artery atherosclerosis. I Infect Dis 1998;177:209212 .

Adler SP. Cytomegalovirus infection in parents of children at day-care centers. N Engl J Med $1986 ; 315: 1164-1165$.

Bamji A, Salisbury R. Cytomegalovirus and vasculitis, Br Med I1978;1:623-624.

Becker RC, Cannon CP, Bovill EG, Tracy RP, Thompson B, Knatterud GL, Randall A, Braumwald B.Prognostic value of plasma fibrinogen concentration in patients with unstable and non- $Q$-wave myocardial infarction. Am $\mathbb{J}$ Cardiol 1996;78:142-147.

Beisser PS, Vink C, van Dam JG, Grauls $G$, Vanherle $S J$, Bruggeman CA. The R33 G protein coupled receptor gene of rat cytomegalovirus plays an essential role in the pathogenesis of viral infection. $J$ Virol $1998 ; 72: 2352-2363$.

Benditt EP, Barrett T, Mc Dougall JK. Viruses in the etiology of atherosclerosis. Proc Natl Acad Sci USA $1.983 ; 80: 6386-6389$.

Berberian PA, Myers W, Tytell M, Challa V, Bond MG. Immunohistochemical localization heat shock protein-70 in normal appearing and atherosclerotic specimens of human arteries. Am J Pathol $1990 ; 136: 71-80$.

Bevan IS, Daw RA, Day PJ, Ala FA, Walker MR. Polymerase chain reaction for detection of human cytomegalovirus in a blood donor population. Br J Hematol 1991;78:94-99.

Bhawan J, Gellis S, Ucci A, Chang T-W. Vesiculobullous lesions caused by cytomegalovirus infection in an immunocompromised adult. J AM Acad Dermatol 1984;11:743-747.

Bieber CP, Hunt Sa, Schwimm DA, Jamieson SA, Reaitz BA, Oyer PE, Shumway NE, Stinson EB. Complications in long-term survivors of cardiac transplantation. Transplant Proc 1981;XIII:207-211.

Billingham ME. Cardiac Transplant Proc 1987;19:19-25.

Billingham ME. Histopathology of graft coronary disease. J Heart Lung Transplant 1992;11:\$38-44.

Birnie D, Mc Kay IC, Hood S, Mc Coll KEJ, Hillis WS, Association between antibodies to mycobacterial heat shock protein 65 and coronary atheroscerosis; possible mechanism of action of Helicobacter pylori in increasing vascular risk. Heart 1996;75(suppl):

Blasi F, Denti F, Erba M, Cosentini R, Racanelli R, Rinaldi A, Fagetti L, Esposito G, Ruberti U, Allegra L. Detection of Chlamydia pneumoniae but not Helicobacter pylori in plaques of atherosclerotic aneurysms. J Clin Microbiol 1996;34:2766-2769.

Borish $B$, Jahn $G$, Scholl BC, Filger-Brillinger $J$, Heymer B, Fleckensyein B, Müller-Fermelink HK. Detection of human cytomegalovirus DNA and viral antigns in tissues of different manifestations of CMV infection. Virchows Arch B Cell Pathol 1988;55:93-99.

Bramagan TH. 3rd Retrovirol-associated vasculitis of the nerwous system. Neurol Clin 1997;15:927944.

Bruggeman CA, Debie WHM, Grauls GELM, Majoor G. Infection of laboratory rats with a new CMVlike virus. Arch Virol 1983;76:189-199. 
Bniggeman CA, Meijer $H_{3}$ Bosman F, van Boven CPA. Biology of rat cytomegalowirts infection. Intervirology $1985 ; 24: 1-9$

Bruning $\mathrm{JH}$. Cytomegalovirus infections in renal transplantation. Study in a rat model. PhD Thesis, 1988, Maastricht.

Bulpitt KJ, Brahn E. Systemic lupus erythematosus and concurrent cytomegalovirus vasculitis:Diagnosis by antemortem skin biopsy. J Rheumotol 1989;16:677-680.

Burke $G_{3}$ Nichols L, Balogh $K$, Hammer $S$, Jensen W, Pomposelli $F$, Jenkins R. Perforation of the terminal ileum with cytomegalovirus vasculitis and Kaposi's sarcoma in a patient with acquired immunodeficiency syndrome. Surgery 1987;102:540-545.

Campbell DA, Piercey JRA, Shnitka TK, Goldsand G, Devine RDO, Weinstein WM.

Cytomegalovirus-associated gastric ulcer. Gastroenterology 1977;72:533-535.

Campbell LA, O'Brien ER, Cappuccia AL, et al. Detection of Chlanydia pneumoniae TWAR in human coronary atherectomy tissues. I Infect Dis $1995 ; 172: 585-588$.

Campbell LA, Moazed TC, Kuo CC, Grayston JT. Mouse models of atherosclerosis and Chlamydia pneumoniae. Proc Third Eur Soc Chlam Res 1996;3:106(abstract).

Cassol SA, Poon MC, Pal R, Naylor MJ, Culver-James J, Bowen TJ, Russell JA, Krawetz SA, Pon RT, Hoar DI. Primer-mediated enzymatic amplification of cytomegalovirus (CMV) DNA. Application to the early diagnosis of CMV infection in marrow transplant recipients. J Clin Invest 1989;83:110911.15 .

Chandler SH, Handsfield HH, McDougall JK. Isolation of multiple strans cytomegalovirus from women attending a clinic for sexually transmitted diseases. J Infect Dis 1987;155:655-670.

Chiu B, Vira E, Tucker W, Fong IW. Chlamydia pneumoniae cytomegalovirus and herpes simplex virus in atherosclerosis of the carotid artery. Circulation 1997;96:2144-2148.

Collier AC, Handsfield HH, Roberts PL, DeRoven T, Meyers JD, Leach L, Murphy VL, Verdon M, Corey $\mathrm{L}$. Cytmegalovirus infection in women attending a sexually transmitted disease clinic. $J$ Infect Dis $1990 ; 162: 46-51$.

Cook PI, Lip GH, Beevers DG, Wise R, Honeyboume D. Chlamydia pneumoniae and acute arterial thrombotic disease. Circulation 1995:92:3148-3149.

Cooper HS, Raffensperger EC, Jonas L, Fitts WT. Cytomegalovirus inclusions in patients with ulcerative colitis and toxic dilatation requirig colonic resection. Gastroenterology $1977 ; 72: 1253-1256$.

Curtis $\pi$, Egbert BM. Cutaneous cytomegalovirus vasculitis: an unusual clinical presentation of a common opportunistic pathogen. Hum Pathol 1982;13:1138-1141.

Danesh $J$, Collins $R$, Peto R. Chronic infections and coronary heart disease:is there a link? Lancet $1997 ; 350: 430-436$.

Dankner WM, McCuthan JA, Richman DD, Hirata, Spector SA. Localization of human cytomegalovirus in peripheral leucocytes by in situ hybridization. I Infect Dis 1990;161:31-36.

Davies MJ, Thomas A. Thrombosis and acute coronary-artery lesions in sudden cardiac ischemic death. N Engl J Med 1984;310:1137-1140.

Dawies MJ, Woolf N, Rowles PM, Pepper J. Morphology of the endothelium over atheroselerotic plaques in human coronary arteries. Br Heart J 1988;60:459-463.

Desmoulière A, Gabbiani $G$. The role of arterial smooth muscle cells in the pathogenesis of atherosclerosis. Cerobrovasc Dis 1992;2;63071. 
Diepersloot RUA, Kroes ACM, Wisser W, Jiwa M, Rothbart PH. Acute ulcerative proctocolitis associated with primary cytomegalowirus infection. Arch Int Med 1990; 150:1749-1751.

Doerr HW, Cytomegalovirus infection in pregnancy. I Virol Methods 1987;17:127-132.

Doherty M, Bradfield JWB. Polyarteritis nodosa associated with acute cytomegalovirus infection. Ann Rheum Dis 1981, $40: 419-421$.

Eich D, Thompson JA, Ko D, Hastillo A, Lower R, Katz S, Katz M, Hess ML. Hypercholesterolemia in long-term survivors of heart transplantation; an early marker of accelerated coronary artery disease. $J$ Heart Lung Transplant 1991;10:45-49.

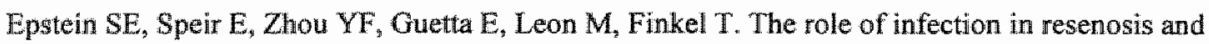
atherosclerosis: focus on cytomegalowirus.Lancet 1996;348(Suppl 1):\$13-\$17.

Etingin OR, Haijar DP. Evidence for cytokine regulation of chollesterol metabolism in herpesvinusinfected arterial cells by the lipoxygenase pathway. J Lipid Res 1990;31:299-305.

Everett JP, Hershberger RE, Norman DJ, Chou S, Ratkovec RM, Cobanoglu A, On GY, Hosenpud JD. Prolonged cytomegalovirus infection with viremia is associated with development of cardiac allograft vasculopathy. J Heart Lung Transplant 1992;11:S133-137.

Fabricant $\mathrm{CG}$, Fabricant J, Litrenta MM, Minick CR. Virus-induced atherosclerosis. J Exp Med $1978 ; 148: 335-340$.

Fabrikant CG. Herpesvirus-induced atherosclerosis. Diabetes 1981a:30;(Suppl 2):29-31.

Fabrikant $\mathrm{CG}_{4}, \mathrm{Hajjar}$ DP,Minick CR, Fabricant J. Herpesvirus infection enhances cholesterol and cholesteryl ester accumulation in cultured arterial arterial smooth muscle cells. Am J Pathol $1981 b_{*} 105(2): 176-184$.

Fabricant CG, Fabricant J, Minick CR, Litrenta MM. Herpesvirus-induced atherosclerosis in chickens. Fed Proc 1983;42:2476-2479.

Faggiotto A, Ross R, Harker L. Studies of hypercholesterolaemia in the non human primate. I. Changes that lead to fatty streak formation. Arterisclerosis 1984a;4:323-340.

Faggiotto A, Ross R. Studies of hypercholesterolaemia in the non human primate. II. Fatty streak conversion to fibrous plaque. Arteriosclerosis $1984 b ; 4: 341-356$.

Felcman PS, Walker AN, Baker $\mathbb{R}$. Cutaneous lesions heralding disseminated cytomegalovirus infection. J Am Acad Dermatol 1982;7:545-548.

Foucar E, Mukai K, Foucar K, Sutherland DER, Van Buren CT. Colon ulceration in lethal cytomegalovirus infection. Am J Clin Pathol 1981;76:788-801.

Francis ND, Boylston AW, Roberts AHG, Parkin JM, Punching AJ. Cytomegalovirus infection in gastrointestinal tracts of patients with HIV-I or AIDS. J Clin Pathol 1989;42;1055-1064.

Frank D, Raicht RF. Intestinal perforation associated with cytomegalovirus infection in patients with acquired immunodefieiency syndrome. Am J Gastroenterol 1984;79;201-205.

Freedman PG, Weiner BC, Balthazar EJ. Cytomegalovirus esophagogastritis in a patient with acquired immunodeficiency syndrome. AM J Gastroenterol 1985;80:434-437.

Gao SZ, Schroeder JS, Alderman EL. Hunt SA, Silverman JF, Wiederholt V, Stinson EB. Clinical and laboratory correlates of accelerated coronary artery disease in the cardiac transplant patient. Circullation $1987 ; 76$ (SupplV):56-61.

Gao SZ, Alderman JS, Schroeder JF, Silwerman JF, Hunt SA. Accelerated coronary vascular disease in the heart transplant patient; coronary arteriographic findings. J Am Coll Cardiol 1988; 12:334-340. 
Gaydos CA, Summersgill JT, Shaney NN, Ramirez JA, Qumn TC. Replication of Chamydia pneumoniae in vitro in human macrophages, endothelial cells, and aortic artery smooth musele cells. Infect Immunity 1996;64:1614-1620.

Guetta E, Guetta V, Shibutani T, Epstein SE. Monocytes harboring cytomegalovirus: interactions with endothelial cells, smooth muscle cells, and oxidized low-density lipoprotein. Possible mechanisms for activating virus delivered by monocytes to sites of vascular injury. Circ Res. 1997;81:8-16.

Golden MP, Hammer SM, Wanke CA, Albrecht MA. Cytomegalovirus vasculitis. Case reports and review of the literature. Medicine 1994;73:246-255.

Goodgame RW. Gastrointestinal cytomegalovirus disease. Ann Intern Med 1993;119:924-935.

Goodman MD, Porter DD. Cytomegalovirus vasculitis with fatal colonic hemorrhage. Arch Pathol 1973;96:281-284.

Grattan MT, Moreno Cabral CE, Starnes VA, Oyer PE, Stinson EB, Shumway NE. Cytomegalovirus infection is associated with cardiac allograft rejection and atherosclerosis. JAMA 1989;261:3561-3566.

Grayston JT, Kuo CC, Wang SP, Alman J. A new Chlamydia psittaci strain called TWAR from acute respiratory tract infections. N Engl J Med 1986;315:161-168.

Grayston JT, Kuo CC, Coulson AS, et al. Chlanydia pneumoniae (TWAR) in atherosclerosis of the carotid artery. Circulation 1995;92;3397-3400.

Guarda LA, Luna MA, Smith JL, MansellPWA, Gyorki F, Roca AN. Acquired immune deficiency syndrome: Postmortem findings. Am J Clin Pathol 1984;81:549-557.

Guetta E, Guetta V, Shibutani T, Epstein SE. Monocyts harboring cytomegalovirus:interactions with endothelial cells, smooth muscle cells, and oxidized low-density lipoprotein. Possible mechanisms for activating virus delivered by monocytes to sites of vascular injury. Circ Res 1997:81:8-16.

Gupta S, Leathann EW, Carrington D, Mendall MA, Kasi JC, Camm AJ. Elevated Chlamydia pneumoniae antibodies, cardiovascular events, and azithromycin in male survivors of myocardial infarction. Circulation 1997;96:404-407.

Gurfinkel E, Bozowich $G$, Daroca A, Beck $E_{3}$ Mautner $B$. Randomised trial of roxithromycin in non-Qwave coronary syndromes: ROXIS pillot study. Lancet 1997;350:404-407.

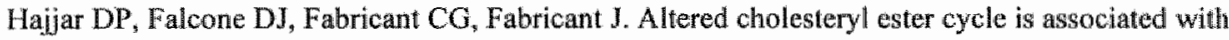
lipid accumulation in therpesvirus-infected arterial smooth muscle cells. J Biol Chem 1985;260:6124* 6128 .

Hajjar DP, Fabricant CG, Minick CR, Fabricant J. Virus-induced atherosclerosis. Herpesvirus infection alters aortic cholesterol metabolism and accumulation. Am J Pathol 1986;122:62-70.

Hansson GK, Jonasson L, Holm J, Claesson-Welsh L. Class II MHC antigen expression in the atherosclerotic plaque:smooth muscle cell express HLA-DR, HLA-DQ and the invariant gamma chain. Chin Exp Immunol 1986;64:261-268.

Hansson GK, Jonasson L, Lojsthed B, Stemme $\mathrm{S}$, Kocher $\mathrm{O}$, Gabbiani G. Localisation of $\mathrm{T}$ lymphocytes and macrophages in fibrous and complycated human atherosclerotic plaques.Atherosclerosis 1988;72:135-141.

Hansson GK, Holm J, Jonasson L. Detection of activated $\mathrm{T}$ lymphocytes in the human atherosclerotc plaque. Am J Pathol 1989;135:169-175.

Hansson GK. Immunological control mechanisms in plaque formation. Basic Res Cardiol 1994;89:4146 . 
Haverkate $\mathrm{F}_{*}$, Thompson $\mathrm{SG}_{*}$ Pyke SD, Gallimore JR, Pepys MB. Production of C-reactive protein and risk of coronary events in stable and unstable angina. European Concerted. Action on Trombosis and Disabilities Angina Pectoris Study Group. Lancet 1997;349:462

Hăyry P, Mennander A, Raisannen-Sokolowski A, Ustinov J, Lemström K. Aho P, Yilmaz S, Lautenschlager I, Paavonen T. Pathophysiology of vascular wall changes in chronic allograft rejection. Tramsplasnt Rev 1993;7:1-20.

Hendrix MGR, Dormans $\mathrm{PH}_{3}$ Kitselaar $\mathrm{P}$, Bosman $\mathrm{F}$, Bruggeman $\mathrm{CA}$. The presence of cytomegalovirus mucleic acids in arterial walls of atherosclerotic and non-atherosclerotic patients. Am I Pathol 1989:134:1151-1157.

Hendrix RMG, Wagenaar M, Slobbe RL, Bruggeman CA. Widespread presence of cytomegalovirus DNA in tissuses of healthy trauma victims. J Clin Pathol 1997;50:59-63.

Hinnant $\mathrm{KL}_{\text {, }}$ Rotterdam $\mathrm{HZ}$, Bell ET, Tapper ML. Cytomegalovirus infection of the alimentary tract: a clinicopathological correlation. Am I Gastroenterol 1986;81:944-950.

Hirota K, Muraguchu K, Watabe N, Okumura M, Kozu M, Takahashi K, Machida Y, FunayamaX, Numazaki $Y$. Prospective study on maternal intrauterine and perinatal infections with cytomegalovirus in japan during 1976 1990.J Med Virol 1992;37:303-306.

Ho M, Cytomegalowirus, Biology nd Infection. New York, Plenum Medical Books 1991.

Hosenpud JD, Shipley GD, Wagner CR. Cardiac allograft vasculopathy; current concepts, recent developments, and future directections J Heart Lung Transplant 1992;11:9-23.

Hruban RH, BBeschorner WE, Baumgartner WA, Augustine SM, Ren H, Reitz BA, Hutchins GM. Accelerated arteriosclerosis in heart transplant recipients is associated with a T-lymphocyte-mediated endothelialitis. Am $\mathrm{J}$ Pathol 1990;137:871-872.

Isik FF, McDonald TO, Ferguson M, Yamanaka E, Gordon D. Transplant arteriosclerosis in a rat aortic model. Am J Pathol 1992:141:1139-11:49.

Jiwa NM, van de Rijke FM, Mulder A, van der BIJ,W, The TH, Rotbarth PH, Velzing J, vad der Ploeg M, Raap AK. An improved immunocytochemical method for the detection of human cytomegalovinus antigens in peripheral blood leucocytes. Histochemistry 1989a;91:345-349.

Jiwa NM, van Gemert GW, Raap AK, van de Rijke FM, Mulder A, Lens PF, Salimans MMM, Zwaan $F^{2}$, van Dorp $W$, van der Ploeg $M$. Rapid detection of human cytomegalovirus DNA in peripheral leucocytes of viremic transplant recipients by the polymerase chain reaction. Transplantation $19896 ; 48: 72-76$.

Johnson DE, Alderman EL, Scliroeder JS, Gao SZ, Hunt S, Dacmpli WM, Stinson E, BillinghamM. Transplant coronary artery disease: histopathologic correlations with angiographic morphology. J Am Coll Cardiol 1991:17:449-457.

Jonasson L, Holm J, Skalli O, Gabbiani G, Harsson GK. Expression of class II transplantation antigen on varscular smooth muscle cells in human atherosclerosis. J Clin Invest 1985; 76:125-131.

Jonasson L, Holm J, Skalli O, Bondjers G, Hansson GK. Regional accumulations of T cells, macrophages, and smooth muscle cells in the human atherosclerotic plaque. Arteriosclerosis $1986 ; 6: 131-138$.

Jonasson L, Holm J, Hansson GK. Smooth muscle cells express Ia antigens during arterial response to injury. Lab Invest 1988;58:310-315.

Jordan MC, Rousseau WE, Noble GR, Association of cervical cytomegaloviruses with veneral disease. N Engl J Med 1973;288:932-93:4. 
Kalayijan RC, Cohen ML, Bonumo RA, Flanigan. Cytomegaloviurus ventriculoencephatitis in AIDS:A symdrome with distinct clinical and pathologic features Medicine (Baltimore) 1993;72:67 77.

Kaye MP. The registry of the international society for heart and lung transplantation:tenth official report. J Heart Lung Transplant 1993;12:541-548.

Kimura K, Kaburagi S, Tamura T, Yokoi H, Nakagawa Y, Yokoi H, Hamasaki N, Nosoka H, Nobuyoshi $M$,

Klatt EC, Shibata D. Cytomegalovirus infection in the acquired ummunodeficiency syndrome: Clinical and autopsy findings. Arch Pathol Lab Med 1988;112:540m544.

Klotman ME, Henry SC, Greene RC, Brazy PC, Klotman PE, Hamilton. Detection of miouse cylomegalovirus nucleic acid in latently infected mice by in vitro enzymatic amplification. I Infect Dis $1990 ; 161: 220-225$.

Knapp AB, Horst DA, Eliopoulos G, Gramm HF, Gaber LW, Falchulk KR, Falchuk ZM, Trey C. Widespread cytomegalovirus gastroenterocolitis in a patient with the acquired immunodeficiency syndrome. Gastroenterology 1989;85:1399-1402.

Koeppen AH, Lansing LS, Peng S-K, Smith RS. Central nervous system vasculitis in cytomegalovirus infection. J Neurol Sci 1981;51:395-410.

Koskinen PK, Krogerus LA, Nieminen MS, Mattila SP, Hayry PI, Lautenschlager IT. Quantitation of cytomegalovirus infection-associated histologic findings in endomyocardial biopsies of heart allografts. J Heart Lung Transplant 1993a; 12:343-354.

Koskinen PK, Nieminen MS, Krogerus LA, Mattila SP, Hayry PJ, Lautenschlager IT. Cytomegalovirus. infection accelerates cardiac allograft vasculopathy: correlation between angiographic and endomyocardial biopsy findings in heart transplant patents. Transpl Int 19936;6:341-347.

Koskinen PK, Nieminen MS, Krogerus LA, Mattila SP, Hayry PJ , Lautenschlager IT. Cytomegalovirus infection and accelerated cardiac allograft vasculopathy in human cardiac allografts. J Heart Lung Transplant 1993c;12:724-729.

Koskinen PK. The association of the induction of vascular cell adhesion molecule-I with cytomegalovirus antigenemia in human allografts. Transplantation 1993d;53:1103-1108.

Koskinen PK, Lemström KB, Bruggeman CA, Lautenschlager IT, Häyry. Acute cytomegalowinus infection induces a subendothelial inflammation (endothelialitis) in the allograft vascular wall. A possible linkage with enhanced al lograft arteriosclerosis. Am I Pathol 1994; 144:41-50.

Kundo K, Kaneshima H, Mocarski ES. Human cytomegalovirus latent infection of granulocyte. macrophage progenitors. Proc Natl Acad Sci USA 1994;91:11879-11883.

Kundo K, Mocarski ES. Cytomegalowirus Jatency and latency-specific transcription in hemopietic progenitors. Scand JInfect Dis Suppl 1995; Suppl 99:63-67.

Kundo K, Xu J, Mocarski ES. Human cytomegalovirus latent gene expression in granulocytemacrophage progenitors in culture and in seropositive individuats. Proc Natl Acad Sci USA 1996;93:11137-11142.

Kuo CC, Gown AM, Benditt EP, Grayston IT. Detection of Chlanydia pneumoniae in aortic lesions of atherosclerosis by immunocytochemical stain. Arterioscler Thromb 1993;13:1501-1504.

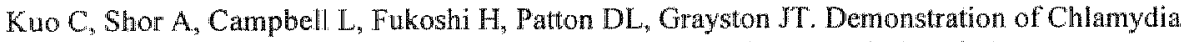
pheumoniae in aortic lesions of coronary arteries. J Infect Dis 1993;167:841-849.

Kuo CC, Grayston JT, Campbell LA, Goo YA, Wissler RW, Benditt EP. Chlamydia pneumoniae (TWAR) in coronary arieries of Young adults (15-34 years old). Proc Natl Acad Sci USA 
$1995 ; 92: 6911-6914$

Lafont A, Guzman LA, Whitlow PL, Goomastic M, Cornhill JF, Chisholm GM. Restenosis after experimental angioplasty. Intimal, medial, and adventitial changes associated with constrictive remodeling. Circ Res 1995,76:996-1002.

Lee JYY. Cytomegalowirus infection involving the skin in immunocompromised hosts. A clinicopathologic study. Ams Pathol 1989:92:96-100.

Leinonen M. Pathogenetic mechanisms and epidemiology of Chlamydia pneumoniae. Eur Heart I $1993 ; 14$ Suppl $\mathrm{K}: 57-61$.

Lemström KB, Brüning JH, Bruggeman CA, Lautensichlager IT, Hayry PJ. Cytomegalovirus infection cnhances smooth muscle cell proliferation and intimal thickening of rat aortic allografts. J Clin Invest $1993 ; 92: 549-558$.

Lemström KB, Aho PT, Bruggeman CA, Hayry PJ. Cytomegalovirus enhances MRNA expression of platelet-derived growth factor $\mathrm{BB}$ and transforming growth factor-beta 1 in rat aortic allografts. Possible mechanism for cytomegalovirus-enhanced graft arteriosclerosis. Arterioscler Thromb $1994 a ; 14: 2043-2052$.

Lemström KB, Bruning $\sqrt{ }$, Koskinen P, Bruggeman C, Lautenschlager I, Hayry P. Triple-drug immunosuppression significantly reduces chronic rejection in non-infected and RCMV-infected rats. Transplant Proc 1994b;26:1727-1728.

Lemström KB, Bruning JH, Bruggeman CA, Koskinen $\mathrm{PK}$, Aho PT, Yilmaz S, Lautenschlager IT, Hayry PJ. Cytomegalovirus infection-enhanced allograft arteriosclerosis is prevented by DHPG prophylaxis in the rat. Circulation 1994c;90:1969-1978.

Lemström KB, Brüning JH, Bruggeman $\mathrm{CA}$, Lautenschlager IT, Hayry PJ. Triple drug immunosuppression significantly reduces immume activation and allograft arteriosclerosis in cytomegalovirus-infected rat aortic allografts and induces early latency of wiral infection. Am J Pathol $1994 d ; 144: 1334-1347$.

Lemström $\mathbb{K}$, Koskinen $\mathbb{K}, P$, Krogerus L, Daemen M, Bruggeman C, Hayry P. Cytomegalovirus antigen expression, endothelial cell proliferation, and intimal thickening in rat cardiac allografts after cytomegalovirus infection. Circulation 1995;92:2594-2604.

Levinson W, Bennets RW. Cytomegalovirus colitis in acquired immunodeficiency syndrome:A chronic disease with varying manifestations. Am J Gastroenterol 1985;80:445-447.

Li F, Grauls $G$, Yin M, Bruggeman C. Correlation between the intensity of cytomegalowirus infection and the amount of perivasculitis in aortic allografts. Transpl Int 1996a;9S340-S344.

Li F, Grauls $G$, Yin M, Bruggeman $C$. Initial endothelial injury and cytomegalovirus infection accelerate the development of allograft arteriosclerosis. Transplantation Proceedings 1996b;27:35523554 .

Libby $\mathrm{P}$, Hansson $\mathrm{GK}_{\mathrm{y}}$ Inwolvement of the immune system in human atherogenesis:current knowledge and unanswered questions. Lab Invest 1991;64:5-15.

Lin CS, Penha PD, Krislnan MN, Zak FG. Cytomegalic inclusion disease of the skin. Arch Dermatol $1981 ; 117: 282-284$.

Loebe $\mathrm{M}$, Schuler $\mathrm{S}$, Zais $\mathrm{O}$, Warnecke $\mathrm{H}$, Fleck E, Hetzer R. Role of cytomegalovirus infection in the development of coronary artery disease in the transplanted heart. J Heart Transplant 1990;9:707-711.

Masuda J, Ross R. Atherogenesis during low level hypercholesterolaemia in the non human primate. I. Fatty streak formation. Arteriosclerosis 1990;10:164-177. 
Masuda $J_{\text {, Ross }} \mathrm{R}$. Atherogenesis during low level hypercholesterolaemia in the non human prinate, II. Fatty streak conversion to fibrous plaque. Arteriosclerosis 1990;10:178-187.

Matilla KJ, Valtonen VV, Nieminen MS, Asikannen S. Role of infection as a risk factor for atherosclerosis, myocardial infarction, and stroke. Clin Infect Dis 1998;26:719-734.

Mc Donald K, Rector TS, Braulin EA, Kubo SH, Olivari MT. Association of coronary artery disease in cardiac transplant recipients with cytomegalowirus infection. Am J Cardiol 1989;64:359-36

Mc Gill HC jr. Persistent problems in the pathogenesis of atherosclerosis. Arteriosclerosis $1984 ; 4: 443-$ 451 .

Mejer H, Dormans PHJ, Geelen JLMC, van Boven CPA. Rat cytomegalovirus:studies on the virid: genome and the proteins of virions and nucleocapsids. Arch Virol 1986;89:45-46.

Melnick $\mathrm{J}$, Hu C, Burek J, Adam E, DelBakey ME. Cytomegalovirus DNA in arterial wall of patients with atherosclerosis. J Med Virol 1994;42:170-174.

Melnick JL, Petrie BL, Dreesman GR, Burek J, McCollum CH, DeBakey ME. Cytonegalovinus antigen within human arterial smooth muscle cells, Lancet $1983 ; 2: 644-647$.

Mendall MA, Goggin PM, Molineaux $\mathrm{N}_{\text {, Levy }} \mathrm{J}_{\text {, Toosy }} \mathrm{T}$, Strachan $\mathrm{D}_{n}$ Camm AJ, North field TC. Relation of Helicobacter pylori infection and coronary heart disease. Br Heart J 1994;71:437 439.

Mendall MA, Patel $P$. Ballam L, Strachan D, Northfield $[C, C$ reactive protein and its relation to cardiovascular risk factors: a population based cross sectional study. BMJ 1996;312:1061-1065.

Mendall MA, Patel P, Ballam L, Strachan D, Northfield TC. C reactive protein and its relation to cardiovascular risk factors:a poulation based cross sectional study. BMJ 1996;312:1061-1065.

Mennander A, Tiisala S, Halttunen $J$, Yilmaz S, Pawonen T, Hayry $P$. Chronic rejection in rat aortic allografts. An experimental model for transplant arteriosclerosis. Arterioscler Thromb 1991;11:671680 .

Mercer JA, Spector DH. Pathogenesis of acute murine cytomegalovirus infection in resistant and susceptible strains of mice. J Virol 1986;57:497-504.

Mercer JA, Wiley CA, Spector DH.Pathogenesis of murine cytomegalovirus infection: identification of infected cells in the spleen during acute acute and latent infections. J Virol 1988;62*987-997.

Minare N, Siverman JF, Eacobar MR, Martinez AJ. Fatal cytomegalic inclusion disease. Arch Dermatol 1977;113:1589-1571.

Minick CR, Fabricant CG, Fabricant J, Litrenta MM. Atheroarteriosclerosis induced by infection with a herpesvirus. Am J Pathol 1979;96:673-706.

Mintz GS, Kent KM. Pichard AD, Satler LF, Popma JJ, Leon MB. Contribution of inadequate arterial remodeling to the development of the focal coronary artery stenoses. An intravascular ultrsound study. Circulation 1997;95:1791-1798.

Minz GS, Popma J, Leon MB. Remodelling of human coronary arteries undergoing angioplasty or atherectomy. Circulation 1997;96:475; 483 .

Moazed TC, Kuo CC, Grayston JT, Campbell LA. Murine models of Chlamydia pnenmoniae infection and atherosclerosis. J Infect Dis 1997;175:883-890.

Morgello S, Cho ES, Nielsen S, Devinski O,Petito CK. Cytomegalovirus encephalitis in patients with acquired immunodeficiency syndrome:An autopsy study of 30 cases and a review of the literature. Human Pathol 1987;15:289-297.

Mori T, Sazaki J, Kawaguchi H, Handa K, Takada X, Matsunaga A, Kono S, Arakawa K. Serum 
glycoproteins and severity of coronary aheroscherosis. Am J Heart I 1995;129:234-238.

Muhlestein $\mathrm{JB}_{3}$ Hammond $\mathrm{EH}_{4}$, Carlquist JF, Radicke E, Thomson MJ, Karagounis $\mathrm{L}$ A, Woods ML, Anderson JL. Increased incidence of Chlamydia species within the coronary arteries of patients with symptomatic atherosclerotic versus other forms of cardiovascular disease. I Am Coll Cardiol. $1996: 27: 1555-1561$.

Muhlestein JB, Anderson IL, Hammond EH, Zhao L, Trehan S, Schwobe EP, Carlquist JF. Infection with Chlamydia pneumoniae accelerates the development of atherosclerosis and treatment with azithromycin prevents it in a rabbit model. Circulation. 1998;97:633-636.

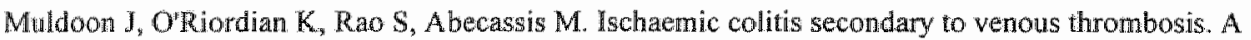
rare presentation of cytomegalovirus vasculitis following renal transplantation. Transplantation $1996: 61: 1651-1653$.

Muller-Stameau A, Senn H., Emody G. Epidemiolysis in a case of severe cytomegalovinu infection. B Med J 1974;3:609-610.

Munro JM, Cotran RS. The pathogenesiss of atherosclerosis: atherogenesis and inflammation. Lab Invest $1988 ; 58: 249-261$

Murray LJ, Bamfort KB, OReilly DPS, Mc Crum EE, Evans AE. Helicobacter pylori infection: relation with cardiovascular risk factors, ischaemic heart disease, and social class. Br J Heart J 1995;74;497501 .

Musiani M, Zurbini ML, Muscari A, Puddu GM, Gentilomi G, Gibellini D, Gallinella G, Puddu P, La Placa M.

Antibody patterns against cytonegalovirus and Epstein-Barr virus in human atherosclerosis. Microbiologica 1990;13:35-41.

Narrod J, Kormos R, Armitage J, Hardesty R, Ladowski J, Griffith B. Acute rejection and coronary artery disease in longaterm survivors of heart transplantation. J Heart Transplant 1989;8:418-420.

Nicholson AC, Hajjar DP. Herpesviruses in atherosclerosis and thrombosis. Etiologic agents or ubiquitous bystanders. Arterioscler Thromb Vasc Biol 1998;18:339-348.

Niedt GW, Schinella RA. Acquired immunodefeciency syndrome:Clinicopathologic study of 56 autopsies. Arch Pathol Lab Med 1985;109:727-734.

Nieto FJ, Adam E, Sorlie P, Farzadegan H, Melnick JL, Comstock GW, Szklo M. Cohort study of cytonegalovirus infection as a risk factor for carotid intimal-medial thickening, a measure of subclinical atherosclerosis. Circulation 1996;94:922-927.

Njenga KM, Dangler CA. Endothelial MHC class II antigen expression and endarteritis associated with Marelk's disease virus infection in chickens. Vet Pathol 1995;32:403-411.

Nienga MK, Dangler CA. Intimal lipid accretion and elevated serum cholesterol in Marek's disease virus-inoculated chickens. Vet Pathol 1996;33:704-708.

Nomann SI, Salomon DR, Leelachchaikul P, Khan SR, Staples ED, Alexander JA, Mayfield WR, Knaf DG, Sadler LA, Selman $S$. Acte vascular rejection of the coronary arteries in human heart transplantation pathology and correlations with immunosuppression and cytomegalovirus infection. $f$ Heart Lung Transplant 1991;10(5Pt):674-687.

OBrien ER, Alpers CE, Stewart DK, Ferguson M, Tran N, Gordon D, Benditt EP, Hinohara T, Simpson JB, Schwartz SM. Proliferation in primary and restenotic coronary atherectomy tissue. Implications for anti-proliferative therapy. Circ Res 1993;73:223-231.

Olvari MT, Homans DC, Wilsin RF, Kubo SH, Ring WS. Coronary artery disease in cardiac transplant patients receiving triple drug immunosuppressive therapy. Circulation 1989;80:(SupplIn):111-115. 
Ong G, Thomas BJ, Mansfield AO, Dawidson BR, Taylor Robinson D. Detection and widespread distribution of Chlamydia pneumoniae in the vascular system and its posilble implications. 1 Clin Pathol 1996:49:102-106.

Orloff J, Saito $\mathbb{R}$, Lasky $S$, Dave H. Toxic megacolon in cytomegalovirus colitis. An I Gastroenterol 1989;54:1021-1035;

Palinski W, Rosenfeld ME, Ylä-Herttuala S, Gurtner GC, Socher SS, Butler SW et al. Low density lipoprotei undergoes oxidative modification in vivo. Proc Natl Acad Sci USA 1989;86:1372-1376.

Pass RF, August AM, Dworsky M, Reynolds DW. Cytomegalovitus infection in a day-care center. $N$ Engl J Med 1982;307;477-479.

Pass RF, Hutto SC, Reynolds DW, Polhill RB. Increased frequency of cytomegalovirus infection in children in group day-care. Pediatrics 1984;74:121-126.

Pass $\mathbb{R F}$, Hutto $\mathrm{SC}$, Ricks $\mathrm{R}$, Cloud GA. Increased rate of cytomegalovirus infection among parents of children attending day-care centers. N Engl J Med 1986;307:1414-1418.

Patel P, Mendall MA, Carrington D et al. Association of Helicobacter pylori and Chlamydia preumoniae infections with coronary heart disease and cardiovascular risk factors. BMJ 1995311:711. 714. (Erratum BMJ 1995;311:985)

Pauletto $\mathrm{P}$, Pisoni G, Boschetto R, Zoleo M, Pessina AC, Palu G. Human cytomegalovirus and restenosis of the internal carotid artery. Stroke 1996;27:1669-1671.

Petrie BL, Melnick IL, Adam E, Burek J, McCollum CH, DeBakey ME. Nucleic acid sequences of cytomegalovirus in cells cultured from human arterial tissue. J Infect Dis 1987; 155:158 1159.

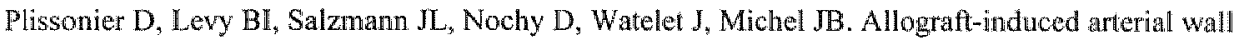
injury and rasponse in normotensive and spontaneously hypertensive rats. Arterioscler Thromb $1991 ; 11: 1690-1699$.

Plissonier D, Nochy D, Poncet P, Mandet C, Minglais N, Bariety J, Michel JB. Sequential inmunological targetting of chronic experimental arterial allograft. Transplantation 1995:60:414-424.

Pomeroy C, Hilleren PJ, Jordan MC.Latent murine cytomegalovirus DNA in splenic stromal cells of mice J Virol 1991;656:3330-3334.

Pouteil-Noble C, Ecochard R, Landrivon G, Donia-Mged A, Tardy IC, Bossshard S, Colon S, Betuel $\mathbb{H}$, Aymard M Touraine JL. Cytomegalovirus infection -an etiological factor for rejection. A prospective study in 242 renal transplant patients. Transplantation 1993;55:851-857.

Puolakkainen M, Kuo CC, Shor A, Wang SP, Grayston IT, Campbell LA. Serological ressonse to Chlamydia pneomoniae in adults with coronary arteriall fatty streaks and fibrilipid plaques. $J \mathrm{Clin}$ Microbiol 1993;31:2212-2214.

Radovancevic B, Poindexter S, Birovljev S, Velebit V, MacAllister HA, Duncan JM, Vega D, Lonquist J, Burnett CM, Frazier OH. Risk factors for the development of accelerated coronary artery disease in cardiac transplant recipients. Eur J Cardiothorac Surg 1990;36:M555-M558.

Raza Ahmad A, Klasen GA, Murhy DA, Sullivan JA, Kinley CE, Landymore RW, Wood JR. Evidence of type 2 herpes simplex infection in human coronary arteries at the time of coronary artery bypass surgery. Can J cardiol 1995; 11:1025-1029.

Ridker PM, Cushman M, Stampfer MJ, Tracy RP, Hennekens CH. Plasma concentration of C-reactive protein and risk of developing peripheral vascular disease. Circulation 1998;97:425-428.

Roberts WH, Sneddon JM, Waldman J, Stephens RA. Cytomegalovirus infection of gastrointestinal endothelium demonstrated by simultaneous nucleic acid hybridisation and immunocytochemistry. Arch 
Pathol Lab Med 1989;113:461:464.

Robertson AL Jr, Katsura Y, Stein RU. Viral genomes and arterial disease. Am N Y Acad Sci $1995 ; 748: 57-72$.

Rosenfield ME, Tsukada T, Gown AM, Ross R. Fatty streak initiation in Watanable heritable hyperlipidemic and comparably hyperchesterolemic fat-fed rabbits. Arteriosclerosis 1987:7:9-23.

Koss $R_{\text {}}$ Glomset JA. The pathogenesis of atherosclerosis. New Engl J Med 1976;295:369-377, 420425 .

Ross R. Atherosclerosis: a defense mechanism gone awry. Am J Pathol 1993;143:987-1002.

Ross R. The pathogenesis of atherosclerosis - An Update. New Engl J Med 1986;314:488-499.

Ross R. The pathogenesis of atheroscterosis: a perspective for the 1990s. Nature 1993;362:801-809.

Rubin RH, Wilson EJ, Barrett LV, Medearis DN. Primary cytomegalovinus infection following cardiac transplantation in a murine model. Transplantation 1984;37:306-310.

Russell ME, Fujita M, Masek MA, Rowan RA, Billingham ME. Cardiac graft vascular disease. Nonselective involwement of large and snall vessels. Transplantation 1993;56:762-764.

Saikku P, Leinonen M, Mattla $K$ et all. Serologic evidence of an association of a novel Chlamydia, Twar, with chronic coronary heart disease and acute myocardial infarction. Lancet 1988; 7-10.

Salonen JT, Yü-Hertuala $\mathrm{S}$, Yamamoto R, Butler S, Korpela H, Salonen R et al. Autoantibody against axidised LDL and progression of carotid atherosclerosis. Lancet 1992;339:883-887.

Sandler A, Snedeker JD. Cytomegalovirus infection in an infant presenting with cutaneous vasculitis. Pediatr Infect Dis J 1987;6:422-423.

Schulte HJ, Schonfield R, Kohler E, Assmann G. Association of variables of coagulation, fibrinolysis and acute-phase with atherosclerosis in coronary and peripheral arteries and those arteries supplying the brain. Thromb Haemost 1995;73:374-379.

Shanley Jd, Biczak L, Forman SJ. Acute murine cytomegalovirus infection induces lethal hepatitis. J Infect Dis 1993;167:264-269.

Sharples LD, Caine N, Mullins P, Scot JP, Solis E, English TA, Large SR, Schofield PM, Wallwork J. Risk factor analysis for the major hazards following heart transplantation--rejection, infection, and coronary occlusive disease. Transplantation. 1991;52:244-252.

Stibata D. Klatt ec. Analysis of human immunideficiency virus and cytomegalovirus by polymerase chain reaction in the acquired immunodeficiency syndrome. Arch Pathol Lab Med 1989;113:1239. 1244.

Shih JCH, Pullman EP, Kao Ku. Genetic selection, general characterization and histology of atherosclerosis-susceptible and-resistant Japanese quail. Atherosclerosis $491983 ; 49,41-53$.

Sidi S, Graham JH, Razvi SA, Banks PA. Cytomegalovirus infection of the colon associated with ulcerative colitis. Arch Surg 1979;114:857-859.

Sonnenberg A. Concordant occurrence of gastric and hypertensive diseases. Gastroenterology $1088 ; 95: 42-48$

Sorlie PD, Adam E, Melnick SL, Folsom A, Skelton T, Chambles LE, Barnes R, Melnick JL. Cytonnegalovirus/herpesvirus and carotid atherosclerosis: the ARIC Study. J Med Virol 1994;42:33-37.

Span AHM, Endert J, van Bowen CPA, Bruggeman CA. Virus induced adherence of monocytes to endothelial cells. FEMS Microbiol Immunol 1.989; 47:237-244 
Span AIM, van DAM-Mieras MCE, Mullers W, Endert J, Muller AD, Bruggeman CA. The effect of virus infection on the adherence of leucocytes or platelets to endothelial cells. Eur J Clin Inwest 1991; $21: 721-731$

Span AHM, Frederik PM, Grauls $G$, van Bocen CPA, Bruggeman CA. CMV induced vascular injury: an electron microscopic study in the rat. In viwo 1993;7:567-574.

Speir E, Modali R, Huang ES, Leon, Shawl F, Finkel T, Epstein SE. Potential role of human cytomegalovirus and p53 interaction in coronary retenosis. Science 1994;265:391-394.

Stagno S, Pass RF, Dworsky ME, Henderson RE, Moore EG, Walton PD, Alford CA. Congenital cytomegalowirus infection: The relative importance of primary and recurrent matemal infection. $N$ Engl J Med. 1982;306:945-949.

Stals FS, Bosman F, van Boven CPA, Bruggeman CA. An animal model for therapeutic intervention studies of CMV infection in the immunocompromised host. Arch Virol 1990;114:91-107.

Stals FS, Steinhoff G, Wagenaar SS, van Breda Vriesman IP, Haverich A, Dormans P, Moeller F, Bruggeman $\mathrm{CA}$. Cytomegalovirus induces interstitial lung disease in allogeneic bone marrow transplant recipient rats independent of acute graft-versus-host response. Lab Invesit. 1996;74:343-352.

Stanier P. Taylor DL, Kitchen AD, Wales N, Tryhorn Y, Tyms AS. Persistence of cytomegalovirus in mononuclear cells in peripheral blood from blood donors. Br Med J 1989;299:897-898.

Stary $\mathrm{HC}$. Evolution and progression of atherosclerotic lesions in coronary arteries of children and young adults. Arteriosclerosis 1989; (suppl 1) 9:119-132.

Steinberg D., Parthasarathy S, Carew TE, Khoo JC, Witztum JL. Beyond cholesterol. Modifications of low-density lipoprotein that increase its atherogenicity. N Engl J Med 1989;320:915-924.

Steinhoff $G_{y}$ You XM, Steinmuller $C$, Boeke $K_{\text {, }}$ Stals FS, Bruggeman CA, Haverich A. Induction of endothelial adhesion molecules by rat cytomegalovirus in allogeneic lung transplantation in the rat. Scand J Infect Dis Supp 1995;99:58-60.

Steinhoff G, You XM, Steinmuller C, Bauer D, Lohmamn-Matthes ML, Bruggeman CA, Haverich A. Enhancement of cytomegalovirus infection and acute rejection after allogeneic lung transplantation in the rat. Transplantation 1996;61:1250-1260.

Stemme S, Holm J, Hansson GK. T lymphocytes in human atherosclerotic plaques are memory cells expressing CD45RO and the integrin VLA-1. Arterioscler Thromb 1992;12:206-211.

Stemme $S_{4}$ Rymo $L_{a}$, Hansson $\mathrm{GK}_{\mathrm{s}}$. Polyclonal origin of $\mathrm{T}$ tymphocytes in human atherosclerotic plaques. Lab Invest 1991;65:654-660.

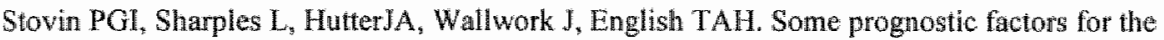
development of transplant-related coronary artery disease in human cardiac allografts. J Heart Lung Transplant 1991;10:38-44.

Tamura H. Acute ulcerative colitis associated with cytomegalic inclusion virus. Arch Pathol $1973 ; 96: 164-167$.

Tatum ET, Sun PCI, Cohn DL. Cytomegalovirus vasculitis and colon perforation in a patient with the acquired immunodeficiency syndrome. Pathology 1989;21:235-238.

Thompson SG, Kienast J, Pyke SD, Haverkate $F$, van de Loo JC. Hemostatic factors and the risk of myocardial infarction or sudden death in patients with angina pectoris. European Concerted Action on Thombosis and Disabilities Angina Pectoris Study Group. Nem Engl J Med 1995;332:635-641.

Tilney NL. Thoughts on the immunobiology of chronic allograft rejection. Transplant Proc $1995 ; 27: 2123-2125$. 
Tucker T, Dix RD, Katzen C, Davis RL, Schmidley JW. Cytomegalovirus and herpes simplex vinus ascending nyelitis in a patient with the acqiured immunodeficiency syndrome. Ann Neurol $1985 ; 18: 74-79$.

Tulius SG, Tilney NL. Both alloantigen-dependent and -indeoendent factors influence chronic allograft rejection. Transplantation 1995;59:313-318.

Uretsky BF, Murali S, Reddy PS, Rabin B, Lee A, Griffith BP, Hardesty RL, Trento A, Bahnson HT.Development of coronary artery disease in cardiac transplant recipients receiving immunosuppressive therapy with cyclosporine and prednisone. Circulation 1987;76:827-834.

Vink $C_{2}$ Beuken $\mathrm{E}$, Bruggeman $\mathrm{CA}$. Structure of the rat cytomegalovirus genome termini. J Virol 1996:70:5521-5529.

Vink $C_{\text {, }}$ Cloning and functional characterisation of the origin of lytic phase DNA replication of rat cytomegalowirus. J Gen Virol 11997,78:2969-2973.

Vinters HV, Kwok MK, HO HW, Aders KH, Tomiyasi U, Walfson WL, Robert P. Cytomegalovirus in the nervous system of patients with the acquired immunodeficiency syndrome. Brain 1989;112:245268.

Visseren FL, Bouter KP, Pon MJ, Hoekstra JB, Erkelens DW, Diepersloot RJ. Patients with diabetes mellitus and atherosclerosis; arole for cytomegalovirus? Diabetes Res Clin Pract 1997;36:49-55.

Waldman WY, Knight DA, Fuang EH, Sedmak DD. Bidirectional transmission of infectious cytomegalovirus between monocytes ans vascular endothelial cell: an in vitro model. J Infect Dïs $1995 ; 171: 263-272$.

Walker JD, Cesney TM. Cytomegalovirus infection of the skin. Am J Dermatopathol 1982;4:263-265.

Weck KE, Dal Canto AJD, Gould JD, O'Guin AK, Roth KA, Saffitz JE, Speck SH, Virgin HW. Murine -herpesvirus 68 causes severe large-vessel arteritis in mice lacking interferon-responsiveness:A new model for virus-induced vascular disease. Nat Med 1997:3:1346-1353.

Weigand DA, Burgdorf WHC, Tarpay MM. Vasculitis in cytomegalovirus infection. Arch Dermatol 1980:118:11.74-1176.

Wilcox CM, Diehl DL, Cello JP, Margaretten W, Jacobson MA. Cytomegalovirus esophagitis in patients with AIDS. A clinical, endoscopic, and pathologic correlation. Ann Int Med 1990;113:589593.

Wiley CA, Nelson JA. Role of human immunodeficiency virus and cytomegalovirus in AIDS encephalitis. Am J Pathol 1986;133:73-81.

Williams G. Stretton TB, Leonard JC. Cytomegalic inclusion disease and Pneumocystis carinii intection in an adult. Lancet 1960;2:951-955.

Winters GL, Kendall TJ, Radio SJ, Wilson JE, Constanzo-Nordin MR, SwitzerBL, Remmenga JA, McManus. Posttransplant obesity and hyperlipidemia:majot predictors of of severity of coronary arteriopathy in failed human heart allografts. J Heart Transplant 1990

Wreghit TG, Hakim M, Gray JJ, Kucia S, Cory-Pierce R, Wallwork J, English TAH, A detailed study of cytomegalovirus infections in the first 160 heart/lung recipients at Papworth Hospital, Cambridge England. Transplant Proe 1987;19:2495-2496.

Wu TC, Hruban RH, Ambinder RF, Pizzomo M, Cameron DE, Baumgartner WA, Reiltz BA, Hayward GS, Hutchins GM. Demonstration of cytomegalovirus nucleic acids in the coronary arteries of transplanted hearts. Am J Pathol 1992;140:739-747.

Xu Q, Dietrich H, Steiner HJ, Gown AM, Schoel B, Mikuz G, et al. Induction of atherosclerosis in 
nomocholesterolemic rabbits by immunization with haet shock protein 65 . Arterioscler Thromb $1992 ; 12: 789-799$.

Xu Q, Willeit J, Marosi M, Kleindienst R. Oberhollenzer $\mathrm{F}$, Kiechl S et al. Association of serum antibodies to heat-shock protein 65 with caritid atherosclerosis. Lancel $1993 ; 341: 255-259$.

Yasunaga M. Small intestinal perforation due to cytomegalovirus infection in patients with nonHodgkin's lymphoma. Acta Haematol 1995;9392-4):98-100.

Yokota $T$, Hansson GK. Immunological mechanisms in atherosclerosis. J Int Med 1995;238:479-489.

Young JB, Windsor NT, Kleiman NT, Lowry R, Coanougher B, Lawrence EC. The relationship of soluble interleukin-2 receptor levels to allograft arteriopathy after heart transplantation. I Heart Lung Transplant 1992;11:S79-82.

Zhou X. Stemme S, Hansson GK. Evidence for a local immune response in atherosclerosis. CD4+ T cells infiltrate lesions of apolipoprotein-E-deficient mice. Am J Pathol 1996;149:359-366.

Zhou YF, Leon MB, Waclawiw MA, Popma J, Yu ZX, Finkel T, Epstein SE. Association between prior cytomegalovirus infection and the risk of restenosis after coronary atherectomy. New Engl J Med $1996 ; 335: 624-630$. 

Chapter 2

Multiple organ involvement during experimental cytomegalovirus infection is associated with disseminated vascular pathology.

MCJ Persoons, FS Stals, MCE van Dam Mieras, CA Bruggeman.

Journal of Pathology 1998;184:103-109. 


\begin{abstract}
Since much of the pathogenesis of cytomegalovirus (CMV) disease is still unknown and vascular involvement may be of importance, a rat model was used to study the nature and course of CMV induced vascular pathology.

In this model, local CMV infection was established by subcutaneous inoculation of rat specific CMV (RCMV) in the sole of the foot. Signs of endothelial activation, including leucocyte adhesion, preceded detectable RCMV infection of these cells. Ultimately, vasculitis and thrombotic occlusion were accompanied by diffuse tissue inflammation and necrosis.
\end{abstract}

Generalized RCMV infection was induced in rats by intraperitoneal administration of the virus, which resulted in multiple organ pathology, including haemorrhages, inflammation and gastrointestinal ulceration. RCMV encoded antigens were found especially in mononuclear inflammatory cells in the organs and peripheral blood. In addition, multiple haemorrhages and disturbed haematological parameters indicated diffuse intravascular coagulopathy.

In conclusion, this study provides evidence for extensive vascular involvement and haematological consequences during disseminated $\mathrm{CMV}$ infection. The nature and chronology of RCMV induced pathological vascular events were demonstrated, indicating the importance of endothelial damage. These data and further study may lead to a better understanding of the pathogenesis of CMV multiple organ disease. 
had been removed by use of a polycarbonate filter with $50 \mathrm{~nm}$ sized pores (Poretics inc, Livermore, USA).

\section{Design of the animal experiments}

Two rat models were used, representing local and generalized RCMV infection. In both models the rats were, temporarily, immunosuppressed by 6 Gray total body Xirradiation one day before virus inoculation.

To induce local infection, RCMV was subcutaneously injected in the sole of the foot of the right hind paw at a low $\left(210^{3} \mathrm{PFU}\right)$ and a high $\left(10^{5} \mathrm{PFU}\right)$ virus dose. Mock infection was established in the left hind paw of the same animal. Both hind paws were evaluated daily and paw thicknesses were measured using a digital micrometer (Digimatic type ID-1 10M; Mitutoya, Tokyo, Japan). Each determination was performed 10 times; standard deviations of series of 10 determinations did not exceed $10 \%$ from the mean.

Rats $(n=5$ per timepoint in the high dose group, $n=3$ per time point in the low dose group) were killed by aortic bleeding under ether anaesthesia at 1, 3,6, 10 and 14 days or at five weeks after infection. Skin biopsies taken from both hind paws were microscopically evaluated using routine and immunocytochemical staining procedures. To establish generalized RCMV infection, rats were intraperitoneally inoculated with $10^{5}$ PFU RCMV as described previously (Stals et al. 1990). At regular times after infection, citrate anti-coagulated blood was collected by venous puncture to determinate different haematologic parameters. Spleen, liver, lungs and kidneys were harvested for histological and immunocytochemical evaluation and stored at $-70^{\circ} \mathrm{C}$ for quantification of virus infection by plaque titration assays. In addition, mononuclear cells were isolated from the peripheral blood for the quantification of infectious virus. Mock infected animals were used in control experiments. In general, each group consisted of at least five rats.

\section{Histopathology}

Tissues were fixed in $3.7 \%$ formaldehyde in phosphate buffered saline, routinely processed and paraffin embedded. Sections $(3 \mu \mathrm{m})$ were cut and mounted on chromium alum gelatin coated and glutaraldehyde inactivated glass slides for haematoxylin-eosin staining and immunohistochemical techniques. In addition, hind paw specimens were also embedded in the plastic Kulzer Technovit 7100 and sections $(3 \mu \mathrm{m})$ were stained with toluidine blue.

RCMV early antigens were stained as described before (Stals et al. 1990). A mixture was used of two mouse monoclonal antibodies designated as McAb 8 and 35 and directed against early nuclear and cytoplasmic RCMV antigens (Bruning et al. 1987). Subsequently, biotinylated, affinity purified, sheep anti mouse IgG antibodies (Amersham, Nederland B.V., Houten, the Netherlands) and streptavidine HRP complex (Amersham, Nederland B.V., Houten, the Netherlands) were inoculated. Specific antibody-antigen binding was visualized using diaminobenzidin substrate. Sections were counterstained with haematoxylin and embedded in entellan (Merck, Darmstadt, Germany). To rule out aspecific staining, control sections were stained with an antihuman CMV, which does not react with RCMV, as well as with control mouse ascites 
(Sigma Immuno Chemicals, St Louis, USA).

$\mathrm{McAb}$ ED-1, specific for rat macrophages and monocytes and $\mathrm{MCAb}$ W3/13, reacting with rat $\mathrm{T}$-lymphocytes, were used to characterize infiltrated cells. A fter incubation with peroxidase conjugated rabbit anti mouse immunoglobulins (DAKO, Glostrup, Denmark), reactive antigens were visualized with diaminobenzidin substrate.

\section{Isolation of leucocytes}

For the isolation leucocytes, EDTA blood samples were washed with ice-cold $\mathrm{NH}_{4} \mathrm{Cl}$ to lyse erythrocytes. Leucocytes were separated using ficoll-paque (Pharmacia Biotechnics, Soluntuna, Sweden) gradient centrifugation. Mononucleat cells were isolated from the gradient interface, while polymorphonuclear cells were obtained from the pellet. Cells were washed in Eagles Minimal Essential Medium for use in virus plaque assays.

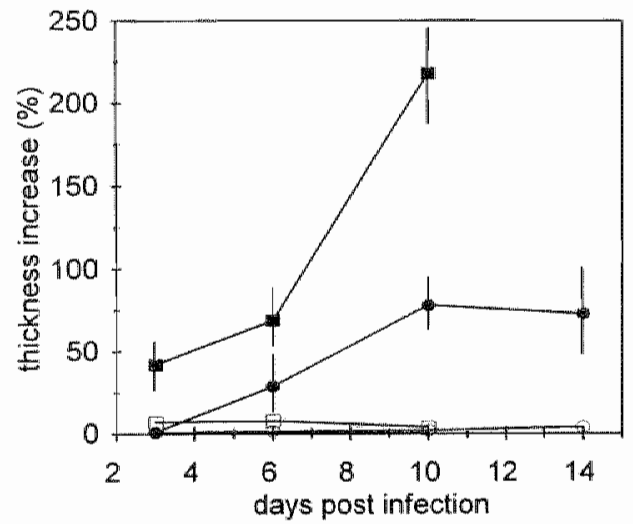

Figure 2.1 Thickness increases of rat hind paws at were counted to express the amount of

different times after RCMV or mock infection. RCMV.

Thickness values are expressed as the percentage of increase in relation to day 0 . Rats had received 6 Gy total body X-irradiation for immunosuppression before subcutaneous inoculation of RCMV in the foot path of the right hind paw and mock infection of the left hind foot.

- Right foot after $210^{3}$ PFU RCMV;

Left foot of same animals after mock infection.

Right foot after $10^{5}$ PFU RCMV;

$\square$ Left foot of same animals after mock infection.
Virus plaque assay

A virus plaque assay was used to quantitate the amount of RCMV present in the different organs and in leucocytes from the peripheral blood during generalized RCMV infection, as described previously (Bruggeman et al. 1985). Briefly, samples of spleen, kidneys, liver, lungs were homogenized and diluted 1:10 (w/v) in Eagles Minimal Essential Medium. Peripheral leucocytes were dilluted in $0.2 \mathrm{ml}$ medium. Ten fold dilutions were added to cultures of rat embryonic cells and the numbers of PFU

\section{Haematological parameters}

The numbers of leucocytes, thrombocytes and erythrocytes as well as haemoglobin concentrations in the citrate anticoagulated blood of rats were determined using a cell counter (Sysmex M-2000, Charles Goffin, Tiel, the Netherlands), according to manufacturer's procedures. Additionally, haematocrit values were determined by routine procedures. $\mathrm{CH} 50$ and AP50 haemolytic assays as measures for total complement activity and the alternative pathway dependent mode of complement activation respectively, were performed at the Department of Nephrology, University Hospital, Leiden, the Netherlands. Finally, prothrombin time (PT), activated partial 
prothrombin time (APTT) and thrombin time (TT), as well as the levels of fibrinogen, factor II and $\mathrm{V}$, were determined using standard methods (Van Dam-Mieras et al. 1984).

\section{Statistics}

Data were expressed as mean \pm standard deviation. Student's t-test was used to calculate the statistical significance of differences in all variables. $\mathbb{P}$ values of $<0.05$ were considered to indicate statistical significance.

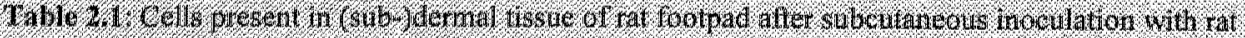

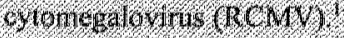

Low dose RCMV High-dose RCMV

\begin{tabular}{|c|c|c|c|c|c|c|c|c|c|c|}
\hline $\begin{array}{l}\text { Cell } \\
\text { population }\end{array}$ & Day 1 & Day 3 & Day 6 & Day 10 & Day 14 & Day 35 & Day 1 & Day 3 & Day 6 & Day $10^{3}$ \\
\hline $8 / 35^{2}$ & \pm & + & $+t$ & $+1+$ & + & - & + & + & +1 & +4 \\
\hline $\mathrm{ED}-1^{3}$ & - & \pm & $9+$ & +1 & $+t+$ & - & - & +1 & +1 & ++ \\
\hline$W 3 / 13^{4}$ & - & \pm & + & +1 & ++ & - & - & \pm & + & + \\
\hline PMN & \pm & $+n$ & $+1+$ & $+t$ & + & - & + & $t+t$ & +1 & + \\
\hline
\end{tabular}

Rats had received a total body X-irradiation of $6 \mathrm{~Gy}$ before inoculation with a low dose (21030 $\mathrm{PFU})$ RCMV or a high dose $\left(10^{5}\right.$ PFU) RCMV.

${ }^{2}$ Cells reactive with MCAb 8 and 35 , specific for RCMV early antigens.

${ }^{3}$ Cells reactive with McA.b ED-1, specific for monocytes/macrophages.

${ }^{4}$ Cells, reactive with McAb W3/13, specific for T-lymphocytes.

${ }^{5}$ Rats which had received a high dose RCMV, were sacrificed at day 10 p.i. for ethical reasons. The presence of cells was assessed semi-quantitatively. Absence of cells was scored as - ; sporadic cells as \pm ; small numbers of cells as + ; considerable numbers of cells as ++ ; high numbers of cells as ++ +. PMN=polymorphonuclear cells.

\section{Results}

\section{Macrosicopic pathology}

Paw thickening and erythema were observed as soon as three days after local inoculation of the hind paw with a low dose ( $\left.210^{3} \mathrm{PFU}\right)$ of RCMV. Subsequently, purpura appeared and hind paw thickening increased (Figure 2.1). These changes were maximal at 10-14 days after virus inoculation and decreased to complete disappearance at 4 weeks after inoculation.

After local inoculation with the high dose $\left(10^{5} \mathrm{PFU}\right) \mathrm{RCMV}$, symptoms were far more severe and resulted in ulcerative skin lesions extending to the upper part of the hind paw. In addition, the hind paw showed significantly more thickening than after low dose infection $(P<0.05)$. At day 10 after virus inoculation, rats were killed for ethical reasons. No changes were observed in the mock infected paws.

In rats suffering from a generalized RCMV infection, severe symptomatic disease was observed as described earlier (Stals et al. 1990). In these animals, macroscopic 
haemorrhages were present in lungs, liver, spleen and kidneys. Along the gastrointestinal tract purpura were present accompanied by ulcerative lesions (Figure 2.2). In addition, free blood was abundantly present in the pleural and abdominal cavities.

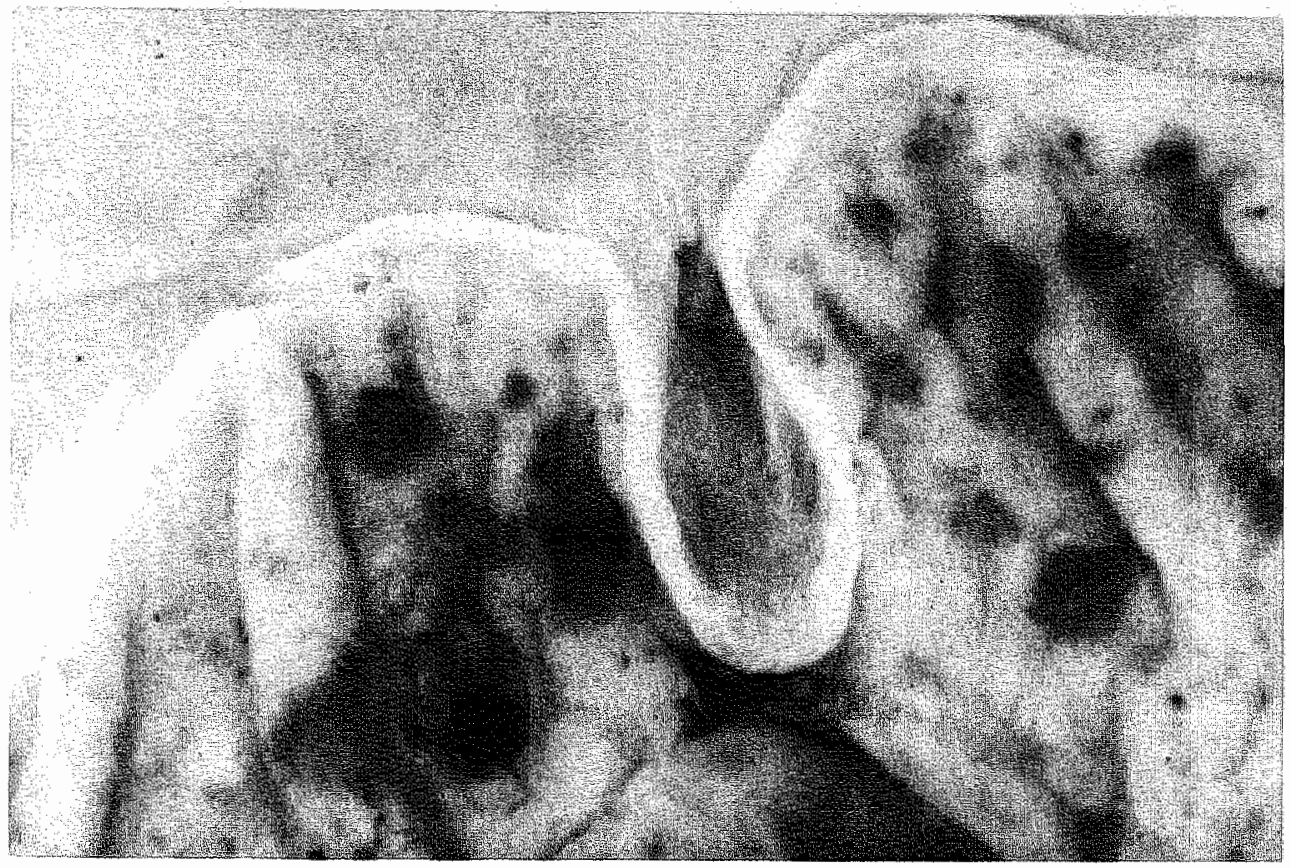

Figure 2.2 Mucosa of stomach from rat with generalized RCMV infection after total body X- irradiation and intraperitoneal inoculation of $10^{5} \mathrm{PFU}$ RCMV. Multiple haemorrhages are visible.

\section{Histopathology and virus isolation}

One day after local inoculation with a low dose of RCMV, histopathologic signs of infection were noticed (Table 2.1). At the site of inoculation, only a few cells were reactive with the RCMV-specific monoclonal antibodies (McAb 8 and 35). At day three after inoculation, endothelial cells of the (sub-)dermal vessels showed a ballooned appearance with concomitant adherence of polymorphonuclear and mononuclear cells to the endothelial surface (Figure 2.3). At that time, the endothelial cells did not contain RCMV antigens nor RCMV-specific inclusions, while inflammatory cells did infiltrate into the perivascular area. At 10-14 days after inoculation, the amount of ED-1 and W3/13 reactive mononuclear cells increased to maximall levels, frequently associated with occlusion of capillaries and small arterioles and venules. Many mononuclear infiltrating cells did stain with the RCMV specific $\mathrm{McAb} 8 / 35$. Moreover, the endothelium of predominantly, (post-) capillary venules harboured RCMV antigens at that time (Figure 2.4). Many of these cells were enlarged and showed CMV-specific intranuclear inclusions (Figure 2.5). Intravascular fibrin deposition (Figure 2.5) and finally diffuse thrombotic vascular occlusion were observed. Throughout the dermal and subdermal layer, numerous erythrocytes and 
pycnotic cells surrounded vessels or vascular remnants. Inflammation decreased and at five weeks after RCMV inoculation fibrotic tissue with few histiocytes remained. In the animals that were infected with the high dose of RCMV, inflammatory responses were even more pronounced and ultimately resulted in vascular disruption, necrosis and complete destruction of tissue morphology at 10 days after RCMV inoculation. In the hind paws that had been mock infected, no histopathology was found.

During generalized RCMV infection, virus was isolated from the spleen, starting at 3 days after inoculation, while infectious virus could be isolated from the liver, lungs and kidneys from 5 days after inoculation. The isolation of infectious virus from the internal organs corresponded with the presence of viral antigens, as shown by reactivity with McAb 8 and 35 . In the peripheral blood, infectious RCMV could be isolated from mononuclear cells from 7 days after inoculation. This viraemic phase was associated with symptomatic disease as previously described (Stal et al 1990). At this time, microvascular endothelial cells contained viral antigens and showed cytomegaly with intranuclear eosinophilic inclusions characteristic for CMV. Infiltrates consisted mainly of mononuclear cells that frequently harboured RCMV encoded antigens. Capillaries and post-capillary venules were occluded by cellular and thrombotic sludge. Vascular damage was manifested by the presence of many erythrocytes in the tissues. Organ specific histopathological changes were seen as previously described earlier (Stals et al. 1990).

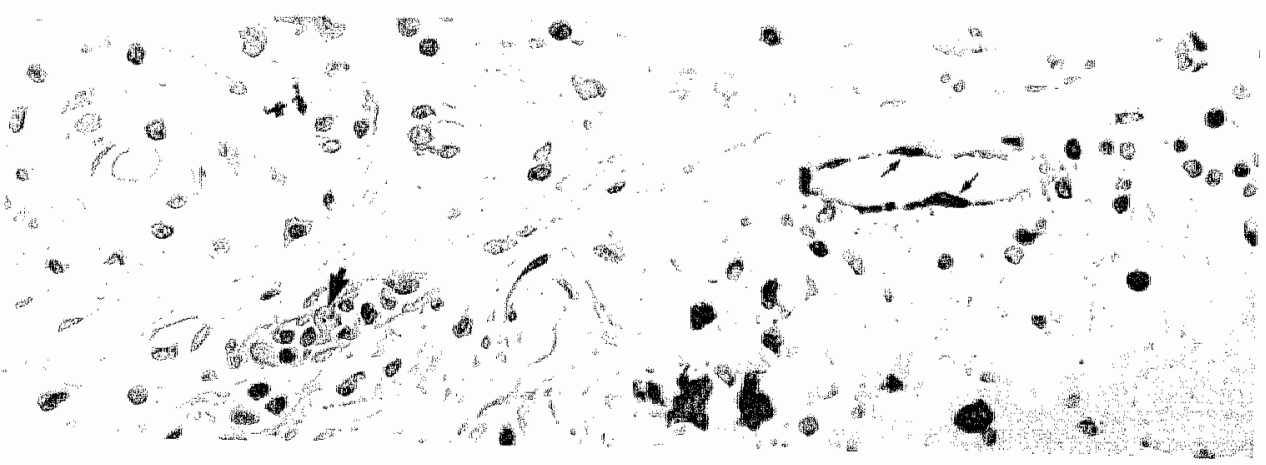

Figure 2.3 Haematoxylin-eosin staining of rat sub- Figure 2.4 Immunoperoxidase staining of endothedermal tissue, three days after subcutaneous inocu- lial cells of rat subdermal venule (arrows) with lation of $10^{5}$ PFU. Endothelial ballooning (arrows) RCMV specific monoclonal antibodies (McAb 8 and leucocyte adhesion are seen. and 35), 10 days after subcutaneous inoculation of $210^{3}$ PFU RCMV.

\section{Haematological parameters}

Compared with the mock infected controls, the numbers of leucocytes in the peripheral blood of rats that suffered from generalized RCMV infection, decreased significantly. This occurred at 6-9 days after the virus had been inoculated $(\mathrm{P}<0.05$, Table 2.2). Additionally, in the RCMV infected group the numbers of thrombocytes and 
erythrocytes decreased, with low haemoglobin concentrations and haematocrit values (Table 2.2). At that time, fibrinogen and clotting factors II and $V$ were very low compared with controls $(\mathrm{P}<0.05)$, (Figure 2.6). Consequently, activated partial thromboplastin time (APTT), (Figure 2.6) and prothrombin time (PT) increased, while thrombin time (TT) decreased ( $\mathrm{P}<0.05$, data not shown). In RCMV infected animals, $\mathrm{CH} 50$ and AP5O levels, as measures for total complement activity and the alternative pathway dependent mode of complement activation respectively, increased with a peak at 7 days after RCMV inoculation. These values were significantly higher in RCMV infected animals than in the mock infected controls ( $P<0.05$, data not shown).

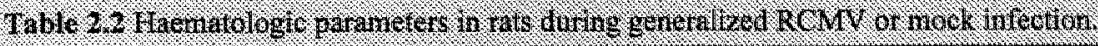

\begin{tabular}{lcccccc}
\hline & \multicolumn{5}{c}{ RCMV infection } & \multicolumn{3}{c}{ Mack infection } \\
\cline { 2 - 6 } & day 3 & day 6 & 2 day 8 & day 3 & day 6 & 2 day 8 \\
\hline Leucocytes $\left(10^{9} / 1\right)$ & $0.65 \pm 0.21$ & $0.52 \pm 0.11^{1,3}$ & $0.20 \pm 0.12^{1,2,3}$ & $0.78 \pm 0.19$ & $1.04 \pm 0.24$ & $1.30 \pm 0.57$ \\
$\begin{array}{l}\text { Thrombocytes } \\
\left(10^{9} / 1\right)\end{array}$ & $633 \pm 133$ & $58 \pm 48^{1,3}$ & $14 \pm 4^{1,3}$ & $758 \pm 112$ & $208 \pm 99$ & $66 \pm 29$ \\
$\begin{array}{l}\text { Erythrocytes } \\
\left(10^{12} / 1\right)\end{array}$ & $6.2 \pm 0.5$ & $5.0 \pm 1.2^{1.3}$ & $1.5 \pm 0.6^{1,2,3}$ & $6.5 \pm 0.2$ & $6.7 \pm 0.2$ & $4.4 \pm 0.5$ \\
$\begin{array}{l}\text { Hemaglobulin } \\
\text { (mmol/1) }\end{array}$ & $8.3 \pm 0.4$ & $6.2 \pm 1.4^{1,3}$ & $2.0 \pm 0.6^{1,2,3}$ & $8.5 \pm 0.2$ & $8.1 \pm 0.5$ & $6.0 \pm 0.6^{1,2}$ \\
$\begin{array}{l}\text { Haematocrit } \\
\text { (fraction) }\end{array}$ & $0.35 \pm 0.02$ & $0.26 \pm 0.06^{1,3}$ & $0.08 \pm 0.03^{1,2,3}$ & $0.36 \pm 0.01$ & $0.35 \pm 0.01$ & $0.25 \pm 0.03^{1.2}$ \\
\hline
\end{tabular}

Rats had received a total body X-irradiation of $6 \mathrm{~Gy}$ before intraperitoneal inoculation with $10^{5} \mathrm{PFU}$ RCMV or mock infection (see text)

' decrease compared with day $3(\mathrm{P}<0.05)$

${ }^{2}$ decrease compared with day $6(\mathrm{P}<0.05)$

${ }_{3}^{3}$ decrease compared with mock infected controls $(\mathrm{P}<0.05)$

\section{Discussion}

The rat model used in this study proved to be valuable for the demonstration of the vascular events that are induced by CMV infection and their importance in the pathogenesis of CMV disease. This study indicates major vascular involvement in CMV associated pathology, manifested by damage of microvascular endothelium, vasculitis, thrombotic occlusions and haemorrhages.

Signs of early endothelial activation, such as endothelial ballooning and leucocyte adhesion, are noticed before infection of these cells can be detected. Similar observations have been previously described in the aorta of infected rats (Span et al. 1993) and in CMV infected human endothelial cells in vitro (Span et al. 1993, Span et al. 1989). Although the mechanism by which these endothelial changes are induced is 
unclear, there is some evidence that direct interaction between the virus or virus infected blood cells and the endothelium can induce activation of endothelial cells (Nokta et al. 1987, Van Dam-Mieras et al. 1987).

As infection progresses, infiltrates consist mainly of mononuclear cells. These cells (including the mononuclear cells in the peripheral blood) are often RCMV infected, as proved by the presence of RCMV encoded antigens and characteristic intranuclear inclusions, as well as by the isolation of infectious virus from them. During symptomatic CMV disease in humans, the presence of leucocytes that contain viral DNA and antigens has also been described (Dankner et al. 1990, Salzman et al. 1992). From these findings it may be suggested that mononuclear cells are involved in the transport of the virus throughout the body. This is further supported by in vitro experiments which showed that transmission of infectious CMV to human endothelial cells can be mediated by monocytes (Waldman et al. 1995). Additionaliy, inflammatory cells may enhance endothelial $\mathrm{CMV}$ infection by modulating the intracellular redox status of endothelial cells, which causes reduced anti-oxidant protection (Scholz et al. 1996, Vossen et al. 1997).

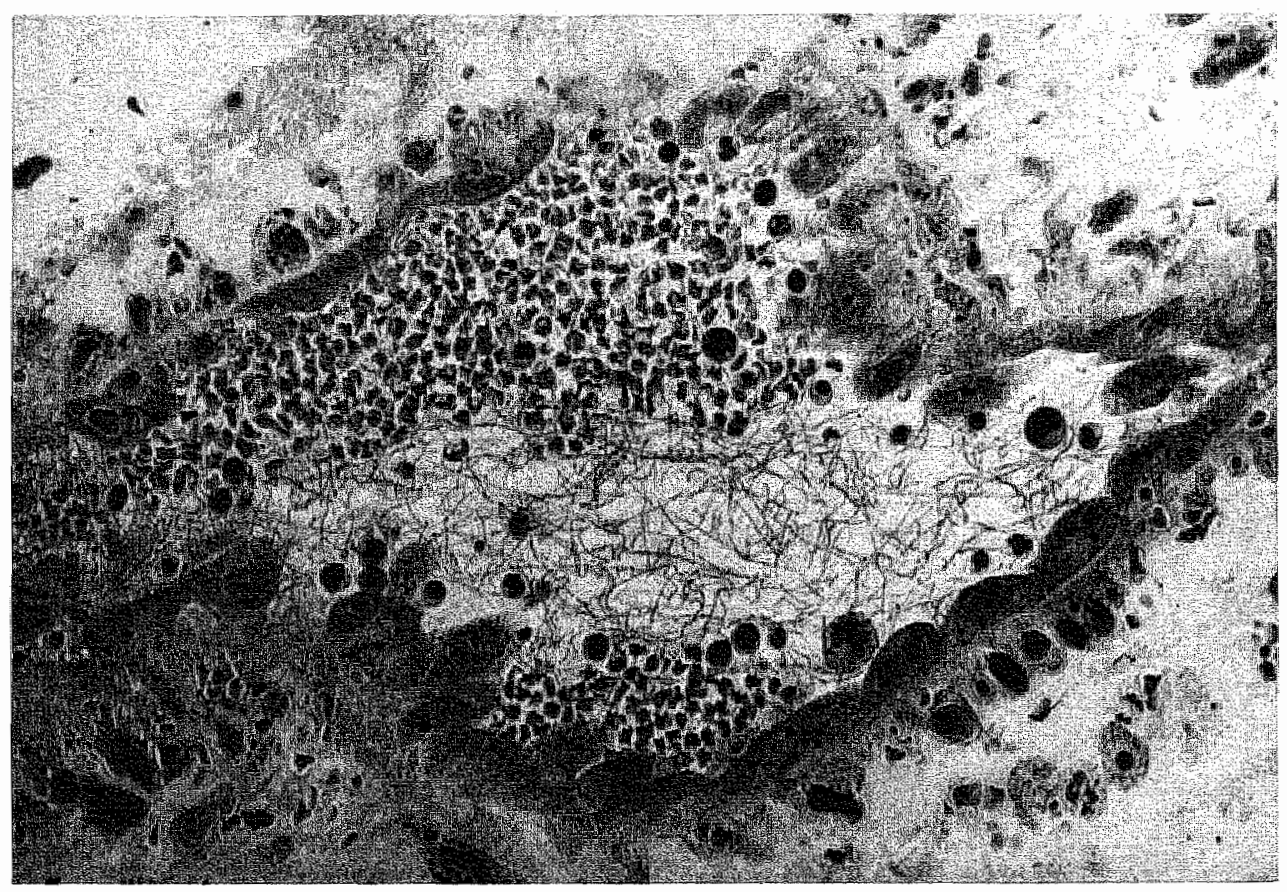

Figure 2.5 Toluidine blue staining of rat subdermal venule, embedded in Technovit 7100, 10 days after subcutaneous inoculation with $10^{5}$ PFU RCMV. Almost every endothelial cell is infected as is shown by their CMV specific 'owl eye' appearance; they contain an intranuclear inclusion surrounded by a halo (arrows). Note also cytomegalic cells surrounding the venule. Intravascullar fibrin and predomimantly lymphocytes are seen. Around the venule pycnotic cells as well as erythrocytes are visible. 
In our rat model, viral infection of the endothelial cells, as shown by the presence of viral antigens, proved to be a relatively late event of local CMV infection. Infected endothelium becomes detached from the basement membrane and extended vasculitis and necrosis are finally seen in the infected tissues. The severity of pathology proved to be highly dependent on the viral dose. Our data are compatible with the findings in immunocompromised humans, mainly AIDS patients, were CMV infection of endothelial cells and vasculitis have been described (Golden et al. 1994). The organ systems most commonly infected are the gastro-intestinal tract (Foucar et al. 1981, Francis et al. 1989, Muldoon et al. 1996), the nervous system (Morgello et al. 1987)
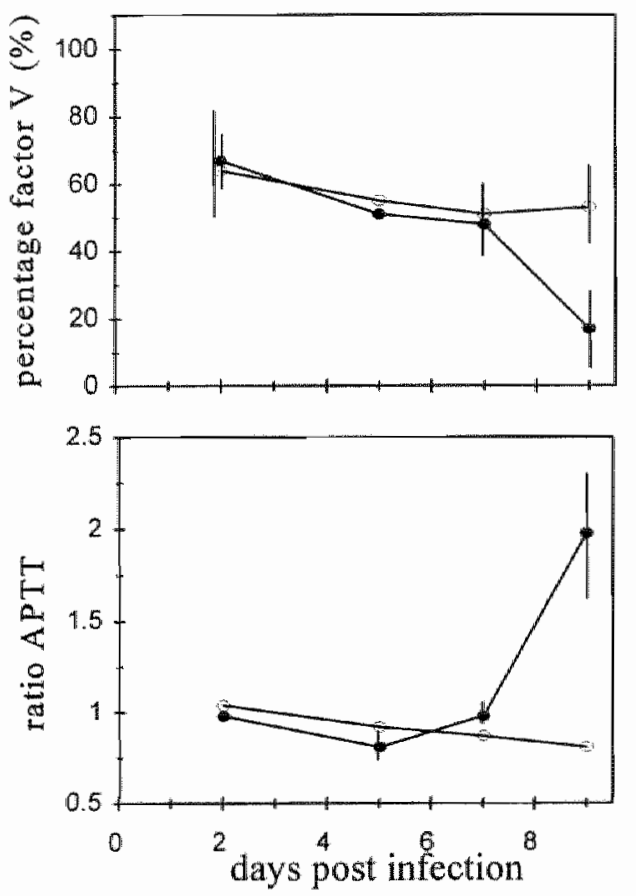

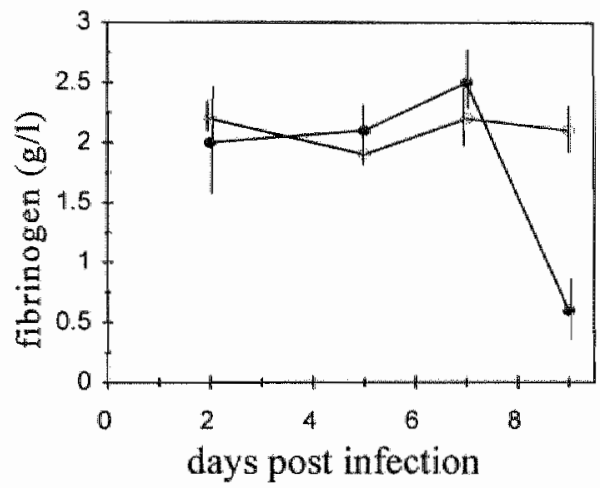

Figure 2.6 Fibrinogen, factor $\mathrm{V}$ and activated thromboplastin time (APTT) in immunosuppressed rats after intraperitoneal inoculation of $10^{5}$ PFU RCMV ( ) or mock infection (O). Immunosuppression was achieved by total body $X$ irradiation of $6 \mathrm{~Gy}$. Factor $\mathrm{V}$ and $\mathrm{APPT}$ are expressed as percentage and ratio of values in non-immunosuppressed, non-infected control rats.

and the skin (Lin et al. 1981, Lee et al. 1989).

Moreover, the presence of circulating CMV infected endothelial cells in patients with generalized CMV disease (Percivalle et al. 1993, Grefte et al 1993) seems very likely to be the result of detachment of infected endothelial cells.

The finding of widespread thrombotic vascular occlusion during RCMV infection suggests an enhanced procoagulant activity of the microvascular endothelium.

Thrombocytopenia and decreased levels of coagulation factors indicate the existence of diffuse intravascular coagulopathy. This is manifested by increased bleeding times, skin purpura and multiple intra-organ haemorrhages. Previously, we have described that CMV infection of cultured endothelial cells resulted in increased procoagulant activity (Van Dam-Mieras et al. 1987, 1992). It has been suggested that the interaction between the viral envelope and endothelial cells induces membrane perturbation which 
subsequently results in enhanced procoagulant activity (Woodroffe et al. 1993). In vivo, the change of the endothelial membrane to a more procoagulant state may be initiated by the interaction of CMV encoded antigens, expressed at the surface of mononuclear blood cells, with the endothelial cell membrane. Additionally, increased procoagulant activity can be caused via cytokines (Woodroffe et al. 1993, Bevilacqua et al. 1986) and finally, detachment of endothelial cells also contributes to thrombotic events.

In summary, it was shown that CMV induces pronounced vascular pathology. The rat model of local CMV infection proved to be very useful in revealing CMV induced vascular events. The data from our study support the idea that activation and damage of microvascular endothelium may be of great importance in the pathogenesis of multiple organ disease during generalized CMV infection. Further insight in the exact cellular mechanisms, resulting in CMV induced pathology in different organs, may offer new possibilities for therapeutic intervention in severe CMV infection.

\section{References}

Alford CA, Stagno S, Pass RF, Britt WJ. Congenital and perinatal cytomegalovirus infections. Rev Infeet Dis 1990; 12, Suppl.7:S745-S753

Bevilacqua MP, Pober JS, Majeau GR, Fiers W, Cotran RS, Gimbrone JR. Recombinant tumor necrosis factor incluces procoagulant activity in cultured human vascular endothelium: Characterization and comparison with the actions of interleukin 1. Proc Natl Acad Sci USA $1986 ; 83: 4533-4537$

Bruggeman CA, Meijer $\mathbb{H}$, Bosman F, van Boven CPA. Biology of rat cytomegalovirus infection. Interwirology 1985;24:1-9

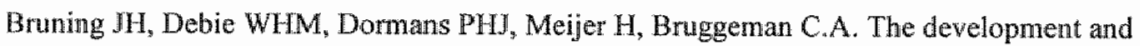
characterization of monoclonal antibodies against rat cytomegalovirus induced antigens. Arch Virol $1987 ; 94: 55-70$

Bruming JH, Persoons MCJ, Lenstrom KB, Stals FS, De Clereq E, Bruggeman CA. Enhancement of transplantation associated atherosclesosis by $\mathrm{CMV}$, which can be prevented by antiviral therapy in the form of HPMPC. Transplant Int. 1994; 7, Suppl.1:365-370

Dankner WM, Mc Cutchan JM, Richman DD, Hirata K, Spector SA. Localization of human. cytomegalovirus in peripheral blood lewcocytes by in situ hybridization. J Infect Dis 1990;161:31-36

froncar E, Mukai K, Foucar $K$, Sutherland DER, Van Buren $C T$. Colon ulceration in lethal cytomegalovirus infection. Am J Clin Pathol 1981; 76:788-801

Francis ND, Boylston AW, Roberts AHG, Parkin .M, Pinching AJ. Cytomegalowirus infection in gastrointestinal tracts of patients with HIV 1 or AIDS. J Clin Pathol 1989; 42: 1055-1064

Golden MP, Hammer SM, Wanke CA, Albrecht MA. Cytomegalovirus vasculitis. Case reports and reviews of the literature. Medicine 1994; $73: 246-255$

Grattan MT, Moreno-Cabral CE, Starnes VA, Oyer PE, Stinson EB, Shumway NE. Cytomegalovirus infection is associated with cardiac allograft rejection and atherosclerosis. JAMA. 1989; 261:35613566

Grefte, J.MM, van der Giessen M, van Son WJ, The TH. Circulating human cytomegalovirus (HCMV)-infected endothelial cells in patients with an active HCMV infection. JI Inf Dis 1993; 


\section{Introduction}

Cytomegalovirus (CMV) is a ubiquitous herpes virus in man. Although primary infections usually remain asymptomatic and become latent, the virus is a major cause of morbidity and mortality in immunocompromised patients, especially in transplant recipients receiving immunosuppressive therapy and in patients with the acquired immunodeficiency syndrome (AIDS). Clinically, CMV infections in these patients are manifested by a variety of symptoms and are associated with pathology of almost every organ system. The mechanism of virus induced pathology is largely unknown. Increasing evidence indicates vascular involvement during chronic CMV infection: the virus has been detected in large arteries during asymptomatic infection, both in men and rats (Minick et al. 1983, Yamashiroya et al. 1988, Hendrix et al. 1991, Persoons et al. 1994) and has been associated with accelerated atherosclerosis in heart and aortic allografts in both species (Grattan et al. 1989, Bruning et al. 1994, Koskinen et al. 1994). Moreover, there is substantial support for microvascular disease in patients with acute symptomatic CMV infection, as may be manifested by ulcerative lesions along the gastrointestinal tract (Foucar et al. 1981, Francis et al. 1989, Wilcox et al. 1990) and purpura of the skin (Lin et al. 1981, Lee, 1989). The presence of cytomegalic endothelial cells in the peripheral blood (Percivalle et al. 1993, Grefte et al. 1993) of immunocompromised patients during acute CMV infection underlines vascular involvement, as does the thrombopenia which may be associated with congenital CMV disease (Alford et al. 1990).

To gain a better understanding of the pathogenesis of CMV disease and especially of the potential importance of vascular pathology, a rat model was developed to study the nature and chronology of CMV induced vascular events. In this model, local inoculation with rat specific CMV (RCMV) was established to observe virus induced sequential microvascular events, while vascular involvement was furthermore studied in rats suffering generalized RCMV infection with multiple organ pathology.

\section{Materials and methods}

\section{Animals and virus}

According to institutional ethical guidelines, 8-week-old male Wistar Kyoto rats were used. The animals were specific pathogen free bred at the Department of Experimental Animal Service, University of Maastricht, Maastricht, The Netherlands. During the experiments the rats were given standard rat chow and tap water at libitum. The RCMV Maastricht strain used in all experiments had been isolated and characterized in our laboratory (Bruggeman et al. 1985). A pool of homogenized salivary glands, derived from acutely infected laboratory rats, was used for all experiments. Mock infection was performed with a homogenate of salivary glands from non-infected rats. To control for factors in the inocullum other than RCMV, animals were inoculated with infected salivary gland suspension from which the virus 
Hendrix MGR, Daemen MJAP, Bruggeman CA. Cytomegalovirns nucleic acids distribution within the human vascular tree. Am J Pathol 1991; 138:563-567

Koskinen P, Lemström K, Bruggeman $C_{*}$ Lautenschlager I, Hăry P. Acute cytomegalovirus infoction induces a subendothekial infammation (endothelialitis) in the allograft vescular wall, A possible linkage with enhanced allograft ateriosclerosis. Am J Pathol 1994; 144:41-50

Lee JYY. Cytomegallowirus infection involving the skin in irronunocompromised hosts. A clinicopathologic study. Am I Pathol 1989; 92:96-100

Lin CS, Penha PD, Krishnan MN, Zak FG. Cytomegalic inclusion disease of the skin. Arch Dermatol $1981: 117: 282-284$

Minick CR, Dreesman GR, Mc Collum CH, Petrie BL, Burek J, De Bakey ME. Cytomegalovirus antigen within human arterial smooth muscle cells. Lancet $1983 ; 2: 644-647$

Morgello S, Cho E-S, Nielsen S, Devinsky O, Petito CK. Cytomegalowirus encephalitis in patients with the acquired immunodeficiency syndrome: an autopsy study of 30 cases and a review of the literature. Human Pathol 1987; 18:289-297

Muldoon J, O'Riordan K, Rao S, Abecassis M. Ischaemic colitis secondary to venous thrombosis. A rare presentation of cytomegalovirus vasculitis following renal transplantation. Transplantation 1996; 61(12):1651-1653

Nokta $M$, Eaton D, Steinsland OS, Albrecht T. Ca 2+ responses in cytomegalovirus infected fibroblasts of human origin. Virology 1987; 157:259-267

Percivalle E, Revello MG, Vago L, Morini F, Gerna G. Circulating endothelial giant cells permissive for human cytomegalovirus (HCMV) are detected in disseminated HCMV infections with organ involvement. $\mathrm{J}$ Clin Invest 1993; 92:663-670

Persoons MCJ, Daemen MJAP, Bruning JH, Bruggeman CA. Active cytomegalovins infection of arterial smooth muscle cells in immunocompromised rats. A clue to Herpesvirus-associated atherogenesis? Circ Res 1994; 75:214-220

Salzman RL, Quirk MR, Jordan MC. High levels of circulating cytomegalovirus DNA reflect visceral organ disease in viremic immunosuppressed patients other than marrow recipients. J Clin Invest 1992; $90: 1832-1838$

Scholz M, Cinatl J, Gross V, VogelJU, Blaheta RA, Freisleben HJ, Markus BH, Doerr HW. Imupact of oxidative stress on human cytomegalovirus replication and on cytokine-mediated stimulation of. endothelial cells. Transplantation 1996; 61(12):1763-1770.

Span AHM, Endert J, van Boven CPA, Bruggeman CA. Virus induced adherence of monocytes to endothelial cells. EEMS Microbiol Immunol 1989; 47:237-244

Span AHM, Frederik PM, Grauls G, van Boven CPA, Bruggeman CA. CMV induced vascular injury: an electron microscopic study in the rat. In vivo $1993 ; 7.567-574$

Span AHM, van DAM-Mieras MCE, Mullers W, Endert J, Muller AD, Bruggeman CA. The effect of virus infection on the adherence of leucocytes or platelets to endothelial cells. Eur $\mathrm{J}$ Clin Invest 1991 ; $21: 721-731$

Stals FS, Bosman F, van Boven CPA, Bruggeman CA. An animal model for therapeutic intervention studies of CMV infection in the immunocompromised host. Arch Wirol 1990; 114:91-108

Van Dam-Mieras MCE, Bruggeman CA, Muller AD, Debie WHM, Zwaal RFA. Induction of endothelial cell procoagulant activity by cytomegalovirus infection. Thromb Res $1987 ; 47: 69-75$ 
Wan Dam-Mieras MCE, Muller AD, van Dieyen $G$, Hemker HC. Blood coagulation factors II, V, VII, DX, and XI. Determination by clotting assiays. In: Methods of enzymatic analysis. Vol. V, Verlag Chemie GmbH. D-6940 Weinheim, FRG, 1984

Van Dam-Mieras MCE, Muller AD, Van Hinsbergh WWM, Mullers WJHA, Bomans PHH, Bruggeman CA. The procoagulant response of cytomegalovins infected endothelial cells. Thromb Haemostasis $1992 ; 68: 364-370$

Vossen RcRM, Persoons MCJ, Slobbe van Drunen MEP, Bruggeman CA, van Dam Mieras MCE. Intracellular thiol redox status affects cytomegalovirus infection of vascular cells. Virus Res $1997 ; 46: 65-74$.

Waldman WJ, Knight DA, Huang EH, Sedmak DD. Bidirectional transmission of infectious cylomegalovirus between monocytes and vascular endothelfal cells: an in vitro model. J Infect Dis $1995 ; 171: 263-272$

Wilcox CM, Diehl DL, Cello JP, Margaretten W, Jacobson MA. Cytomegalovirus esophagitis in patients with AIDS. A clinical, endoscopic, and pathologic correlation. Ann Int Med 1990; 113:589593

Woodroffe SB, Garnett HM, Danis VA. Interleukin-1 production and cell activation response to cytomegalowirus infection of vascular cells. Arch Virol 1993; 133:295-308

Yamashiroya HM, Ghosh L, Yang R, Roberison AL. Herpesviridae in the coronary arteries and aorta of young trauma victims. Am J Pathol 1988; 130:71-79 


\section{Appendix}

\section{Case reports}

To illustrate the pathology of disseminated human CMV disease and the great similarities with the pathology of generalized RCMV infection, as desribed in this chapter, two cases of severe congenital CMV disease are described here. The most prominent and characteristic pathology of these neonates is shortly described below.

\section{Cose 1}

A male child was delivered after an amenorthoea of 29 weeks by a sectio caesario, because of deterioration of fetal condition. Pregnancy had been complicated by signs of toxicosis and hydrops fetalis. The neonate suffered severe renal and respiratory dysfunction. The length matched with an ammenorrhoea of 24 weeks; dysmaturitas was symmetric. An extreme thrombocytopenia $\left(<5010^{\circ}\right)$, low hacmatocrit $(22 \%)$ and anaemia $(\mathrm{Hb}<3 \mathrm{mmol} / \mathrm{l})$ existed. Respiratory failure finally resulted in neonatal deatl, two days after birth.

At autopsy a pronounced hydrops fetalis was found. The peritoneum showed focal haemorrhages. Hepatosplenomegaly was associated with microscopic evidence for extramedullary haematopoiesis and haemorrhages. Enlarged cells in the liver contained typical CMV associated inclusions (figure 2A.1). Immature lungs with signs of hyalin membrane disease showed extensive intra- bronchiolar haemorrhages and the focal presence of cytomegalic cells with typical CMV inclusions (figure 2A.2). Cytomegalic cells were abundantly found in kidney tubuli, pancreas (acinar and island cells), periventricular brain areas and salivary glands as well. Immunohistochemical staining proved the presence of CMV antigens. Generalized CMV infection was further confirmed by culture of the virus from multiple organs.

\section{Case 2}

A female child was delivered by a sectio caesario because of fetal distress after an amenorrhoea of 30.5 weeks. A symmetric dysmaturitas was observed. The neonate was hypotensive. Laboratory investigations revealed extreme anaemia ( $\mathrm{Hb}<2 \mathrm{mmol} / \mathrm{l})$, thrombopenia $\left(1410^{9} / 1\right)$ and extremely low haematocrit values. An increasing loss of blood was established from the lungs, stomach and anal region. The skin showed many petechiae. Circulatory failure was manifest and the child died one day after birth. At autopsy a hydrops fetalis was noticed. Petechiae were observed in the gastric region, the brain and in the lungs, while a small amount of blood was present in the fossa cranii posterior. The latter was associated with microscopic finding of haemosiderophages, indicating the chronic nature of the haemorrhages. Cytonegalic cells with viral inclusions were observed in the liver, kidneys and pituitary gland. Immunohistochemical staining confirmed CMV infection of these cells. The virus was not cultured from any of the organs. 


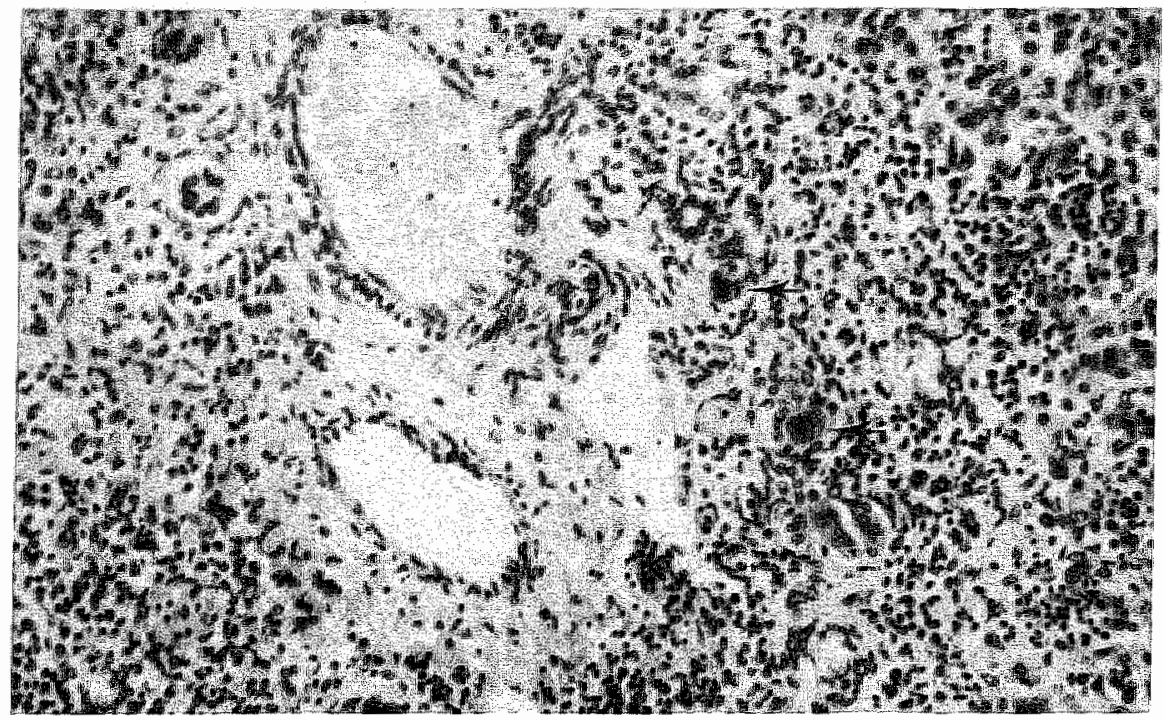

Figure 2A.1 Haenatoxilin-eosin staining of liver from neonate with congenital CMV disease. Widely scattered erythrocytes illustrate extensive haemorrhaging, while disruption of a venule is seen. Pycnotic cells are massively present. Two cytomegalic cells containing typical intranuclear CMV inclusions are shown (arrows).

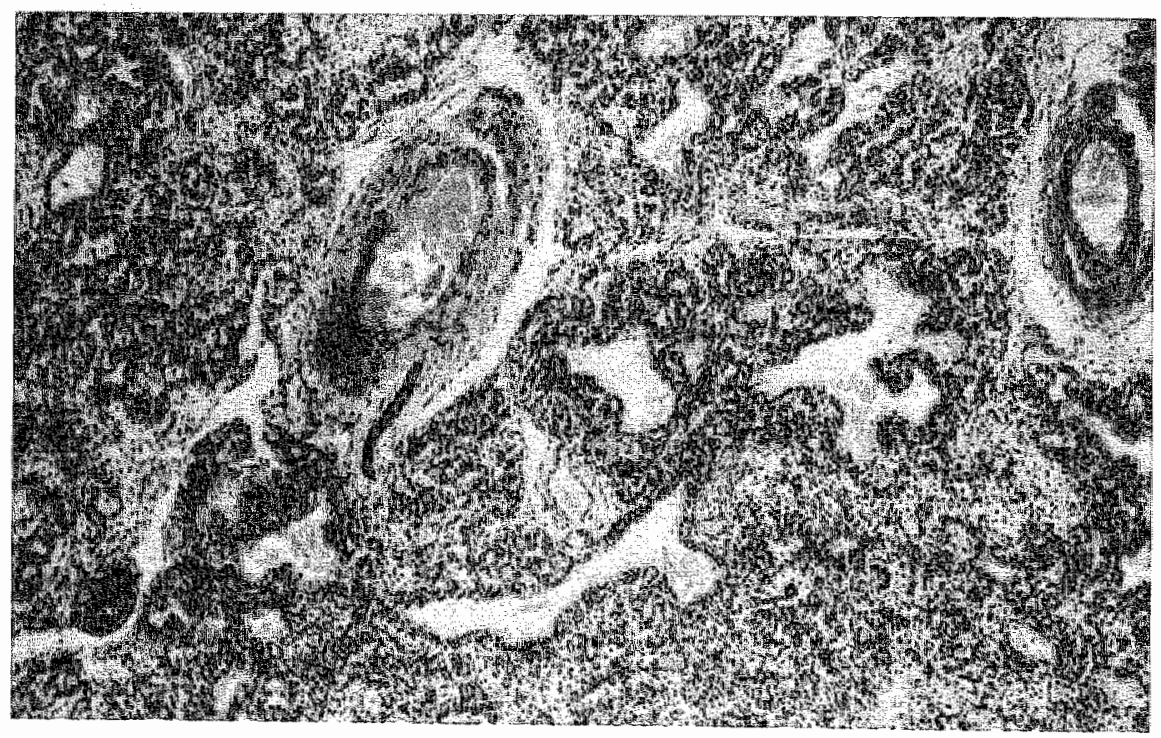

Figure 2 A.2 Haematoxilin-eosin staining of lung from a neonate with congenital CMV disease. Intra- and extrabronchial haemorrhages and infiltrates are shown. 


Chapter 3

\section{Enhancement of transplantation associated atherosclerosis by cytomegalovirus, which can be prevented by prophylaxis with HPMPC}

Based on

Enhancement of transplantation-associated atherosclerosis by CMV, which can be prevented by antiviral therapy in the form of HPMPC. JH Bruning, MCJ Persoons, $\mathrm{K}$ Lemström, FS Stals, E de Clerq, CA Bruggeman. Transplant International 1994;7 [Suppl.1]: S365-S370. 


\begin{abstract}
Effects of acute cytomegalovirus (CMV) infection on transplantation associated arteriosclerosis were studied in a rat model for chronic allograft rejection. Rats underwent abdominal allogeneic aorta transplantation. Neointima formation and media thinning was quantitated by measurement of cross sectional surface areas at day 50 post transplantation.

Administration of rat specific CMV (RCMV) at the moment of maximum intimal proliferation and influx of inflammatory cells in the adventitia, resulted in enhanced neointima formation, which correlated with an increased presence of smooth muscle cells (SMCs) in the intima. These effects could be completely inhibited by prior administration of $1 \mathrm{HPMPC}$, a very potent and selective inhibitor of CMV replication, indicating the virus specificity of their origin. Medial thinning was not affected by RCMV infection.

The data indicate that CMV enhances alloimmune graft reactions, as manifested by augmentation of 'atherosclerotic' changes and that anti-CMV prophylaxis (like HPMPC ) may be considered in allogeneic graft recipients.
\end{abstract}




\section{Introduction}

Cytomegalovirus (CMV) infections are a serious source of complications among immunosuppressed transplant recipients, exhibiting significant effects on long term allograft survival. Clinical studies have shown a clear correlation between CMV infections and allogeneic transplant associated arteriosclerosis with allograft rejection (Grattan et al. 1989, Loebe et al. 1990, McDonald et al. 1989). Moreover, it has been demonstrated that a positive correlation does exist between the presence of the CMV genome in the arterial wall and the grade of atherosclerotic changes found in nonimmunosuppressed patients (Hendrix et al. 1989, Hendrix et al. 1990). Recently, it has been shown in rats that rat specific CMV (RCMV) induces changes in the arterial wall that strongly resemble the early stages of atherosclerosis (Span et al. 1992). These changes comprise enhanced leukocyte adhesion to the endothelium, influx of leukocytes into the subendothelial space and deposition of fat granules. Based on these data, a causative or enhancing role of CMV on atherosclerotic processes has been suggested.

For studying the nature of the effects of CMV on allograft survival, an appropriate animal model is needed. In the study presented here, CMV influences on neointima formation in rat aortic allografts was investigated, using a modified model for chronic allograft rejection as described by Mennander et al. (1991). This rat model, together with the availability of a well defined rat specific CMV (Bruggeman et al. 1982), seems to offer a good opportunity to unravel the complex of factors that are associated with chronic rejection and diminished allograft survival and to determine whether CMV infections may play a role in this.

\section{Materials and methods}

\section{Animals}

Experiments were performed with male Brown Norway $\left(B N / M ; R T_{1 n}\right)$ and Lewis $\left(\mathrm{LEW} / \mathrm{N} ; \mathrm{RT}_{11}\right.$ ) that had been bred under specific pathogen free conditions at the Department of Experimental Animal Service at the University of Limburg, Maastricht, the Netherlands. The rats weighed $200-250 \mathrm{~g}$ at the time of transplantation, and were 23 months of age.

\section{Transplantations}

Transplantations were performed under sterile conditions from BN-to-LEW (allogeneic) or from LEW-to-LEW (syngeneic). In short, under ether anaesthesia a section of the abdominal aorta of the donor rat, between the left renal artery and the bifurcation, was prepared free under sterile conditions. All small branches were ligated with 7-0 silk. The donor rat was injected with $50 \mathrm{IU}$ of heparin through the penis vene, after which the aortic graft of approximately $2.5 \mathrm{~cm}$ was taken out and inserted orthotopically into the recipient rat. Graft recipients were often, but not always, 
operated on in groups of two, both of them receiving their grafts from the infrarenal abdominal aorta of a single donor. The order in which these two segments were inserted was random. The end to end anastomoses were sutured with 8-0 Ethicon prolene in one continuous suture with an atraumatic needle, during which procedures both ends of the recipient aorta were approximated using an Ikuta approximator (Stöpler Instruments B.v., Utrecht, The Netherlands) to avoid any traction. Total ischemia time was between 20 to 50 minutes, depending on the order of insertion. The animals were anaesthetized with ether.

\section{Experimental design}

Aortic grafts, $1 \mathrm{~cm}$ in length, of either Lewis or BN origin were prepared, as described and transplanted into non-immunosuppressed LEW recipients. Both groups received either no further treatment, RCMV infection alone, or RCMV infection and anti-viral prophylaxis. With respect to RCMV infection, recipient rats were injected intraperitoneally with $10^{5} \mathrm{PFU}$ of the virus, either at day 0 , or day 21 and 24 after transplantation. With respect to anti-viral prophylaxis, recipient rats were injected intraperitoneally with HPMPC ( $20 \mathrm{mg} / \mathrm{kg}$ rat weight) on day 20 and 28 . All recipients were killed at day 50 . The abdomen and thorax were opened under ether anaesthesia and a perfusion was carried out with buffered saline containing $200 \mathrm{mg} / \mathrm{L}$ nifedipine, until kidneys and liver had turned completely pale. The nifedipine was added to the perfusion fluids to obtain optimal SMC relaxation and thus vasodilatation.

Subsequently, perfusion was performed with $3,7 \%$ formaldehyde added to the perfusion fluid. Biopsies were taken of the transplants and of the other main organs. These biopsies were divided into smaller sections to be either frozen in isopentane on dry-ice and stored at $70^{\circ} \mathrm{C}$, or fixed in paraformol-lysine-periodate and embedded in paraffin. The time point that was chosen for killing the recipient rats (day 50 ), was based on previous studies, that have shown a maximal increase in diameter, maximum changes of intimal and medial thickness, as well as maximal cellular infiltration of intima and adventitia at that time (Mennander et al. 1991). See Table 3.1 for a summary of the experimental groups.

\section{Tissue sections and staining}

Tissue sections $(4-5 \mu \mathrm{m})$ were made of the paraffin embedded graft biopsies and used for histology and immunohistochemistry. The sections were investigated for the presence of RCMV associated antigens by immunoperoxidase staining, using RCMV specific monoclonal antibodies as described before (Bruning et al. 1987). In standard hematoxilin-eosin stained tissue sections the number of infiltrating cells was estimated, as well as the total number of nuclei that were present in media and neointima. In elastin stained sections (van Gieson) cross sectional areas of media and neointima were measured.

\section{Cross sectional areas}

Cross sectional areas of neointima and media were measured in elastin stained (Gieson) sections, using a computer assisted Leitz morphometer (Leitz 570). The geometric mean was calculated out of at least three measurements. 


\section{In sritu hybridisation}

In situ hybridisation to detect the viral genome was carried out as described previously (Stals et al. 1990). The probe that was used, consisted of a mixture of three biotinlabelled DNA fragments accounting for $23,7 \%$ of the RCMV genome. To rulle out nonspecific hybridisation, the same procedures were performed with sections that had previously been proven to be RCMV negative. Moreover, in situ hybridisation procedures were accomplished without the DNA probe using the plasmid vector as a control.

\section{Anti-viral prophylaxis}

(S)-1-(3-Hydroxy-2-Phosphonylmethoxypropyl)-Cytosine (HPMPC) was symthesised by Rosenberg and Holy (Czechoslovak Acadeny of Sciences, Prague,

Czechoslovakia). The freeze dried compound was reconstituted in buffered saline to a concentration of approximately $5 \mathrm{mg} / \mathrm{ml}$ and administered to the recipient rats intraperitoneally on day 20 and 28 post transplantation at a dose of $20 \mathrm{mg} / \mathrm{kg}$ rat weight. This dosage scheme resulted in an effective antiviral plasma level during the period of viremia and possible viral replication (Snoeck et al. 1988, Stals et al. 1991).

Valle 3.1 summing of experincont groups.

\begin{tabular}{|c|c|c|c|}
\hline group & $\begin{array}{l}\mathrm{Nr} \text {, of } \\
\text { rats } \\
(\mathrm{N})\end{array}$ & $\begin{array}{l}\text { syngeneic } \\
\text { or } \\
\text { allogeneic }\end{array}$ & treatment \\
\hline A & 9 & allo & None (Control) \\
\hline $\mathrm{B}$ & 6 & allo & RCMV infection at day 0 \\
\hline $\mathrm{C}$ & 6 & allo & RCMV infection at day 21 and $24\left(10^{5}\right.$ PFU) \\
\hline $\mathrm{D}$ & 11 & allo & $\begin{array}{l}\text { RCMV infection at day } 21 \text { and } 24\left(10^{5} \mathrm{PFU}\right) \text { and } \\
\text { HPMPC proplylaxis }(20 \mathrm{mg} / \mathrm{kg}) \text { at day } 20 \text { and } 28\end{array}$ \\
\hline $\mathrm{E}$ & 3 & allo & HPMPC prophylaxis $(20 \mathrm{mg} / \mathrm{kg})$ at day 20 and 28 \\
\hline $\mathrm{F}$ & 6 & syn & None (Control) \\
\hline G & 6 & syn & RCMV infection at day 0 \\
\hline $\mathrm{H}$ & 6 & syn & $\begin{array}{l}\text { RCMV infection ( } 10^{\circ} \text { PFU) at day } 0 \text { and HPMPC } \\
\text { prophylaxis (20mg/kg) at day }-11 \text { and } 7\end{array}$ \\
\hline
\end{tabular}

\section{Virus}

In this study, the Maastricht strain of RCMV (Bruggeman et al. 1982) was used. The virus pools that were used for in vivo infection, consisted of clarified suspensions of salivary gland tissue from RCMV infected rats. Rat recipients receiving RCMV, were 
injected intraperitoneally with $10^{5}$ PFU either on day 0 , or day 21 and 24 .

Statistical analysis.

Results of cross sectional area measurements and nuclear counts in different groups were statistically compared with the aid of the Student t-test.

\section{Results}

Fifty transplantations were carried out successfully without animal failures. Table 3.1 summarises the experimental groups and numbers of transplantations that were carried out.

\section{Cross sectional areas}

As was expected, control isografts (Group F) did not show intimal proliferation, nor decrease of medial thickness. In the infected isograft group (Group G) one out of six rats that were infected at the day of transplantation, showed slight neointima formation. The control (non-infected) allograft group (Group A) showed prominent neointima formation and decrease of medial thickness. Infection of the recipient rats at the day of transplantation (Group B), had no influence on these processes (results not shown). However, when allograft recipient rats were infected at day 21 and 24), neointima formation was enhanced by RCMV infection by $32 \%$, as compared to control noninfected recipients (Group C vs $\mathrm{A}, \mathrm{p}=0.03$ ). The difference in decrease of medial thickness between these two groups was only $5 \%(p=0.23)$. In the allogeneic RCMV infected group treated with HPMPC, neointima formation was significantly decreased $(75 \%)$, as compared to the infected non-treated rats (Group D vs $C, p=0.01$ ). The difference in neointima thickness in the infected and HPMPC treated rats, as compared to neointima thickness in non-infected, non-treated rats was $40 \%$ (Group D vs A, p< 0.01 ). No differences were found between neointima and media cross sectional area in allograft recipients that had received only HPMPC (group E), compared to allograft recipients that had neither received HPMPC nor RCMV (group A) (data not shown). However, the number of rats in the control group $\mathrm{E}$ were too small to reach any significancy (Figure 3.3). Results of neointima and media cross sectional area measurements are presented in Figure 3.1.

\section{Cell counts}

Cell counts were performed in order to get insight in whether CMV induced enhancement of neointima thickness is correlated with increased cell numbers. Since infiltration of (mononuclear) inflammatory cells appeared to be restricted to the adventitia, with hardly any infiltration of inflammatory cells in neointima or media at day 50 post transplantation, nuclear counts were made without making attempts to differentiate between types of cells. More than $90 \%$ of the cells in both neointima and media appeared to be SMCs, as estimated by staining with anti-SMC actin monoclonal antibodies (results not shown). The number of nuclei in the neointima of aorta 
allografts was proved to be significantly increased in RCMV infected recipients, as compared to non-infected controls (Group $C$ vs $A, p=0.01$ ). The amount of nuclei in the allografted media in infected recipients, as compared to non-infected controls, was significantly higher as well (Group $C$ vs $A, p=0.004$ ). Antiviral prophylaxis with HPMPC had no significant influence on the amount of nuclei in the media, but induced a significant decrease in the number of cells that were present in the intima (Group D vs $\mathrm{C}, \mathrm{p}=0.005$ ). This inhibition resulted in SMC levels even below those that were measured in the non-infected controls (Group D vs $A, p=0.006$ ). No differences were found in media and intima cell counts of allograft recipients that had received only HPMPC (Group E), as compared to control allograft recipients (Group A). However the number of rats in the control group $\mathrm{E}$ were too small to reach any significancy. Results of the cell counts are summarized in Figure 3.2.

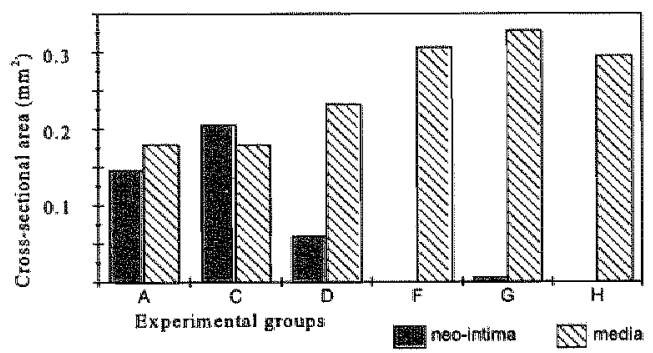

Figure 3.1. Neointima and media cross sectional areas of rat aortic allografts from $\mathrm{RCMV}$ infected and non-infected recipients at 50 days post transplantation. For explanation of groups, see Table 3.1.
Statistical analysis (t-test) neointima

media

A vs $\mathrm{C}, \mathrm{p}=0.03 \quad$ A vs $\mathrm{C}, \mathrm{p}=0.23$

A vs $D, p<0.01 \quad A$ vs $D, p=0.05$

C vs $D, p=0.01 \quad C$ vs $D, p=0.15$

(A vs F, G, H p <0.01)

\section{Infiltration of inflammatory cells}

At day 50 post transplantation, an abundant mononuclear cellular infiltration was present, predominantly in the adventitia. In the media hardly any inflammatory cells were observed, while in the neointima low numbers of mononuclear leukocytes were occasionally observed in the subendothelial space. Although not quantitated, the cellular infiltrate was evidently enhanced by the viral infection in the adventitia, but not in the media and neointima. HPMPC profylaxis in RCMV infected recipients of aortic allografts diminished the amount of cellular infiltration in the allograft adventitia.

\section{Detection of viral antgens and viral genome}

At day 50 post transplantation, no viral antigens, nor viral nucleic acids could be detected in neointima or media. In the adventitia very sporadic RCMV positive inflammatory cells were detectected, either by immunoperoxidase staining of antigens or by in situ hybridisation for detection of the viral genome. 


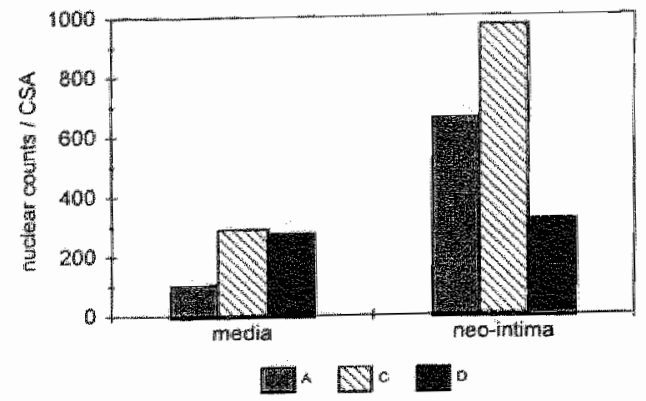

Figure 3.2. Nuclear counts per cross sectionat area of media and neointima in rat aorta rat allografts at 50 days post transplantation. For explanation of groups, see Table 3.1.

\section{Statistical analysis (t-test)}

$\begin{array}{cc}\text { neointima } & \text { media } \\ \text { A w } C, p=0.01 & \text { A vs } C, p=0.004 \\ \text { A vs D, } p=0.005 & \text { A vs } D, p=0.08 \\ C \text { vs } D, p=0.006 & \text { C vs } D, p=0.46\end{array}$

\section{Discussion}

Allogeneic transplantation of abdominal aorta in rats has been proved an appropriate model for studying the aspects of chronic allograft rejection (Mennander et al. 1991, Lemström et al. 1993). In this study it was used to study the effects of CMV on such rejection processes, of which arteriosclerosis is considered to be a main feature. The results we obtained in this study when RCMV had not been administered, closely resemble those of others (Schmitz-Rixen et al. 1988), demonstrating the reproducibility of the model. Moreover, stimulatory effects of RCMV infection on the processes that are involved in chronic rejection, are shown. Neointima formation and mononuclear cellular infiltration in the adventitia was enhanced by viral infection, but only when infection was established during intimal proliferation. In the rat strains that were used, intimal proliferation has been described to start around day 20 post transplantation and to reach its maximum at day 60 (Schmitz-Rixen et al. 1988). This proliferation was correlated with the amount of cellular infiltration in (mainly) the adventitia (SchmitzRixen et al. 1988), Others, using the same Maastricht rat strain of CMV (Lemström et al. 1993), have also found significant enhancing effects of acute RCMV on neointima formation and cellular infiltration. However, in contrast to our findings, they did so only when the infection was established at the time of transplantation, and not thereafter (Lemstrom et al. 1993). In the rat strain combination that was used in those experiments (DA $\times$ WF), although believed to represent an equal allogeneic barrier, proliferation starts immediately after transplantation and reaches peak levels at day 30 . These differences may account for the different findings. However, the combined results of both studies strongly indicate that CMV renders its effects on chronic rejection via manipulation of the early phases of chronic rejection.

Since signs of acute RCMV infection were almost completely absent and the effects of RCMV coincided with enhanced infiltration of inflammatory cells in the adventitia, it might be speculated that CMV induced allograft changes are established indirectly via 
stimulated production of growth factors and cytokines. These factors are released by stimulated and/or infected inflammatory and vascular cells, like endothelial cells and SMCs, while they enhance their release by these cells.

Different bacteria and viruses have been associated with diminished allograft survival. To demonstrate that in this model virus infection and replication itself are responsible for the measured effects, anti-viral prophylaxis was established. For this purpose the anti-viral drug HPMPC, still in the experimental phase of evaluation, but with very promising results both in humans and in animals (Snoeck et al. 1988, Stals et al. 1991), was used. The compound is a nucleoside analogue and has been proved to be a potent and selective inhibitor of both human and rat CMV replication in vivo and vitro (Snoeck et al. 1988, Stals et al. 1991). Compared to other drugs that are used against CMV, such as ganciclovir, HPMPC has the advantage of low toxicity, and very low therapeutic levels. Moreover, it has a long half life time, allowing administration only once a week. When HPMPC was administered at (as experimentally determined) therapeutic levels (Stals et al. 1991) the effects of RCMV infection on both neointima formation and cellular depletion of the media was completely abolished, indicating that replicating RCMV stimulates chronic rejection. HPMPC was found to inhibit neointima formation to a level below that of the (non-RCMV infected) allogeneic controls. This suggests a toxic or proliferation inhibiting effect of the compound itself. However, administration of HPMPC to non-infected recipients of aortic allografts did not clearly show these effects on neointima and media (though the number of rats that had received only HPMPC was too small to draw any definite conclusion from these results).

In conclusion, chronic rejection of aortic allografts, as reflected by neointima formation, with increased numbers of intimal SMCs, and infiltration of mononuclear inflammatory cells in the adventitia, is enhanced by CMV infection in rats. More studies are needed to investigate the mechanisms underlying these CMV induced effects. Whatever the nature, these effects may effectively be prevented by anti-viral prophylaxis with HPMPC, which justifies at least the consideration of prophylactic use of HPMPC in case of allogeneic transplantation.

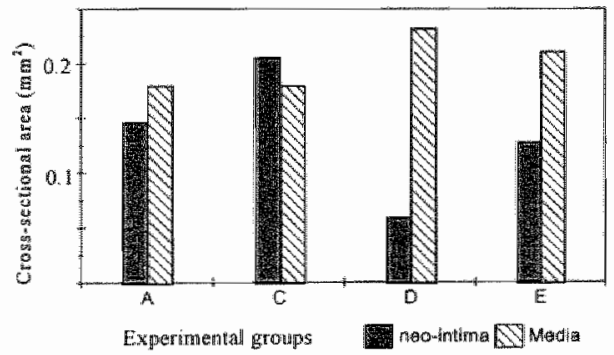

Figure 3.3. The effect of HPMPC on neointima and media cross sectional areas in rat aorta allografts from RCMV infected and non infected recipients, 50 days post transplantation. For explanation of groups, see Table 3.1.
Statistical analysis (t-test) neointima media A vs E, $p=0.32 \quad$ A vs $E, p=0.08$ A vs D, $\mathrm{p}=0.01 \quad$ A vs $D, p=0.05$ $A$ vs $C, p=0.03 \quad$ A vs $C, p=0.23$ Ev vs D, $\mathrm{p}=0.10 \quad$ E vs D, $p=0.38$ Evs $C, p=0.14 \quad$ Evs $C, p=0.19$ 


\section{References}

Bruggeman CA, Meijer H, Domans PHJ, Debie WTM, Grawls GELM, van Boven CPA. Isolation of a cytomegalovirus-like agent from wild rats. Arch Virol 1982,73:231-241.

Bruning JH, Debie WHM, Dormans PH, Meijer H, Bruggeman CA. The development and characterization of monodlonal antibodies against rat cytomegalovirus induced antigens. Arch Viroi $1987: 94: 55-70$.

Gratan MT, Moreno Cabral CE, Starnes VA, Oyer PE, Stinson EB, Shumway NE. Cytmegalovirus infection is associated with cardiac allograft rejection and atherosclerosis. JAMA 1989;261:359-362

Hendrix MGR, Domans PHI, Kitslaar P, Bosman F, Bruggeman CA. The presence of cytomegalovirus nucleic acids in arterial walls of atherosclerotic and non-atherosclerotic patients. Am I Pathol $1989 ; 134: 1151-1157$.

Hendrix MGR, Salimans MMM, van Boven CPA, Bruggeman CA. High prevalence of latently present cytomegalovirus in arterial walls of patients suffering from grade III atherosclerosis. Am J Pathol $1990 ; 136: 23-28$.

Lemström KB, Bruning JH, Bruggeman CA, Lautenschlager IT, Häyry PJ. Cytomegalovirus Infection Enhances Smooth Muscle Cell Proliferation and Intimal Thickening of Rat Aortic Allografts. J Clin Invest 1993:92:549-558.

Loebe M, Schuler $S$, Ortwin Z, Warnecke H, Fleck E, Hetzer R. Role of cytomegalowirus infection in the development of coronary artery disease in the transplanted heart. J Heart Transplant 1990;9:707711 .

McDonald K, Rector TS, Braunlin EA, Kubo SH, Olivari MT. Association of coronary artery disease in cardiac transplant recipients with cytomegalo-virus infection. Am I Cardiol 1989;64:359-362.

Mennander A, Tiisala S, Haltunen J, Yilmaz S, Paavonen T, Häyry P. Chronic rejection in rat allografts: an experimental model for transplant arteriosclerosis. Arterioscler Thromb. $1991 ; 113: 671 \sim 680$.

Schmitz-Rixen Th, Megerman J, Colvin RB, Williams AM, Abbott WM. Immunosuppressive treatment of aortic allografts. J Vasc Surg 1988;7:82-92.

Snoeck R, Sakuma T, de Clercq E, Rosenberg I, Holy A. (S)-1-(3-Hydroxy-2-Phosphonylmethoxypropyl)Cytosine, a potent and selective inhibitor of human cytomegalovirus replication. Antimirob Agents Chemother 1988 32:1839-1844.

Span AFM, Grauls G, Bosman F, van Boven CPA, Bruggeman CA. CMV induces vascular injury in the rat. Atherosclerosis 1992;93:41-52.

Stals $\mathrm{FS}$, Bosman FT, van Boven CPA, Bruggeman CA. An animal model for therapeutic intervention studies of CMV infection in the immunocompromised host. Arch Virol 1990;1 14:91-108.

Stais FS, De Clercq E, Bruggenan CA Comparative Activity of (S)-1-(3-Hydroxy-2-

Phosphony/methoxy-propyl)Cytosine and 9-(1,3-Dihydroxy-2-Propoxymethyl) Guanine against Rat Cytomegalovirus infection In Vitro and In Vivo. Antimirob Agents Chemother 1991;35:2262-2266. 
Chapter 4

Active cytomegalovirus infection of arterial smooth muscle cells in immunocompromised rats. A clue to herpesvirus associated atherogenesis?

MCJ Persoons, MJAP Daemen, JH Bruning, CA Bruggeman.

Circulation Research 1994;75:214-220. 


\section{Summary}

The susceptibility of medial and neointimal arterial smooth muscle cells (SMCs) to acute cytomegalovirus (CMV) infection was investigated in immunocompetent and immunocompromised rats. The left common carotid artery of all animals was injured by balloon catheterisation. On day 14 and 17 after injury, rats were either intravenously infected with a rat cytomegalovirus (RCMV) or mock infected. Active RCMV infection was shown in the neointima of the injured arteries of immonosuppressed rats, characterised by specific cytopathological changes in haematoxylin-eosin stained sections and by the presence of early viral antigens, while the virus itself was visualized at different stages by electron microscopy. Viral genome was shown as well, using in situ hybridisation procedures. However, medial cells were hardly ever infected and RCMV did not infect neointimal parts that were recovered by endothelial cells. No infection was seen in control right carotid arteries or in the injured arteries of immunocompetent rats. Acute intimal RCMV infection was accompanied by infiltration of inflammatory cells, predominantly mononuclear cells that stained positive with an ED-1 monoclonal antibody. The majority of infected neointimal cells were SMCs containing smooth muscle actin. No changes were found in medial or neointimal cross sectional areas of the infected arteries.

In the present study, an active RCMV infection of arterial SMCs was established in vivo and it was concluded that neointimal SMCs were far more susceptible than are medial SMCs and that the absence of endothelium and immunosuppression were necessary conditions for arterial RCMV infection. 


\section{Introduction}

Cytomegalovirus (CMV) is a ubiquitous agent and a common cause of infection in humans. Although the vast majority of infections is asymptomatic, the virus may incite serious, often life-threatening disease in immunocompromised patients (Ho, 1991). Like other herpesviruses, CMV may establish latent or persistent infection and reside lifelong in the infected patient, although the site of latency is not clear. Much emphasis has been laid on an association of herpesviruses with atherogenesis. Fabricant and collegues (Fabrikant et al. 1978, 1983, Minick et al. 1979) described avian herpesvirus induced atherosclerotic changes in chickens, similar to the lesions found in humans. Since then, CMV, in particular, has been found repeatedly in human arterial tissue, predominantly derived from patients suffering atherosclerosis. The presence of CMV antigens (Melnick et all. 1983) and DNA (Petrie et al. 1987) has been described in cultures of smooth muscle cells (SMCs) derived from arterial tissue that had been surgically removed from patients with advanced arterial disease.

Furthermore, CMV antigens and genome were found in coronary arteries and aortas of trauma victims, predominantly in focal intimal areas showing early or advanced atheromatous changes (Yamashiroya et al. 1988). More recently, CMV nucleic acid sequences, but no viral antigens were demonstrated in large arteries of patients with and without atherosclerosis (Hendrix et al. 1991). With the polymerase chain reaction, CMV genome was found in $90 \%$ of arterial specimens obtained from patients with severe atherosclerosis, compared to $53 \%$ of specimens derived from nonatherosclerotic patients (Hendrix et al. 1989).

Epidemiologic support for an association between CMV and human atherosclerosis has come from studies on human heart transplants, where a significantly higher rate of accelerated transplant atherosclerosis was found in CMV infected heart transplant recipients, compared with non CMV infected recipients (Wreghit et al. 1987, Grattan et al. 1989, McDonald et al. 1989). In accordance with these findings in patients, accelerated atherosclerotic alterations were recently described in aorta allografts of rats that had been infected with a rat specific CMV (RCMV) (Bruning et al. 1994, Lemström et al. 1993). Although a correlation between CMV and atherosclerosis has been suggested, the actual role of the virus in atherogenesis remains to be established. Since CMV is found in arterial SMCs and proliferating intimal SMCs are thought to be part of the early atherosclerotic plaque (Ross and Glomset, 1976), it is tempting to consider that (intimal) arterial SMCs play a role in virus induced atherogenic changes. However, although CMV infection and replication have been demonstrated in cultured arterial SMCs (Tumilowicz et al. 1985, Tumilowicz 1990), no active CMV infection of arterial SMCs has been found in the above mentioned in vivo studies. Therefore, it has been hypothesized that the arterial wall may be a place for CMV latency from which the virus can reactivate, starting a productive infection. In the present study, the susceptibility of medial and neointimal SMCs to acute infection with RCMV (Bruggeman et al. 1982) was investigated in immunocompetent and immunocompromised rats in vivo. The characteristics of an active arterial SMC infection were analyzed, 
including a possible effect of the vins on intimal or medial cross sectional area.

\section{Materials and Methods}

\section{Wirus}

The RCMV used in this study, consisted of a pool of homogenated salivary glands of acutely infected laboratory rats (Bruggeman et al. 1982, 1983). Experimental rats were intravenously infected with $10^{5}$ plaque forming units (PFU) of salivary gland derived RCMV, diluted in $1 \mathrm{ml}$ Eagles minimal essential medum, containing $2 \%$ new born calf serum.

\section{Animals}

The experiments were performed, according to institutional guidelines, with 16 to 18 week-old male specific pathogen free Wistar Kyoto rats, bred at the Department of Experimental Animal Service of the University of Limburg, Maastricht the Netherlands. During the experiments, the rats were given standard rat chow and tap water at libitum

\section{Experimental design}

The left common carotid artery of all rats was balloon injured, as previously described. (Clowes et al. $1983 \mathrm{a}$, b). In short, after anaestheting the animals with pentobarbital ( $60 \mathrm{mg} / \mathrm{kg}$ body weight, intraperitoneally), a $2 \mathrm{~F}$ balloon embolectomy catheter (Baxter, Utrecht, The Netherlands) was introduced through the left extemal carotid artery and advanced into the aortic arch. Subsequently, the inflated catheter was withdrawn through the common carotid artery. This procedure was repeated three times. Then the catheter was removed, the external carotid artery was ligated and the wound was closed. The right carotid artery was left untraumatized and served as an internal control. Rats were divided into four groups ( $A-D, n=7$ or per group). Thirteen days after balloon injury, when medial SMC proliferation had returned to control levels but intimal SMC proliferation was submaximal. (Clowes et al. $1983 \mathrm{a}$, b), rats of groups $A$ and $B$ were immunosuppressed by total body roentgen radiation of 5 Gray. One and 4 days later, animals of groups $A$ and $C$ were intravenously injected with $10^{5} \mathrm{PFU}$ RCMV, while rats of group B and D were mock infected with a salivary gland homogenate derived from non infected rats. It has been proved that during these first few days after roentgen radiation, the animals were immunosuppressed sufficiently to give the virus a change to proliferate and initiate an infection (Stals et al. 1990). The choice to administer RCMV 14 days after balloon injury was based on previous experience with the restimulation model (Daemen et al. 1991, van $K$ leef et al. personal communication), were it was showed that neointimal cells are very sensitive to stimuli like angiotensin and do respond in a manner different from medial SMCs. Two weeks after the first RCMV administration, the rats were killed by aortic bleeding under ether anaesthesia and were perfused in situ with $0.9 \% \mathrm{NaCl}$. One hour before death, all animals intravenously received $0.5 \%$ Evans blue in $0.9 \% \mathrm{NaCl}$ to stain nonendothelialised vascular tissue. Two millimetre segments were taken from the central, 
Evans blue retaining part of the balloon injured left common carotid artery, as well as from the proximal part near the aortic arch that was not stained by Evans biue.

Comparable segments were taken from the non-injured right carotid artery. Furthermore, tissue biopsies of liver, spleen, lung and kidney were collected. The salivary glands, preferential sites for CMV, were taken to confirm a generalised RCMV infection.

All tissues were fixed in $3.7 \%$ formaldehyde in phosphate buffered saline, routinely processed and paraffin embedded. Cross sections $(3 \mu \mathrm{m})$ were cut and mounted on chromium-alum gelatin coated, glutaraldehyde inactivated glass slides, for immunohistochemical and in situ hybridisation techniques, as well as for haematoxylin-eosin and Lawson elastin staining.

\section{Virus detection}

For the detection of RCMV early antigens, immunocytochemical techniques were used as previously described (Stals et al. 1990). After blocking of endogenous peroxidase with $0.6 \% \mathrm{H}_{2} \mathrm{O}_{2}$, deparaffinized tissue sections were preincubated with $2 \%$ bovine serum albumin before incubation with a mixture of two mouse monoclonal antibodies ( 8 and 35 (Bruning et al. 1987)) against nuclear and cytoplasmic RCMV antigens. A second incubation was performed with biotinylated, affinity purified, sheep anti-mouse IgG antibodies (Amersham, Nederland B.V,Houten, the Netherlands), followed by incubation with streptavidin-horseradish peroxidase complex (Amersham, Nederland B.V. Houten, the Netherlands). Specific antibody-antigen binding was visualized with diaminobenzidine substrate (DAB). To control for aspecific positive staining, all sections were incubated with an anti-human CMV monoclonal antibody, non-reactive with RCMV, as well as with no monoclonal antibody at all. Antibodies were of IgG 1 subclass and used in the same concentration (1:100). Tissue sections were counterstained with haematoxylin and embedded in Entellan (Merck, Darmstadt, Germany). In situ hybridisation procedures to detect viral genome were performed as previously described (Hendrix et al. 1989). Probe DNA consisted of a mixture of DNA fragments (C, D and E), accounting for $23.7 \%$ of the RCMV genome, as had been analyzed in our laboratory (Meijer et al. 1984). The fragments were labelled with biotin 11 -dU'TP (Sigma, St Louis, USA), using the primed labelling kit (Boehringer, Almere, the Netherlands). The specificity of the DNA probe was evaluated in uninfected rat embryonic fibroblasts. Hybridization was carried out overnight, at $42^{\circ} \mathrm{C}$. Formed hybrids were visualized by use of the BLU-gene TM kit (Bethesda Research Laboratories BRL, Faithersburg, USA). To rule out non-specific hybridization, in situ hybridization procedures were also accomplished without the DNA probe, using the plasmid vector as a control.

For electron microscopy, cross sectional samples of the carotid arteries were fixed in $2.5 \%$ glutaraldehyde in $0.1 \mathrm{~mol} / /$ phosphate buffer, $\mathrm{pH}$ 7.2. The arterial samples were postfixed in $1 \%$ osmium tetroxide, dehydrated in graded alcohol solutions and embedded in EPON 812. Ultrathin sections were cut on a diamond knife, using a Reichert Ultracut and mounted on copper grids. The sections were stained with uranyl acetate and lead citrate and observed with a Philips CM10 electron microscope at 80 $\mathrm{KeV}$. 


\section{Histopathology}

Immunohistochemical staining procedures were carried out to mark arterial SMCs, using HHF 35 (Brunschwig, Amsterdam, the Netherlands), a monoclonal antibody that recognizes actin isotypes ( $\alpha$ and $y$ ) common to all SMCs (Tsukada et al. 1987). After incubation with HHF 35 , the sections were incubated with peroxidase conjugated rabbit anti-mouse immunoglobulins (Dako, Gllostrup, Denmark). Visualization was performed using DAB substrate. Serial sections were staned, either with HHF 35 or monoclonal antibodies $(8+35)$ against viral antigens, to determine the $\mathrm{SMC}$ origin of RCMV infected cells.

To recognize infiltrated cells, immunoperoxidase staining of arterial sections was carried out, using ED-1, a monoclonal antibody reacting with rat macrophages / monocytes (Dijkstra ef al. 1985) and W3/13, a monoclonal antibody that reacts with rat Tlymphocytes (Brown et al. 1981). After incubation with these monoclonals, the sections were incubated with peroxidase conjugated rabbit anti-mouse immunoglobulins (Dako, Glostrup, Denmark). Visualisation was performed with DAB as substrate. To control for specificity of signals, the same procedures were performed with aspecific and with no monoclonall antibodies.
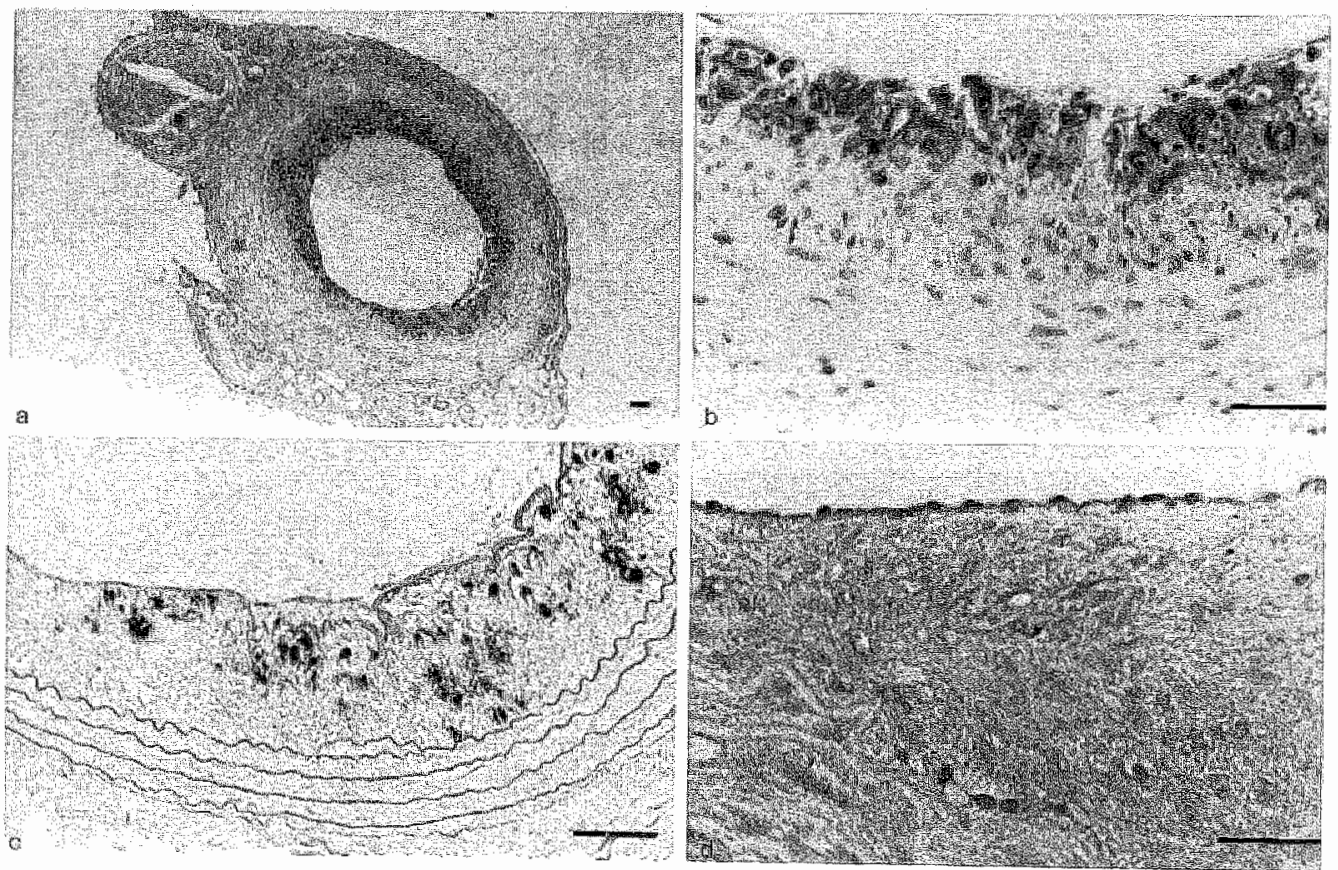

Figure 4.1 Photomicrographs of rat left comtinon carotid artery, 4 weeks after balloon injury. Bar represents $50 \mu \mathrm{m}$. a and b) Immunoperoxidase staining of early rat cytomegalovirus (RCMV) antigens in neointitha with RCMV specific monoclonal antibodies (group A, immunosuppression and RCMV infection). c) In situ DNA hybridisation of RCMV nucleic acids in infected carotid neointima of rat from group A. d) No viral antigens staining positive with the RCMV specific antibodies in carotid neointima, recovered with endothelium, in rat from group $A$. 


\section{Morphometric analysis}

Cross sectional areas of the intima and media of the carotid arteries were measured by using a computer assisted morphometry system (Quantimet, 570; Leica, Cambridge, United Kingdom ) on Lawson stained cross sections. The cross sectional area of the media was defined as the area surrounded by the external and internal elastic lamina. The neointimal cross sectional area was defined by the area surrounded by the internal elastic area and the arterial lumen.

\section{Statistics}

Comparisons of the intimal and medial cross sectional areas between groups were made by a one way ANOVA. Differences between the individual means were further tested by Fishers protected least-squares difference. For comparisons between the intima covered by endothelium and the intima deprived of endothelial cells as well as between left and right media, students $t$ test was used. Significance was assumed at $\mathrm{P}<0.05$.

\section{Results}

\section{Animal conditions}

No apparent clinical signs of illness were observed in any of the animals during the experiments. Starting body weights ranged from $340 \mathrm{~g}$ to $390 \mathrm{~g}$; at the end of the experiments the animal weights ranged from 370 to $440 \mathrm{~g}$. Alhough the infected rats that had been immunocompromised (group $A$ ) tended to gain less body weight compared with the animals from the other groups, these differences were not significant (data not shown).

\section{Virus detection}

Intravenous administration of RCMV led to a generalised infection in the rats as shown by the presence of viral antigens and genome in the salivary glands. The amount of viral DNA or antigens containing cells in these organs, was much higher in immunocompromised animals, which is in agreement with previous observations (Stals 1990). In spleen, liver, lung and kidney, no viral nucleic acids nor antigens were found, which is also a usual finding 2 weeks after infection (Bruggeman et al. 1982). In the RCMV infected animals that had been immunosuppressed (group A), a large number of cells in the intima of the common carotid arteries was positive for RCMV antigens and genome, as shown with immunohistochemical and in situ hybridization procedures (Figure $4.1 \mathrm{a}, \mathrm{b}, \mathrm{c}$ ). Enlarged cells showing typical CMV inclusions and normal shaped SMCs, proved to contain viral antigens and DNA. These cells were predominantly found in the neointimal areas bordering the arterial lumen. Infected cells were present in the outermost intimal parts whereasthey were sporadically found in the underlying media. RCMV positive cells were only present in the neointimal 

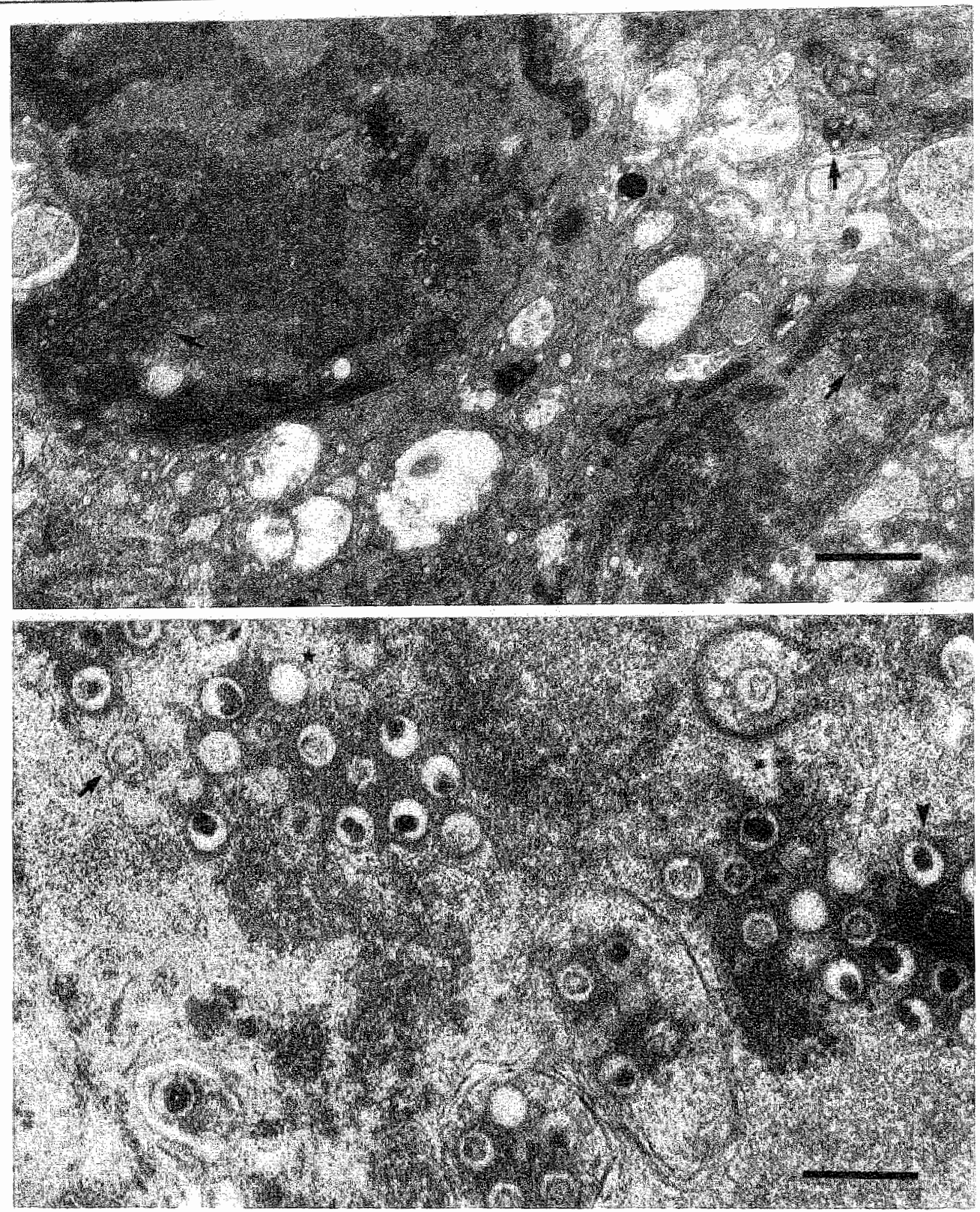

Figure 4.2 Electron micrographes of rat cytomegalovirus (RCMV) infected carotid neointimal smooth muscle cells (group A). a) Large amounts of viral nucleocapsids (arrows) present in nucleus and cytoplasm of smooth muscle cells. Bar represents $1.4 \mathrm{~m}$. b) Intra-nuclear RCMV nucleocapsids; capsids with a hexogenal core (arrow), capsids with ellectron dense material (arrow head) and empty capsids (asterix). Bar represents $250 \mathrm{~nm}$. 
parts that were not covered by endothelial cells. In sections of the proximal parts of the common carotid artery retaining no Evans blue, where an endothelial cell layer overlaid the neointima, no viral antigens nor DNA were ever found (Figure 4. $\mathrm{d}$ ). Electron microscopy confimed the presence of RCMV in the carotid intimas of RCMV infected rats of group A. Massive amounts of viral nucleocapsids in diflerent stages of maturation were observed in nuclei and cytoplasm of SMCs (Figure 4.2) and in some inflammatory cells. In the arteries of animals from group B, C and D, no signs of viral infection were found, either with immunohistochenical and in situ hybridisation techniques, or with electron microscopy.

\section{Histopathology}

Four weeks after balloon injury, a multi-layered neointima had been formed in the left carotid arteries. In the roentgen radiated and RCMV infected rats of group A, neointimal cells showed clear evidence of infection and inflammation. Cells were often swollen and contained cytoplasmic and nuclear inclusions, giving them an owl-eyed appearance characteristic of active CMV infection. Mononuclear and polymorphonuclear inflammatory cells, as well as pyknotic cells were seen, predominantly in the innermost parts of the intima (Figure $4.3 \mathrm{a}, \mathrm{b}$ ). No features of infection or inflammation were found in the neointina covered by endothelium nor in any of the arteries derived from rats of group B, C or D (Figure $4.3 \mathrm{c}$ ).

Cells of the media and intima stained positive with HHF 35 , indicating their SMC origin. Most of the infected cells in the neointima of rats from group A stained also positive with the HHF35 antibody (Figure $4.4 \mathrm{a}, \mathrm{b}$ ).

Cells staining with the macrophage/monocyte marker ED-1 were present as well, predominantly in the innermost intimal layer (Figure $4.4 \mathrm{c}$ ). However, they were seen in smaller amounts and did not stain with the anti- RCMV monoclonal antibodies. In heavily infected arteries, large amounts of ED-1 stained cells were present in the adventitia, whereas the media and the outermost intimal parts, only sporadically contained cells staining with ED-1.

Cells staining positive with the T-cell marker W3/13 were also found in the carotid intima of animals from group $\mathrm{A}$. However, only few had the appearance of true lymphocytes. It is known that W3/13 can stain neutrophil granulocytes (Brown et al. 1981 ) and we found that W3/13 predominantly stained polymorphonuclear cells throughout the infected intima, but especially near the lumen. W3/13 or ED-1 positive cells were rarely seen in non-infected arteries.

\section{Morphometric analysis}

The medial cross sectional area of the non-injured right carotid artery was not significantly different for the four experimental groups (Table 4.1). Although the medial cross sectional area of the injured left carotid artery tended to be increased compared to the medial cross sectional area of the right carotid artery, this apparent difference was not statistically significant. No effects of radiation or virus infection were found on media cross sectional area of the left carotid artery.

The neointimal cross sectional area of the carotid artery segments covered with endothelium, was significantly smaller than the neointimal cross sectional area of the 
segments that were not covered by endothelial cells. Neither roentgen radiation (group B), not virus infection (group C) nor the combination of both (group A) changed the neointima crosis sectonal area as compared to the controls (group D).
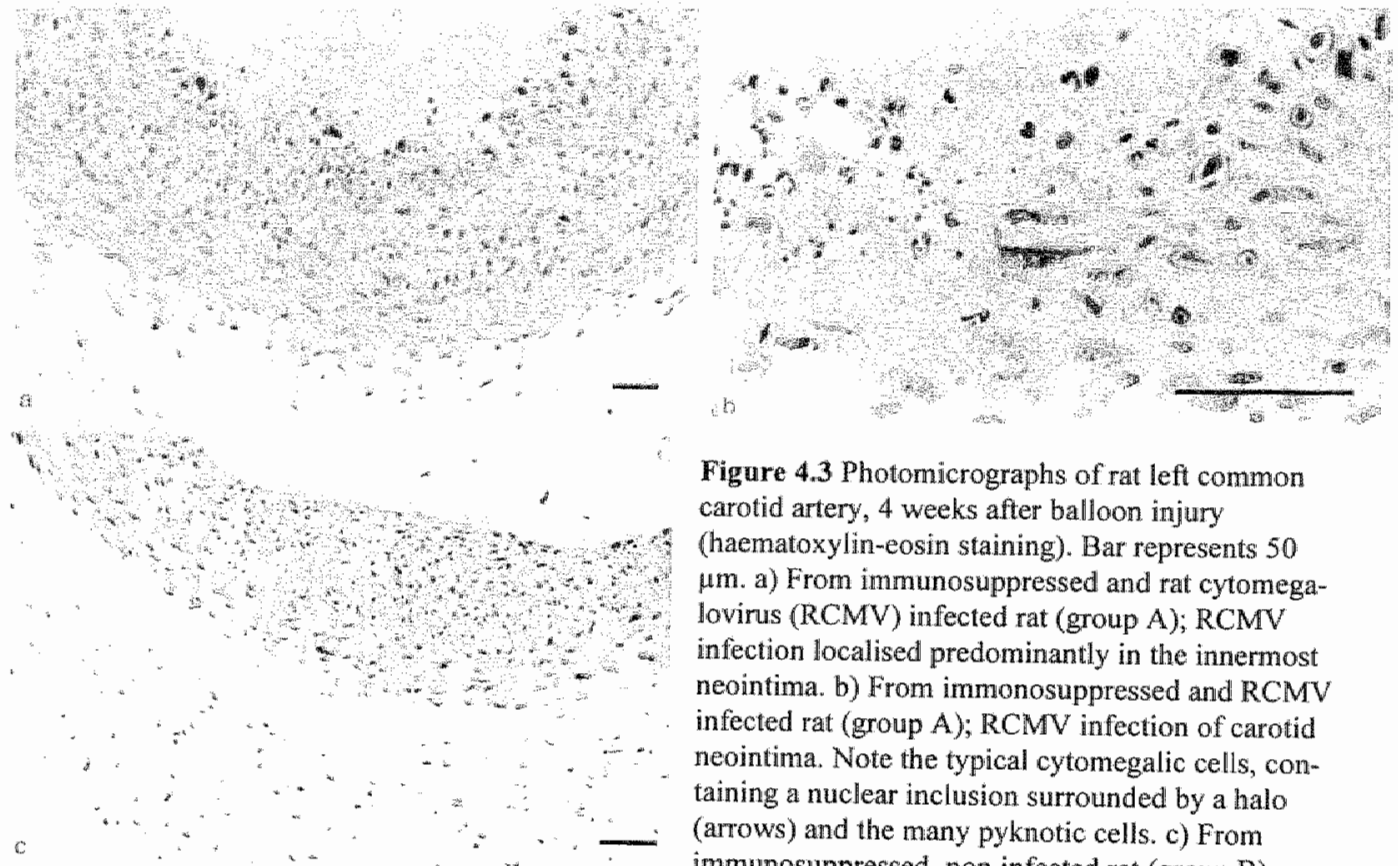

Figure 4.3 Photomicrographs of rat left common carotid artery, 4 weeks after ballow injury (haematoxylin-eosin staining). Bar represents 50 $\mu \mathrm{m}$. a) From immunosuppressed and rat cytomegalovirus (RCMV) infected rat (group A); RCMV infection localised predominantly in the innermost neointima. b) From immonosuppressed and RCMV infected rat (group A); RCMV infection of carotid neointima. Note the typical cytomegalic cells, containing a nuclear inclusion surrounded by a halo (arrows) and the many pyknotic cells. c) From immunosuppressed, non infected rat (group B).

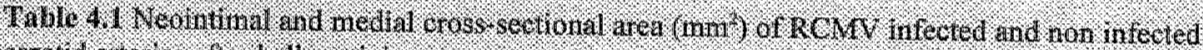

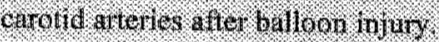

$\begin{array}{llll}\text { group A } & \text { group B } & \text { group C } & \text { group D } \\ (\mathrm{n}=7) & (\mathrm{n}=7) & (\mathrm{n}=8) & (\mathrm{n}=7)\end{array}$

$\begin{array}{lllll}\text { Lef carotid artery } & & & & \\ \text { neointima without EC } & 0.30 \pm 0.16 & 0.26 \pm 0.11 & 0.38 \pm 0.18 & 0.37 \pm 0.22 \\ \text { neointimat with EC } & 0.13 \pm 0.08 & 0.16 \pm 0.09 & 0.19 \pm 0.13 & 0.21 \pm 0.17 \\ \text { medial } & 0.17 \pm 0.02 & 0.17 \pm 0.04 & 0.17 \pm 0.03 & 0.17 \pm 0.02\end{array}$

Right carotid artery

media

$0.13 \pm 0.03$

$0.14 \pm 0.02$

$0.14 \pm 0.05$

$0.13 \pm 0.02$

Values are mean $\pm \mathrm{SD}$. Group $\mathrm{A}$. RCMV infection and $\mathrm{X}$-irradiation; group $\mathrm{B}$, only $\mathrm{X}$-irradiation; group C, only RCMV infection; group D, neither RCMV infection nor X-irradiation (EC; endothelial cells). 


\section{Discussion}

Although CMV nucleic acids have been shown in arterial SMCs of atherosclerotic patients (Petri et al. 1987, Yamashiroya et al. 1988, Hendrix et al. 1989, 1991), a productive infection of arterial SMCs in vivo has never been described before. We investigated the susceptibility of medial and neointimal SMCs in immunocompetent rats as well as in rats that had been immunocompromised by total body roentge radiation. Acute RCMV infection was realized in the latter ones and was almost exclusively localized in the innermost neointima of the injured carotid artery. Acute, so called productive, infection was proved by the presence of typical nuclear CMV inclusions and the presence of early viral antigens in the cytoplasm and nucleus of infected cells. Moreover, at the electron microscopic level the virus was visualized at different stages of maturation and replication. To complete the demonstration of RCMV presence, viral nucleic acids were shown as well. The majority of infected neointimal cells were SMCs as can be concluded from the electron microscopic images and the positivity of these cells for smooth muscle actin, whereas ED-1 and W3/13 positive cells did not contain RCMV early antigens and endothelial cells were absent in the infected areas.

In our model, immunosuppression proved to be a prerequisite for arterial RCMV infection, which is in agreement with other rat studies in which disseminated RCMV infection has only been found in animals with disturbed immunity (Stals et al. 1990). In rats with an intact immune system, RCMV DNA and antigens have beenfound only in the salivary glands that are known to be preferential sites for CMV; in other organs RCMV has been detected at very low levels and in the acute phase only (Bruning et al. 1988). The enhancing effect of immunosuppression on viral replication is a characteristic feature of CMV and other herpesviruses and it is commonly known that in humans CMV may cause serious problems in neonates and patients with disturbed immunity, whereas in most healthy adults the infection remains asymptomatic (Ho, 1991).

We found neointimal cells of the injured arteries to be highly susceptible to RCMV infection, whereas the virus only sporadically infected a medial SMC in these arteries and was never found in control arteries. The absence of RCMV infection in noninjured arteries is compatible with previous findings from our laboratory, which showed that during disseminated RCMV infection the virus was hardly ever found in the large arteries (author's unpublished data).

The presence of endothelium seems to be a barrier for acute RCMV infection of neointimal SMCs, since neointimal infection was only seen in the intimal parts that were not covered by endothelial cells. In the area of the common carotid artery near the aortic arch, where the neointima was overlaid by an endothelial cell layer, no virus was detected. It is very likely that endothelial cells had been present during the entire post infection period, since regrowth of endothelial cells from the aortic arch into the most proximal part of the denuded common carotid artery, has been described within 2 weeks after balloon catheterisation (Clowes et al 1983a). In vitro, endothelial cells have been frequently described to be slightly permissive to CMV infection 

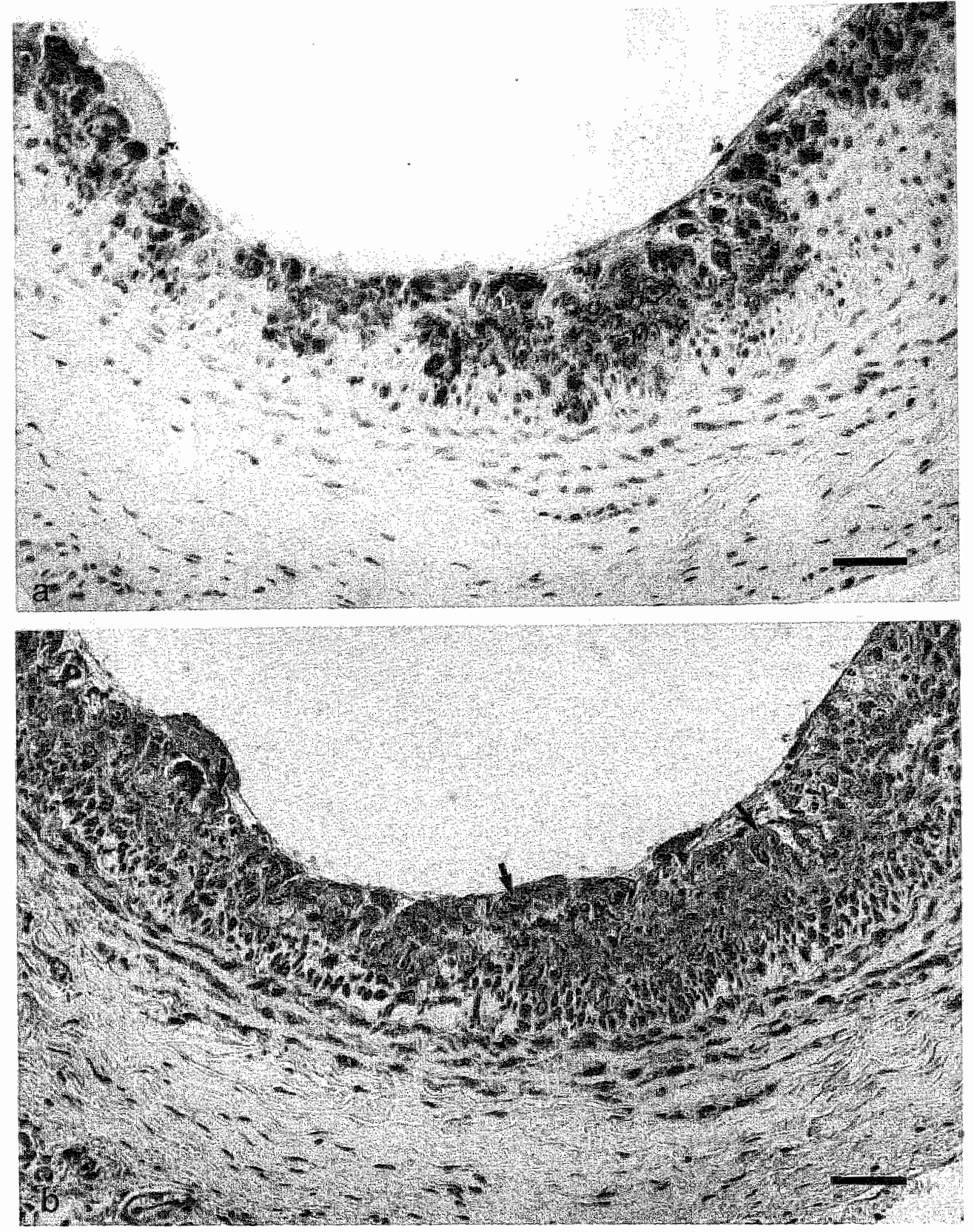

Figure 4.4 Photomicrographs of rat cytomegalovirus (RCMV) infected carotid artery (group A). Bar represents $50 \mu \mathrm{m}$. a) Immunoperoxidase staining of RCMV antigens. b) Same neointima as a. Immunoperoxidase staining of smooth muscle actin with HHT35. Note the specific 'owl eye' appearance of CMV infected cells, positive staining with HHF 35 (arrows) o) Immunoperoxidase staining with ED1. 


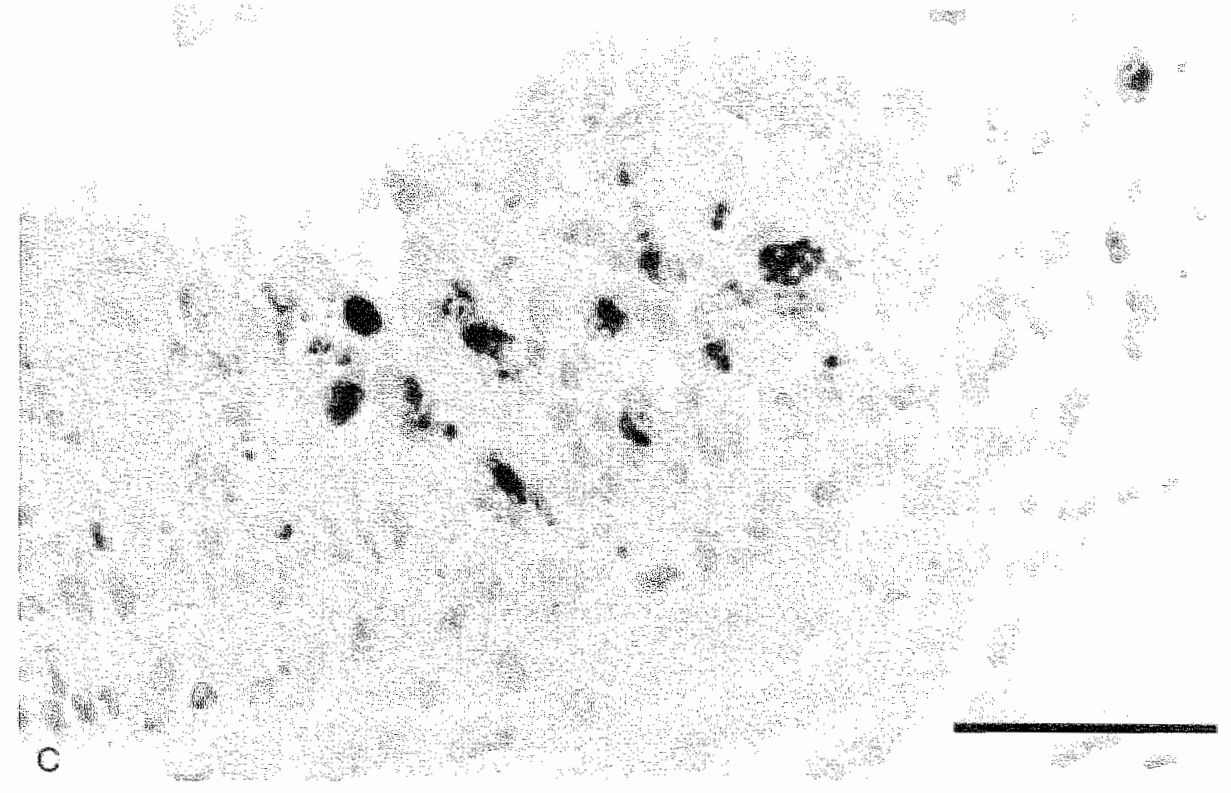

(Bruggeman et al. 1988, Smiley et al. 1988), which supports the hypothesis that endothelium forms a possible mechanical barrier to CMV infection of underlying SMCs in vivo.

This possibility however, does not explain why only neointimal and not medial SMCs were infected. Earlier studies showed that arterial SMCs in vitro are highly permissive to CMV infection (Tumilowicz et al. 1985, 1990) and susceptibility of SMC to herpesvirus infection may be determined by the SMC phenotype (Tumilowicz et al. 1990) or may be developmentally regulated (Kaner et al. 1993). Although there are no in vitro data of the susceptibility of neointimal SMCs to virus infection, intimal and medial SMCs do have distinct properties both in vitro and in vivo (Dartch et al. 1990, Daemen et al. 1991, Majesky et al. 1992) and the susceptibility to CMV infection may be one of these properties.

It may also be possible that the susceptibility of neaintimal cells to RCMV infection is linked to the position of these cells in the cell cycle, since endothelial cells reduce SMC proliferation in culture (Dzau and Gibbons, 1991, Scott-Burden and Vanhoutte, 1993) and neointimal SMC proliferation has been described to cease as soon as endothelium recovered the neointima (Clowes et al. 1983a, b). This might explain the absence of RCMV infection in the neointima when endothelium is present. Moreover, the amount of DNA synthesis in the third and fourth week after balloon injury is higher in the neointimal SMCs than in the underlying media (Clowes et al. 1983) and this may explain the higher susceptibility of the neointimal SMCs to virus infection, compared with medial SMCs.

Intimal SMC migration and proliferation are commonly described features of early atherosclerotic changes and are described phenomena after arterial catheterizations in the clinic, although recent data may question this observation (O'Brien et al. 1993). 
Therefore, the high susceptibility to CMV infection of injured arterial areas, is intriguing in the context of a possible viral contribution to atherogenesis.

In this context too, we studied the presence of inflammatory cells in RCMV infected arteries. After RCMV infection, mononuclear inflammatory cells and to a lesser extent polymorphonuclear cells and T lymphocytes, infiltrated into the infected intimal areas. This is interesting since macrophages, in particular, are found in large amounts in atherosclerotic lesions (Watanabe et al. 1985, Aqel et al. 1985, Jonasson et al. 1986, Gown et al. 1986). These cells synthesize and release a wide range of biologically potent molecules, which are all potential contributors to a local atherogenic process and may influence $\mathrm{SMC}$ proliferation. Mitogenic factors may also be released from infected SMCs.

Our observation that the neointimal cross sectional area was not affected by virus infection may suggest that SMC DNA synthesis was not increased in the infected intima. This is in contrast with our recent findings that RCMV infection enhances SMC proliferation and neointimal thickness in rat aortic allografts (Bruning et al. 1994, Lemström et al. 1993). However, no viral antigens or nucleic acids were found in the allograft neointima, nor were other signs of active RCMV infection. RCMV infected cells could only sporadically be detected in the adventitia (Lemström et al. 1993). On the contrary, in the present study a stimulatory effect of RCMV on neointimal thickness may be obscured by an increased degradation of SMCs in the course of intimal RCMV infection. To analyze SMC proliferation, preliminary studies were performed with bromodeoxyuridine labelling, a thymidine analogue which is incorporated into newly synthesized DNA. However, these were hard to interpret, since the compound was incorporated into the SMCs as well as into viral DNA and the cellular infiltrate (data not shown). Comparable results were obtained with an anti Ki-67 antibody (Immunotech, the Netherlands).

In conclusion, for the first time, acute (meaning active) CMV infection of arterial SMCs in vivo is described. In immunocompromised rats, RCMV infection was established in the intima of injured arteries when endothelial cells were absent. The observation that disturbed immunity is a necessity for active RCMV infection of arterial SMCs, supports the thought that if the arterial SMC is indeed a potential site for latent CMV infection, the virus may reactivate, eg, during immunosuppression or local injury, initiating an acute infection as described here. The model described in the present study, should provide a basis for further study on the short and long term effects of CMV infection on the neointima and the proliferation of SMCs.

\section{References}

Aquel MN, Ball RY, Waldman H, Mitchinson MJ. Identification of macrophages and smooth muscle cells in human atherosclerosis using monoclonal antibodies. J Pathol. 1985;146:197-204.

Brown RA, Barclay AN, Sunderland CA, Wiliams F. Identification of a glycophorin-like molecule at the surface of rat thymocytes. Nature. 1981; 289:456-460.

Bruggeman CA, Debie WHM, Grauls GELM, Majoor G, van Boven CPA. Infection of laboratory rats 
by a new CMV-like wirus. Arch Virol.1983;76:189-199.

Bruggeman CA, Debie WHM, Muller AD, Schutte B, wan Dam Mieras MCE. Cytomegalovirus alters the won Willebrand factor content in human endothellal cells. Thromb Haemost. 1988;59:264-268.

Bruggeman CA, Meijer H, Dormans PHJ, Debie WHM, Grauls GELM, van Boven CPA Isolation of a cytomegalovirus-like agent from wild rats. Arch Virol. 1982;73:231-241.

Bruning $\mathrm{JH}_{4}$ Bruggeman $\mathrm{CA}$, Bosman $\mathrm{F}$. Natural history of rat cytomegalowirus infection: an immunohistochemical study. Cytomegalovirusinfections in renal transplantation. Study in a rat model. (Thesis). 1988;69-82.

Bruning JH, Debie WHM, Dormans PHJ, Meijer H, Bruggeman CA. The development and characterisation of monoclonal antibodies against rat cytomegalovirus induced antigens. Arch Virol. 1987;94:55-70.

Bruning JH, Persoons MCJ, Lemstrom KB, Stals FS, De Clereq Ex, Bruggeman CA. Enhancement of transplantation associated atherosclerosis by $\mathrm{CMV}$, which can be prevented by antiviral therapy in the form of HPMPC. Transplant Int. 1994;7[Supl.1]:S365-S370.

Clowes AW, Reidy MA, Clowes MM. Kinetics of cellular proliferation after arterial injury. I. Smooth muscle cell growth in the absence of endothelium. Lab Invest 1983;49:327-333.

Clowes AW, Reidy MA, Clowes MM. Mechanisms of stenosis after arterial injury. Lab Invest. $1983 ; 49: 208-215$.

Daemen MJAP, Lombardi DM, Bosman FT, Schwarz SM. Angiotensin II induces smooth muscle cell proliferation in the normal and injured arterial wall. Circ Res. 1991;68:450-456.

Dartsch PC, Voisard R, Bauriedel G, Höffling B Betz E. Growth characteristics and cytoskeletal organization of cultured Smooth muscle cells from human primary stenosing and restenosing lesions. Arteriosclerosis. 1990;10:62-75.

Dijkstra CD, Döpp EA, Joling P, Kraal G. The heterogeneity of monomuclear phagocytes in lymphoid organs: distinct macrophage subpopulations in the rat recognized by monoclonal antibodies ED1, ED2 and ED3. Immunology. 1985; 54:589-599.

Dzau VJ, Gibbons GH. Endothelium and growth factors in vascular remodelling of hypertension. Hypotension. 1991;18:115-121.

Fabricant CG, Fabricant J, Litrenta MM, Minick CR. Virus-induced atherosclerosis. I Exp Med. 1978; $148: 335-340$.

Fabricant $C G$, Fabricant J, Minick $C R$, Litrenta MM. Herpesvirus-induced atheroselerosis in chickens. Fed Proc. 1983;42:2476-2479.

Gown AM, Tsukada T, Ross R. Human atherosclerosis. II. Immunocytochemical analasis of the cellular composition of human atherosclerotic lesions. Am J Pathol. 1986;125:191-207.

Grattan MT, Moreno-Cabral CE, Starnes VA, Oyer PE, Stinson EB, Shumway N.E. Cytomegalovirus infection is associated with cardiac allograft rejection and atherosclerosis. JAMA. $1989 ; 261: 3561-3566$.

Hendrix MGR, Daemen MJAP, Bruggeman CA. Cytomegalovirus nucleic acid distribution within the human vascular tree. AM J Pathol. 1991;138:563-567.

Hendrix MGR, Dormans PHJ, Kitselaar P, Bosman F, Bruggeman CA. The presence of CMV nucleic acids in arterial walls of atherosclerotic and non-atherosclerotic patients. Am J

Pathol. 1989;134:1151-1157.

Ho M. Cytomegalovirus. Biology and infection. Plenum. New York. 1991. 
Jonasson L, Holm $\mathrm{J}$, Skalli $\mathrm{O}$, Bondjers $\mathrm{G}$, Hansson GK. Regional accumulations T-cells, macrophages and smooth muscle cells in human atherosclerotic plaque. Arteriosclerosis. 1986;6:131-138.

Kaner RU, Medina J, Nicholson AC, UrseaR, Schwartz SM, Haijar DP. Developmentally regulated herpesvirus plaque formation in arterial smooth cells. Circ Res. 1993;73:10-14.

Lemström KB, Bruning JH, Bruggeman CA, Lautenschlager IT, Häyry PJ. Cytomegalovirus infection enhances smooth muscle cell proliferation and intimal thickening of rat aortic allografts. $J \mathrm{Clin}$ Invest. 1993:92:549-558.

Majesky MW, Giachelli CM, Reidy MA, Schwartz SM. Rat carotid neointimal smooth muscle cells reexpress a developmentally regulated mRNA phenotype during repair of arterial injury. Circ Res. $1992 ; 71: 759-768.31$.

McDonald K, Rector TS, Braunlin TA, Kubo SH, Olvari MT. Association of coronary artery disease in cardiac transplant recipients with cytomegalovirus infection. Am J Pathol. 1989;64:359-362.

Meijer H, Dornans PHJ, Geelen JLMC, van Bowen CPA. Rat cytomegalovinus: Studies on the wiral genome and the proteins of virions and nucleocapsids. J Gen Virol. 1984;65:681-695.

Melnick JL, Dreesman GR, McCollum CH, Petrie BL, Burek J, DeBakey M.E.Cytomegalovirus antigen within human arterial smooth muscle cells. Lancet.1983,2; 644-647.

Minick CR, Fabricant CJ, Fabricant $₫$, Litrenta MM. Atheroarteriosclerosis induced by infection with a herpesvirus. Am J Pathol; 1979,96:673-706.

O'Brien ER, Alpers CE, Stewart DK, Ferguson M, Tran N, Gordon D, Benditt EP, Hinohara T, Simpson JB, Schwartz SM. Proliferation in primary and restenotic coronary atherectomy tissue. Implications for antiproliferative therapy. Circ Res. $1993 ; 73: 223-231$.

Petrie BL, Melnick JL, Adam E, Burek J, McCollum CH, DeBakey ME. Nucleic acid sequences of cytomegalovirus in cells cultured from human arterial tissue. J Infect Dis. 1987; 155:158-159.

Ross R, Glomset J. The pathogenesis of atherosclerosis. N Engl J Med. 1976;296:369-377. Scott-Burden T, Vanhoutte PM. The endothelium as a regulator of vascular smooth muscle proliferation. Circulation Supplement V. 1993;87:51-55.

Smiley ML, Mar EC, Huang ES. Cytomegalovirus infection and viral induced transformation of human endothellial cells. J Med Virol. 1988;25:213-226.

Stals 1 S, Bosman F, wan Boven CPA, Bruggeman CA. An animal model for therapeutic intervention studies of CMV infection in the immunocomprimised host. Arch Virol. 1990; 114:91-107.

Tsukada T, Mc Nutt M,A, Ross R Gown AM. HHF35, a muscle actin-specific monoclonal antibody. II. Reactivity in normal, reactive, and neoplastic human tissues. Am J Pathol. 1987;127:389-402.

Tumilowicz JJ. Characteristics of human arterial smooth muscle cell cultures infected with cytomegalovirus. In Vitro Cell Dev Biol. 1990;26:1144-1150.

Tumilowicz JJ, Gawlik ME, Powell BB, Trentin JJ. Replication of cytomegalovinus in human arterial smooth muscle cells. J Virol. 1985;56:839-845.

Watanabe T, HirataM, Yoshikawa Y, Nagafuchi, Y, Toyoshima H, Watanaba T. Role of macrophages in atherosclerosis. Sequential observations of cholesterol induced rabbit aortic lesion by the immunoperoxidase technique using monoclonal antimacrophage antibody. Lab Invest. 1985;53:80-90.

Wreghit TG, Hakim M, Gray JJ, Kucia S, Cory-Pearce R, Wallwork J, English TAH. A detailed study of cytomegalovirus infections in the first $\mathbb{1 6 0}$ heart/lung transplant recipients at Papworth Hospital, 
Yamashiroya HM, Ghosh L, Yang R, Robertson AL. Herpesviridae in the coronary arteries and aorta of young trauma victims. Am I Pathol. 1988;130:71-79. 

Chapter 5

Neointimal smooth muscle cell phenotype is important in its susceptibility to cytomegalovirus infection: a study in rat.

MCJ Persoons, MJAP Daemen, EM van Kleef, GELM Grauls, E Wijers, CA Bruggeman. Cardiovascular Research 1997;36:282-288. 


\section{Abstract}

Objectives. Recently, we have found that rat CMV (RCMV) infected smooth muscle cells (SMCs) in rat carotid arteries, when administered 14 days after balloon injury. In the present study we investigated $(1)$ the long term effects of CMV infection on neointimal cross sectional area and (2) whether the phenotype of the intimal SMCs. inluences their susceptibility to active CMV infection.

Methods. In the first part of the study, rats received RCMV intravenously, two weeks after balloon catheterisation of the left carotid artery and were killed twenty weeks after catheterisation. Continuous BrdU infusion was performed by subcutaneously implanted osmotic pumps during the last 2 weeks of life. In the second part, RCMV was administered 8 weeks after catheterisation and rats were killed two weeks $l a t e r$. Immunohistochemistry was used to detect viral antigens and to determine BrdU incorporation, as well as the contents of $\alpha$-actin, desmin and vimentin in the carotid arteries. Intimal and mediall cross sectional areas were determined using computerized morphometry.

Results and conclusions. RCMV infection did not induce any differences in intimal or medial cross sectional areas of the injured carotid artery, nor in the extent of SMC proliferation as shown by $\mathrm{BrdU}$ incorporation, 20 weeks after balloon catheterisation. Eight weeks after balloon catheterisation, RCMV no longer infected neointimal SMCs. This non-responsiveness to RCMV was associated with 'redifferentiation' of the 8 weeks old neointima, compared with 2 weeks after catheterization, as shown by the contents of $\alpha$-actin, desmin and vimentin. Our data suggest that intimal SMC phenotype determines its susceptibility to active RCMV infection in vivo. Since dedifferentiation of neointimal SMCs is associated with enhanced proliferation of these cells it is stated that dedifferentiation and/or proliferation is prerequisite for infection. 


\section{Introduction}

Cytomegalovius (CMV) is one of the herpesviruses and a well known cause of severe disease in immunocompromised patients, especially transplant recipients and patients with the acquired immunodeficiency syndrome (AIDS). Although the virus is also a common cause of infection in immunocompetent hosts, these infections in general remain asymptomatic.

$\mathrm{CMV}$ has been detected repeatedly in arterial tissue of humans suffering from severe atherosclerosis (Petrie et al. 1987, Yamashiroya et al. 1988, Hendrix et al. 1989), however, the exact role of the virus in atherogenesis is still questioned. A causal relation has been indicated by the findings of accelerated transplant athero/arterioclerosis in human heart transplant recipients with CMV infection (Grattan et al. 1989, McDonald et al. 1989) and in rat aortic and cardiac allografts after administration of a rat specific CMV (RCMV, Bruning et al. 1994, Lemström et al. 1993,1995 ). Since arterial smooth muscle cells (SMCs) play a key role in the development of an atheromatous plaque and of the neointima after vascular injury (Ross, 1993, Desmouilière, 1992, Schwartz et al.1995), we have used a balloon angioplasty model in the rat to study the susceptibility of arterial SMCs to CMV infection and the effect of the virus on neointima development. In this model, we have previously shown that administration of RCMV 14 days after balloon catheterisation of the carotid artery, induces an abundant active infection of SMCs in the neointima (Persoons et al. 1994) albeit without influencing the neointimal cross sectional area. This observation is in contrast with our findings in a rat aorta transplantation model, in which RCMV administration does increase SMC proliferation and neointimal thickness (Bruning et al. 1994, Lemström et al. 1993). Moreover, in humans it has been described that CMV was associated with restenosis after coronary angioplasty (Speir et al. 1994, Zhou et al. 1996). The apparent discrepancy between our earlier findings in the rat balloon injury model and these latter data may be explained by the possibility that we had only studied the neointima two weeks after RCMV administration, which may have been to short to detect any virus-induced effect on intimal thickness. Therefore, in the present study we examined long term effects of RCMV infection on neointimal area.

Also in our previous experiments, RCMV did infect intimal but not medial SMCs. Thus, we hypothesized that it is well possible that distinctive phenotypic features of the intimal SMC may influence its susceptibility to RCMV infection. Since the phenotype of SMCs in the neointima that develops after balloon injury has been shown to change over time (Kocher et al. 1991, Orlandi et al. 1994), we investigated the susceptibility of the neointima to RCMV infection, eight weeks after balloon catheterisation, at which time SMC phenotype had changed from a synthetic (dedifferentiated) to a more contractile (redifferentiated) phenotype (Kocher et al. 1991, Orlandi et al. 1994). Our study thus describes the interaction of CMV with neointimal SMCs in vivo in a bidirectional way. On the one hand, the long term effect of CMV on neointimal formation was studied and on the other hand a possible influence of the phenotype of 
the neointimal SMC on its susceptibility to CMV infection was investigated.

\section{Methods}

\section{Animals and virus}

15- Week- old Wistar-Kyoto rats were used that had been bred under specific pathogen free conditions at the Department of Experimental. Animal Service at our University. The experiments were performed, according to local institutional guidelines. Animals were given standard rat chow and tap water at libitum.

RCMV consisted of a pool of homogenized saliwary glands of acutely infected laboratory rats (Bruggeman et al. 1982). The rats were intravenously infected with $10^{5}$ plaque-forming units (PFU) of RCMV, after they had been immunosuppressed by at total body roentgen radiation of $5 \mathrm{~Gy}$. This protocol was used since, analogue to human CMV infection, a decreased immunocompetency is a prerequisite for symptomatic RCMV infection (Stals et al. 1990), including infection of the rat aorta and carotid artery and microvascular vessel wall (Persoons et al. 1994, 1998). Control animals were mock infected with a salivary gland homogenate derived from noninfected rats

\section{Experimental design}

In all rats, balloon injury of the left common carotid artery was performed as previously described (Clowes et al. 1983). The right carotid artery was left untraumatized and served as an internal control.

\section{-Experiment 1; Effect of RCMV infection on neointima thickness}

Rats were randomly divided into two groups ( $A$ and $B, n=9$ or 10 per group). All animals received total body roentgen radiation thirteen days after balloon injury, followed by RCMV (group A) or mock (group B) infection, 1 and 3 days later (Figure 5.1). The rats were killed at 18 weeks after RCMV or mock infection. Four weeks after infection the animals were anesthetized with ether and biopsies were taken from the salivary glands to ascertain active RCMV infection. Two weeks before the animals were killed, an osmotic mini-pump (Alzet model 2002, Alza Corp., Palo Alto, CA, USA) previously filled with $5^{\prime \prime}$-bromo-2'-deoxyuridine ( $\mathrm{BrdU}, 20 \mathrm{mg} / \mathrm{mL} 0.9 \% \mathrm{NaCl}$ $0.5 \mu \mathrm{l} / \mathrm{h}$ ), was inserted subcutaneously between the shoulder blades to measure SMC DNA synthesis.

\section{-Experiment 2; Susceptibility of neointimal SMC to RCMV infection}

Two groups of rats (C and $\mathrm{D}, \mathrm{n}=9$ or 10 per group) were formed at random.

All rats received total body roentgen radiation at 8 weeks after balloon injury and were RCMV (group C) or mock ( group D) infected 1 and 3 days later (Figure 5.1). The rats were killed 2 weeks after RCMV or mock infection. Salivary glands were obtained post mortem to confirm the presence of replicative virus.

All rats (experiments 1 and 2) were killed by aortic bleeding, about one hour after they 
had received $0.5 \%$ Evans blue in $0.9 \% \mathrm{NaCl}$ intravenously to stain non-endothelialized vascular tissue. In situ perfusion was performed with $0.9 \% \mathrm{NaCl}$ containing $100 \mathrm{mg} / \mathrm{l}$ sodium nitroprusside (Merck). Several circular segments were taken from both Evans blue retaining and non-retaining areas of the injured left common carotid artery. Control segments were taken from the non-injured right common carotid arteries. All

\section{Experiment 1}

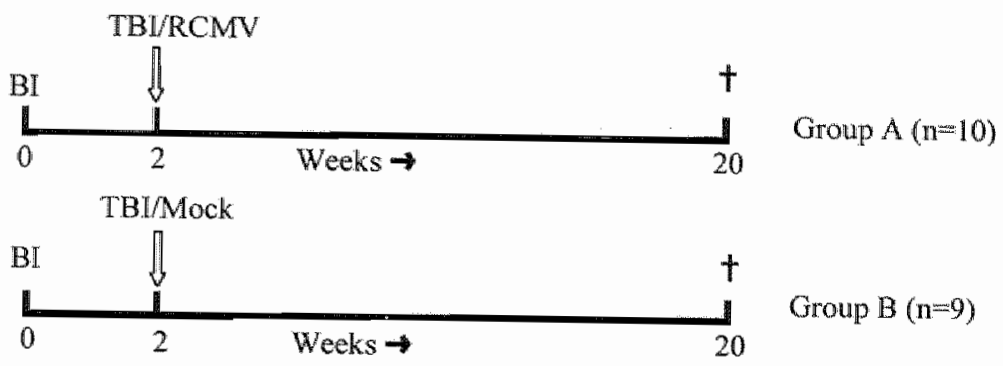

\section{Experiment 2}

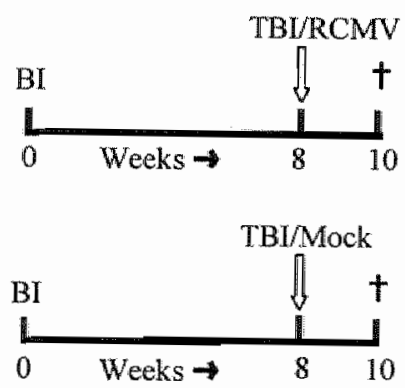

Figure 5.1 Schematic representation of experimental groups.

BI: balloon injury, TBI: total body roentgen imadiation of 5 Gy, RCMV: RCMV infection, $10^{3} \mathrm{PFU}$ iv., Mock: mock infection, salivary gland suspension iw., t: death.

tissues were fixed in $3.7 \%$ formaldehyde in phosphate buffered saline $(\mathrm{pH}=7.4)$, routinely processed and paraffin-embedded. For haematoxylin-eosin, Lawson elastin and immunocytochemical staining procedures $4 \mu \mathrm{m}$ thick cross sections were cut.

\section{Immunohistochemistry}

\section{Viral antigens}

Injured carotid arteries as well as salivary glands were screened for the presence of RCMV antigens. Immunostaining procedures were performed as previously described (Persoons et al. 1994), using mouse monoclonal antibodies against nuclear and 
cytoplasmic RCMV early antigens (Bruning et al. 1987). Subsequent incubations were performed with peroxidase conjugated rabbit antimouse IgG(Dako) and diaminobenzidine substrate.

To rule out nonspecific antigen binding, parallel sections were stained with an antihuman CMV monoclonal antibody, which does not react with RCMV or with control mouse ascites fluid (Sigma Immuno Chemicals). Spleen sections from acutely infected rat served as positive controls.

\section{BrdU incorporation}

Incorporation of the thymidine analogue BrdU was wisualized by staining with an antiBrdU monoclonal antibody as previously described (Persoons et al. 1994). Subsequent incubation steps were performed with biotinylated rabbit anti-mouse IgG (Amersham) and with an avidin/biotin-peroxidase complex (Vectastain-ABC kit, Vector Lab Inc) and diaminobenzidine.

\section{a-Actin, desmin and vimentin}

Staining of the SMC differentiation markers $\alpha$-SMC actin, desmin and vimentin, was performed with monoclonal antibodies.

For $\alpha$-actin and desmin staining, incubation with respectively anti- $\alpha$ SMC IgG (Dako) and anti-desmin II (Organon Technika, Boxtel, The Netherlands) was followed by subsequent incubations with biotin labelled sheep anti-mouse IgG (Amersham), alkaline phosphatase conjugated biotin-streptavidin complex (Amersham) and alkaline phosphatase substrate (kit, Vector Lab. Inc).

For vimentin staining, incubation with the monoclonal anti-vimentin IgG (Boehringer) was followed by incubations with peroxidase conjugated rabbit anti-mouse $\operatorname{IgG}$ and diamin benzidin substrate. To control for possible effects of roentgen radiation and/or infection, staining of $\alpha$-actin, desmin and vimentin was also performed on carotid sections of rats that had not been radiated or infected, at 2, 8 and 20 weeks after balloon catheterisation ( $\mathrm{n}=5$ per group).

\section{Cross sectional areas}

Neointimal and medial cross-sectional areas of carotid arteries were measured using a computer assisted morphometry system (Quantimet 570, Leica) on Lawson stained cross sections as described before (Persoons et al. 1994).

\section{Statistics}

For comparisons of carotid intimal and medial cross sectional areas from rats of experimental and control groups (group A vs B and group C vs D) within both experiments, a one way ANOVA was used. One way ANOVA was used as well for comparing left and right medial cross sectional areas within groups. A two way ANOVA was used for comparing corresponding cross sectional areas from both experiments (group $A / B$ vs group $C / D$ ) with each other and to compare weights at different experimental moments within both experiments. All data are expressed as mean $\pm \mathrm{SD}$. 


\section{Results}

\section{Experiment 1}

At the start of the experiments mean body weights for experimental (group $A$ ) and control (group B) groups were $354 \mathrm{~g}$ and $358 \mathrm{~g}$ respectively. Also, at 18 weeks after RCMV infection no weight differences were observed between the two groups. (Table 5.1).

\section{Virat antigens}

Immunohistochemistry, using specific anti-RCMV monoclonal antibodies, showed the presence of early viral antigens in the salivary glands of rats from group A (Figure 5.2), which proved that early actiwe RCMV infection had taken place in these animals. 18 Weeks after infection none of the carotid arteries from group A rats contained viral antigens. This was the case in both the endothelialized and non-endothelialized parts. Salivary glands and carotid arteries from rats of control group B were always negative.

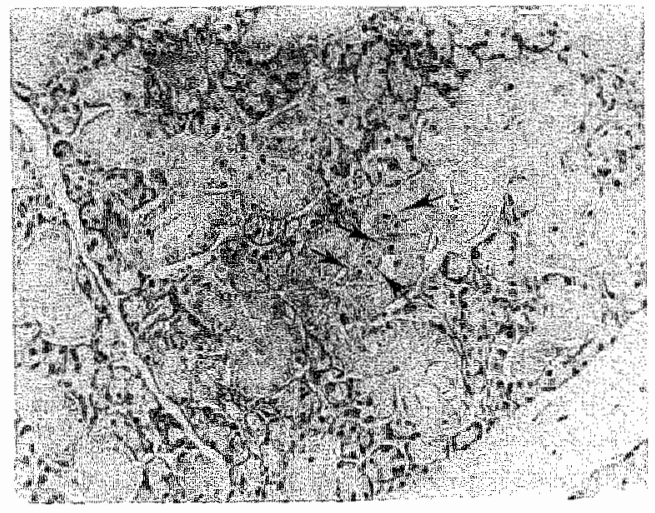

Figare 5.2 Immunohistochemical staining of RCMV antigens in a salivary glands of an RCMV infected rat at two weeks post infection. Arrows show cells containing CMV antigens using RCMV monoclonal antibodies number 8 and 35 .

\section{BrdU labelling}

SMC nuclei in the intima and media of injured carotid arteries from group A rats, only very sporadically stained positive with anti-BrdU. Although labelling fractions have not been quantitated, there were no apparent differences between group $\mathrm{A}$ and $\mathrm{B}$ in the amount of BrdU labelling, which was less than $0.1 \%$ over 14 days.

\section{Cross sectional areas}

Neointimal cross sectional areas of left injured carotid arteries from infected (group A) and non-infected rats (group B) were comparable (Table 5.2) as were medial cross sectional areas. Similarly, there were no significant differences between medial cross sectional areas of non-injured right carotid arteries from animals of group $A$, compared to group $B$.

\section{Experiment 2}

At the start of the experiments, the mean body weights were $323 \mathrm{~g}$ (group C) and $328 \mathrm{~g}$ (group D). Two weeks after infection, however, there were significant differences in weights between the two groups. Rats from group C lost weight during this two weeks $(-18 \mathrm{~g} \pm 8)$, wereas all rats from group $\mathrm{D}$ gained weight in the same period $(17 \mathrm{~g} \pm 8, \mathrm{P}$ $<0.05$, Table 5.1). 


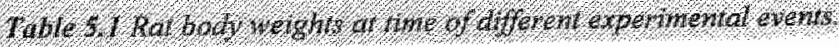

Body weight $(\mathrm{g})$ at time of

\begin{tabular}{|c|c|c|c|c|}
\hline & $\begin{array}{l}\text { Balloon } \\
\text { injwry }\end{array}$ & $\begin{array}{l}\text { RCMW/ } \\
\text { mock }\end{array}$ & Death & $\Delta$ Weight \\
\hline \multicolumn{5}{|l|}{ Experment } \\
\hline group $A$ & $353+23$ & $350 \pm 26$ & $446 \pm 31$ & $107 \pm 18$ \\
\hline group B & $358 \pm 20$ & $361 \pm 19$ & $448 \pm 22$ & $86 \pm 17$ \\
\hline \multicolumn{5}{|l|}{ Experiment 2} \\
\hline group C & $323 \pm 20$ & $376+23$ & $358 \pm 28$ & $-18 \pm 8^{i}$ \\
\hline group D & $328 \pm 16$ & $358 \pm 13$ & $374=14$ & $17 \pm 8$ \\
\hline
\end{tabular}

'P<0.05 as compared with $\Delta$ weight in group $D$

${ }^{2} \Delta$ Weight $=$ weight at death minus weight at RCMV or mock infection. Expressed is the mean $\triangle S D$ of $\Delta$ weights for individual rats.

Values are expressed as mean $\pm \mathrm{SD}$.

\section{Viral antigens}

The salivary glands of group $C$ rats did contain viral antigens as shown by immunohistochemistry, confirming RCMV infection in these animals. In the carotid arteries that were obtained from the rats of group $\mathrm{C}, \mathrm{RCMV}$ antigens could never be detected in the media nor in the intima, which practically excludes active RCMV infection. The absence or presence of endothelial cells had no effect on the RCMV staining. Viral antigens were never present in the mock infected rats from group D.

\section{Cross sectional areas}

RCMV administration in the rats of group $C$ did not affect the carotid neointimal cross sectional area of injured left carotid arteries as compared with group D. Neither were there significant differences between the lumina on comparison of the two groups. Medial cross sectional aneas of balloon injured carotid arteries did not differ between the two groups and were also comparable with the medial cross sectional areas of the non-injured carotid arteries (Table 5.2). Finally, as seen in Table 5.2, intimal and medial cross sectional areas did not differ significantly from corresponding cross sectional areas in experiment 1.

\section{SMC phenotype, SMC $\alpha$-actin, desmin and vimentin}

The phenotypic change was best illustrated with the desmin immunoreactivity. Two weeks after injury, neointimal SMCs were only very sporadically positive for desmin. The amount of desmin positive SMCs gradually increased over time; higher levels were found at 8 weeks whereas 20 -week-old neointimas contained the highest levels of SMCs being positive for desmin (Table 5.3 and Figure 5.3).

It proved to be more difficult to differentiate between the amount of $\alpha$-actin and vimentin containing SMCs at different times after balloon injury, using these 
immunostaining techniques. However, the intensity of $\alpha$-actin staining per SMC in a 2week-old neointima was less than in a neointima at 8 and 20 weeks after balloon injury (Table 5.3). No differences were observed between $\alpha$-actin staining of $8 / 10$-week-old neointimas (experiment 1 ) on the one hand, compared to 20-week-old neointimas (including experiment 2) on the other hand.

The intensity of vimentin staining was the highest in a 2-weeks-old-neointima. Vimentin staining of $8 / 10$ - and 20 -week-old neointimas were comparable (Table 5.3). For all three antibodies there were no differences between the staining results of carotid arteries of RCMV infected and mock-infected rats. Similarly, roentgen radiation did not influence staining intensities of any of these markers of SMC differentiation, as may be concluded from comparable staining results of carotic arteries from experimental and control rats that had not been radiated nor infected (Table 5.3).

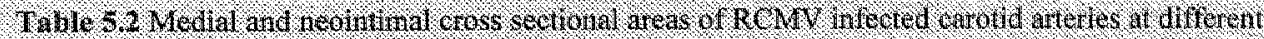
thines wher balfoon catlueterisation.

Cross sectional area $\left(\mathrm{mm}^{2}\right)$

Experiment 1

Experiment 2

group A

group B

group $\mathrm{C}$

group D

$\begin{array}{lllll}\text { Left carotid artery } & & & & \\ \text { neointima } & 0.13 \pm 0.03 & 0.15 \pm 0.04 & 0.16 \pm 0.03 & 0.13 \pm 0.03 \\ \text { media } & 0.13 \pm 0.01 & 0.12 \pm 0.02 & 0.13 \pm 0.02 & 0.13 \pm 0.01 \\ \text { lumen } & 0.13 \pm 0.04 & 0.13 \pm 0.06 & 0.11 \pm 0.06 & 0.13 \pm 0.04\end{array}$

Right carotid artery

media

$0.11 \pm 0.01$

$0.10 \pm 0.01$

$0.13 \pm 0.02$

$0.12 \pm 0.02$

Expressed are the neointimal cross sectional areas without an endothelial layer. No neointina wass present in the non-injured right carotid artery. Values are expressed as mean \pm SD.

\section{Discussion}

The data presented here show that RCMV infection of a rat carotid neointima does not induce an increase of neointimal thickness, even at 18 weeks after infection. Moreover, this study suggests that the susceptibility of neointimal SMCs to CMV may be transient. Whereas an active RCMV infection can be induced in neointimal SMCs at 2 weeks after balloon catheterisation (Zhou et al. 1996), they seem to have become nonsusceptible to RCMV infection at 8 weeks after such injury.

The lack of a RCMV effect on neointimal cross sectional area is in contrast with our finding of RCMV enhanced increase of neointimal thickness and SMC proliferation in 
a rat allograft aortic transplant model (Bruning et al. 1994, Lemström et al. 1993). These stimulatory effects of RCMV were however not noticeable until months after transplantation, which was one of the reasons to search for long term RCMV effects on neointimal thickness in the balloon injury model in the present study. Finding, as presented here, no virus induced differences in neointimal cross sectional area at 20 weeks after balloon catheter induced injury, stresses the different nature of neointimal development in both models. In the transplantation model, the allogenic aorta induces immune responses which are apparently crucial for RCMV to increase neointimal cross sectional area and SMC proliferation, since in syngeneic aorta transplants no such increases were found (Bruning et al. 1994, Lemström et al. 1995). The absence of allogenic immune responses after arterial balloon injury may explain why we do not find RCMV induced differences in neointimal thickness after arterial balloon catheterisation.

In immunocompetent humans, however, an association has been described between the occurrence of arterial restenosis after coronary balloon angioplasty and (previous) infection with CMV (Speir et al. 1994, Zhou et al. 1996). Of course restenosis of atherosclerotic human arteries -in which a prominent proliferation response may be lacking (Leclerc et al. 1993, O'Brien et al. 1993) and remodelling may be more important (Post et al. 1994, Kakuta et al. 1994, Lafont et al. 1995)- differs from the neointima formation in rat arterial balloon injury experiments.

At 20 weeks after balloon injury, no RCMV early antigens were found in the rat carotid neointima, indicating that active RCMV infection does not persist such a long time. In our previous experiments, we showed that soon after arterial injury massive active RCMV infection persists for at least two weeks in the neointima, whereas other organs are negative for RCMV, with the exeption of a low grade infection of the salivary glands (Zhou et al. 1996). In the latter, CMV is known to persist for a long time and the arterial intima likewise may be a preferential site for CMV infection. It would be of great interest to find out if CMV remains latently present in arteries.

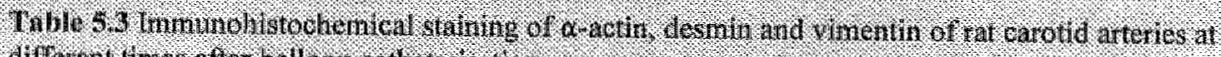
Girferent lines afler hallow cathe terisation

\begin{tabular}{|c|c|c|c|c|c|}
\hline & & $\begin{array}{l}\text { Controls } \\
(\mathrm{n}=5)\end{array}$ & & Experiment 1 & Experiment 2 \\
\hline & 2 weeks & 8 weeks & 20 weeks & $\begin{array}{l}\text { (group } A \text { and } B=20 \\
\text { weeks) }\end{array}$ & $\begin{array}{l}\text { (group } \mathrm{C} \text { and } \mathrm{D}=10 \\
\text { weeks) }\end{array}$ \\
\hline Desmin & - & + & t+ & ++ & + \\
\hline$\alpha-$ Actin & +1 & $t+4$ & $+1+$ & $4-4$ & $+t+1$ \\
\hline Vumentin & $t+t$ & H+ & + & $-4+$ & ++ \\
\hline
\end{tabular}

Staining extent was assessed semi-quantitativelly; no -or very rarely-staining was scored as ; light staining and small staining foci were scored as + ; moderate staining as ++ ; intensive staining as +++ . 

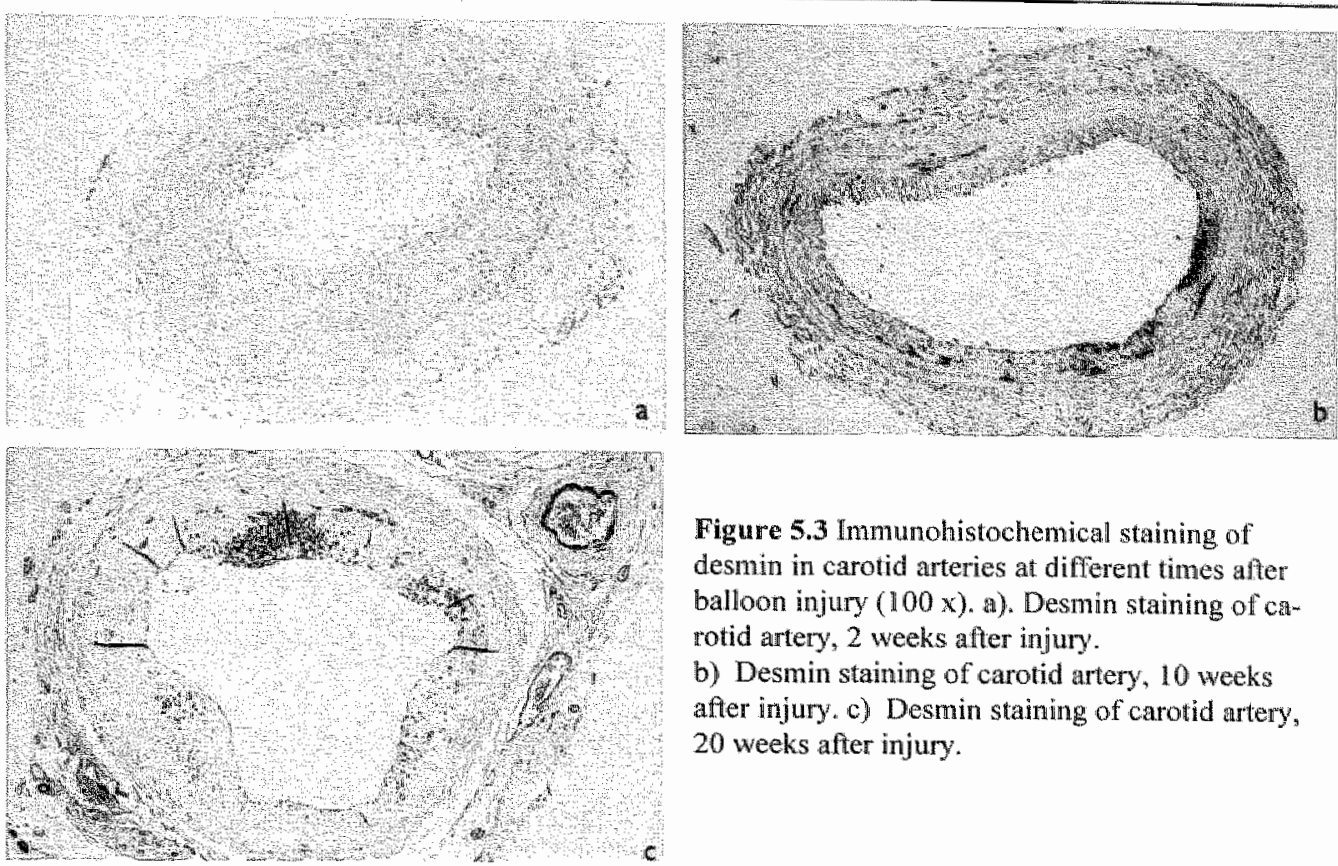

Figure 5.3 Inmunohistochemical staining of desmin in carotid arteries at different times after balloon injury $(100 \mathrm{x})$, a). Desmin staining of carotid artery, 2 weeks after injury.

b) Desmin staining of carotid artery, 10 weeks after injury. c) Desmin staining of carotid artery, 20 weeks after injury.

The observation that an eight-week-old rat carotid neointima can not be infected with high concentrations of infectious RCMV, indicates the transient nature of the susceptibility of the neointimal SMCs to RCMV infection, since administration of the virus two weeks after injury results in an abundant neointimal infection (Persoons et al. 1994). This finding does make it attractive to hypothesize that the phenotype of the intimal SMC may be an important factor in its susceptibility to active CMV infection. Indeed, our immunohistochemical staining results show that in our experiments the phenotype of neointimal carotid SMCs changes over time and indicate that neointimal SMCs change from a dedifferentiated state to redifferentiation as time after injury progresses. Comparable data were published by many other authors, albeit in rats that had not been immunosuppressed (Kocher et al. 1991, Orlandi et al. 1994). Thus, dedifferentiation may be a prerequisite for neointimal SMC susceptibility to active CMV infection. Alternatively, it may be that the proliferation rate of neointimal SMCs regulates their susceptibility to CMV infection. It is known that the fraction of proliferating cells in the rat neointima reaches a maximum at approximately 1 week after balloon injury and gradually diminishes over time to very low levels at the time that rats were infected ( 8 weeks) in our study (Clowes et al.1983). Interestingly, dedifferentiation of SMCs has frequently been associated with proliferation (Schwartz et al. 1986). The in vivo data presented here, do not allow us to determine if (de)differentiation and proliferation (or both) are crucial for RCMV infection of neointimal SMCs.

In conclusion, this study suggests SMC dedifferentiation and/or increased SMC proliferation are prerequisites for CMV infection. This is especially interesting since intimal SMCs with cytoskeletal features of dedifferentiation and increased SMC replication have been found in arterial pathologies that have been associated with 
CMV infection, such as atheromatous plaques, arterial grafts and post-angioplasty arteries (O'Brien et al. 1993, Mosse et al. 1985, Schwartz et al. 1986, Desmouiliere and Gabbiani 1992, Newby and George 1993).

\section{References}

Bruggeman CA, Meijer H, Dormans PUI, Debie WHM, Grawls GELM, van Boven CPA. Isolation of a cytomegalovirus-like agent from wild rats. Archl Virol 1982;73:231-241.

Bruming $\mathbf{H}$, Debie WHM, Dormans PH, Meijer H, Bruggeman CA. The development and characterisation of monoclonal amtibodies against rat cytomegalowirus induced antigens. Arch Vurol $1987: 94: 55-70$.

Bruning JH, Persoons MCJ, Lemstrom KB, Stals FS, De Clereq E, Bruggeman CA. Enhancement of transplantation associated atherosclerosis by $\mathrm{CMV}$, which can be prevented by antiviral therapy in the form of HPMPC. Transplant Int 1994; 7(suppl 1);365-370.

Clowes AW, Reidy MA, Clowes MM. Kinetics of cellular proliferation after arterial injury. I. Smooth muscle cell growth in the absence of endothelium. Lab lnvest 1983:49:327-333.

Desmoulliere $A$, Gabbiani $G$. The cytoskeleton of arterial smooth muscle cells during human and experimental atheromatosis, Kidney Int 1992;41 Suppl 37:S-87 S-89.

Desmouilière A, Gabbiani $G$. The role of arterial smooth muscle cells in the pathogenesis of atherosclerosis. Cerebrovase Dis 1992;2:63-71.

Grattan MT, Moreno-Cabral CE, Starnes VA, Oyer PE, Stinson EB, Shumway N.E. Cytomegalovirus infection is associated with cardiac allograft rejection and atherosclerosis. JAMA 1989;261:3561-3566.

Hendrix MGR, Dormans PHI, Kitselaar P, Bosman F, Bruggeman CA. The presence of CMV nucleic acids in arterial walls of atherosclerotic and non-atherosclerotic patients. Am J Pathol

1989:134:1151-1157

Kakuta T, Currier IW, Haudenschild CC, Ryan TJ, Faxon DP. Differences in compensatory vessel enlargement, not intimal formation, account for restenosis after angioplasty in the hypercholesteremic rabbit model. Circulation 1994;89:2809-2815.

Kocher O, Gabbiani F, Gabbiani G, Reidy M, Cokay MS, Peters H Hittner 1. Phenotypic features of smoolh muscle cells during the evolution of experimental carotid artery intmal thickening. Biochemical and morphologic studies. Lab lnvest 1991;65:459-470.

Latont A: Guzman LA, Whitlow PL, Goormastic M, Cornhill JF, Chisolm GM. Restenosis after experimental angioplasiy. Intimal, medial, and adventital changes associated with constrictive remodelling. Circ Res 1995;76:996-1002.

Lecherc G. Kearncy M, Sclnneider D, Rosenfield K, Losordo DW, Isner JM. Assessment of cell kinetics in human restenotic lesions by in vitro bromodeoxyuridine labeling of excised atherectomyspecimen. Clin Res 1993:41:343A. Abstract.

Lenström KB, Bruning NH, Bruggeman CA, Lautenschlager IT, Häyry PJ.Cytomegalovirus infection enhances smooth muscle cell proliferation and intimal thickening of rat aortic allografts. J Clin Invest $1993: 92: 549.558$.

Lenuström K, Koskinen P, Krogerus L, Daemen, M, Bruggeman C, Häyry. Cytomegalovirus antigen expression, endothelial cell proliferation, and intimal thickening in rat cardiac allografts after cytomegalowirus infection. Circulation 1995;92:2594-2604

McDonald K. Rector TS, Braunlin TA, Fubo SH, Olvari MT. Association of coronary artery disease in 
cardiac transplant recipients with cytonegalovirus infection. Am J Pathol 1989;64:359 362 .

Mosse RL, Campbell GR, Wang ZL, Campbell JH. Smooth muscle phenotypic expression in human carotid arteries. I. Comparison of cells from diffuse intimal thickenings adjacent to atheronatous plaques with those of the media. Lab Invest 1985;53:556-562.

Newby CN, George SJ. Proposed roles for growth factors in mediating smooth muscle proliferation in vascular pathologies. Cardiovasc Res 1993;27:1173-1183.

O'Brien ER, Alpers CE, Stewart DK, Fergusan N, Tran N, Gordon D, Benditt E, HinoharaT, Simpson JB, Schwartz SM. Proliferation in primary and restenotic coronary atherectomy tissue; implications for antiproliferative therapy. Cire Res $1993 ; 73: 223-231$.

Orlandi A, Ehrlich P, Ropraz P, Spagnoli LG, Gabbiani G. Rat aortic smooth muscle cells isolated from different layers and at different times after endothelial denudation show distinct biological features in vitro. Arterioscler Thromb 1994;"14:982-989.

Persoons MCJ, Daemen MJAP, Bruning JH, Bruggeman CA. Active cytomegallovirus infection of arterial smooth muscle cells immunocompromised rats. A clue to herpesvirus associated atherogenesis? Circ Res 1994;75:214-220.

Persoons $\mathrm{MC}$, J Stals FS, van dam Mieras MCE, Bruggeman CA. Multiple organ involventent during experimental cytomegalovirus infection is associated with disseminated vascular pathology. J Pathol. 1998;184:103-109.

Petrie BL, Melnick JL, Adam E, Burek J, McCollum CH, DeBakey ME. Nucleic acid sequences of cytomegalovirus in cells cultured from human arterial tissue. J Infect Dis 1987 ; 155:158-159.

Post MJ, Borst C, Kuntz RE. The relative importance of arterial remodelling compared with intimal hyperplasia in lumen narrowing after balloon angioplasty. A study in the normal rabbit and the hypercholesterolemic Yucatan micropig. Circulation 1994;89:2937-2941.

Ross R. The pathogenesis of atherosclerosis: a perspective for the 1990s. Nature 1993;362:801-809.

Schwartz SM, Campbell GR, Campbell JH. Replication of smooth muscle cells in vascular disease. Circ Res $1986 ; 58: 427-444$.

Schwartz SM, de Blois D, O'Brien ERM. The intima. Soil for atherosclerosis and restenosis. Circ Res 1995;77:445-465.

Speir E, Modali R, Huang ES Huang, Leon MB, Shawl F, Finkel T, Epstein S.E. Potential role of fumman cytomegalovirus and p53 interaction in coronary restenosis. Science 1994;265:391-394.

Stals FS, Bosman F, van Boven CPA, Bruggeman CA. An animal model for therapeutic intervention studies of CMV infection in the immunocomprimised host. Arch Virol 1990; 114:91-107.

Yamashiroya HM, Ghosh $L$, Yang R, Robertson AL. Herpesviridae in the coronary arteries and aorta of young trauma victims. Am I Pathol 1988;130:71-79.

Zhou YF, Leon MB, Wlacawiw MA, Popma JJ, Yu ZX, Finkel t, Epstein SE. Association between prior cytomgalowirus infection and the risk of restenosis after coronary atherectomy. New Engl I Med 1996:335:624-630. 

Chapter 6

Rat medial smooth muscle cells in vivo are not susceptible to active cytomegalovirus infection

MCJ Persoons, MJAP Daemen, EM van Kleef, GELM Grauls, CA Bruggeman (Submitted for publication) 


\section{Abstract}

Rat intimal carotid smooth muscle cells (SMCs) have previously been described to be highly susceptible to cytomegalovirus (CMV) infection, specifically when they are in a proliferative/dedifferentiated state. In this study the susceptibility of rat carotid medial SMCs to CMV was investigated soon after balloon induced injury, which is a period of increased medial SMC proliferation and dedifferentiation of medial SMCs.

Three days after balloon injury of the left carotid artery, rats were intravenously infected with rat CMV (RCMV) or rnock infected. The animals were killed at 2,4 or 14 days after virus administration or mock infection.

No RCMV specific antigens or other signs of infection were found at 2 and 4 days after RCMV administration, neither in the media nor in the intima.

At 14 days, solitary SMCs, or small clusters of SMCs, containing RCMV specific antigens, were sporadically present in the neointima of $50 \%$ of the infected rats.

However, no RCMV antigens, nor any other sign of RCMV infection, were ever found in medial cells.

Since in all cases the virus had been administered before migration of medial SMCs to the intima has started and the media remained negative for RCMV in that migration period, intimal infection at 14 days most likely represent SMCs that had been infected by circulating infected blood cells at later times and not medial SMCs that had been infected before their migration to the intima.

It is concluded that the arterial media, in contrast to the neointima, is no preferential site for active CMV infection. 


\section{Introduction}

Cytomegalovirus (CMV) is a ubiquitous agent and a major cause of serious -multiple organ- disease in immunocompromised patients. Moreover, it has been associated with atherosclerosis (Yamashiroya et al. 1988, Melnick et al. 1983, Petrie et al. 1987, Adam et al. 1987, Hendrix et al. 1990, Chiu et al. 1997) and arterial restenosis (Speir et al. 1994, Zhou ef al. 1996). The nature of this association is unclear, although the findings of accelerated transplant arteriosclerosis during CMV infection in humans as well as in rat, support a causal relation (McDonald et al. 1989, Bruning et al. 1994, Koskinen et al. 1993, Lemström et al. 1993, 1995).

Smooth muscle cells (SMCs) most probably are part of this relation. Using a balloon angioplasty model in the rat, we have previously shown that rat specific CMV (RCMV) can infect neointimal SMCs (Persoons et al. 1994). However, it proved that the susceptibility of these cells to RCMV is transient and that SMC phenotype is crucial. More specifically, dedifferentiation and/or proliferation seem determining factors (Persoons et al. 1997).

In our previous studies we have focussed primarily on CMV infection of intimal SMCs and it would be of interest to learn more about the susceptibility of medial SMCs to active CMV infection. Indeed medial and intimal SMCs may differ in their susceptibility to CMV infection, since it is known that these cells do posess distinct properties (Daemen et al. 1991, Majesky et al. 1992). Although CMV infection and replication have been demonstrated in cultured medial SMCs (Tumilowicz, 1985, 1990, Vossen et al. 1997), active CMV infection of medial SMCs in vivo has not been decribed before. Also, in our previous experinents we have not found RCMV to actively infect medial SMCs (Persoons et al. 1994, 1997).

To further investigate the in vivo susceptibility of medial SMCs, we administered CMV early (three days) after balloon catheterisation of the rat carotid artery, at which time medial SMCs are proliferating at increased levels, but have not started their migration to the intima (Clowes et al. 1983). Subsequently, the carotid media and intima were analyzed for the presence of infection, at different times after virus administration.

\section{Materials and methods}

\section{Animals}

Male Wistar-Kyoto rats that had been bred under specific pathogen free conditions at the Department of Experimental Animal Service at the University of Maastricht, were used at the age of 3 months (mean body weight $318 \pm 18.2 \mathrm{~g}$ ). The animals were given standard rat chow and tap water at libitum. All experiments were performed according to local institutional guidelines.

\section{Virus infection}

The RCMV as used in this study, had been isolated and characterized in our laboratory 
and (Bruggeman et al. 1985). Rats were infected intravenously with a pool of homogenized salivary glands of acutely infected laboratory rats, containing $10^{5}$ plaqueforming units (PFU) of RCMV, after they had been immunosuppressed by a total body roentgen radiation of $5 \mathrm{~Gy}$. Immunosuppression was performed, since, analogue to the human situation, a decreased immunocompetency is a prerequisite for symptomatic RCMV infection in rats (Stals et al. 1990), as well as for neointima RCMV infection in the rat balloon injury model (Persoons et al. 1994). Mock infection of control animals was performed with a salivary gland homogenate derived from non-infected rats.

\section{Experimental design}

Balloon catheterisation of the left carotid artery was performed in all rats as previously described (Persoons et al. 1994). The right carotid artery was not catheterized and served as an internal control. RCMV was administered intravenously, three days after balloon injury, which is one day after the rats had received röntgen radiation as decribed. At the day of infection, an osmotic mini purnp (Alzet model 2002, Alza Corp., Palo Alto, CA, USA) that had previously been filled with $5^{\prime}$-bromo-2'deoxyuridine (BrdU, $20 \mathrm{mg} / \mathrm{ml} 0.9 \% \mathrm{NaCl}$ ), was inserted subcutaneously between the shoulder blades. The pumps delivered BrdU at an infusion rate of $0.5 \mu 1 / \mathrm{h}$. Rats were killed 2,4 or 14 days after virus administration ( $n=8$ per time point). To study a possible effect of RCMV on neointimal thickness, control rats $(n=8)$ were also killed at 14 days after virus administration. All animals were killed by aortic bleeding under pentobarbital anesthesia, approximately one hour after they had received $0.5 \%$ Evans blue in $0.9 \% \mathrm{NaCl}$ intravenously to stain non-endothelialized vascular tissue. In situ perfusion was performed with $0.9 \% \mathrm{NaCl}$ containing $100 \mathrm{mg} / 1$ sodium nitroprusside (Merck). Circular segments were taken from Evans blue retaining areas of the injured left common carotid artery. Control segments were taken from comparable sites of the non-injured right common carotid arteries. The spleen of the rats that were killed at day 2 or 4 after infection and the salivary glands of the rats that were killed at 14 days after infection, were obtained. These organs were used to prove RCMV infection.

All tissues were fixed in $3.7 \%$ formaldehyde in phosphate buffered saline $(\mathrm{pH}=7.4)$, routinely processed and paraffin-embedded. For haematoxylin-eosin, Lawson elastin and immunocytochemical staining procedures, $3 \mu \mathrm{m}$ thick cross sections were cut.

\section{Virus detection}

The presence of RCMV antigens in carotid arteries, spleens and salivary glands was determined by immunohistochemcal staining procedures as previously described, using a mixture of two mouse monoclonal antibodies (McAbs 8 and 35, Bruning et al. 1987) against nuclear and cytoplasmic RCMV early antigens. Subsequent incubation steps were performed with biotin labeled sheep anti-mouse IgG (Amersham), alkaline phosphatase conjugated biotin-streptavidin complex (Amersham) and alkaline phosphatase substrate (Vector Lab Inc). To rule out nonspecific antigen binding, parallel sections were stained with an anti-human CMV monoclonal antibody that does not react with RCMV, and with control mouse ascites fluid (Sigma Immuno 
Chemicals).

$S M C-$ actin

Arterial SMCs were identified with the use of HHF 35 (Brunschwig), a monoclonal antibody that recognizes actin isotypes ( $\alpha$ en $\gamma$ ) common to all SMCs. A three layer indirect alkaline phosphatase immunostaining was performed as described for RCMV antigen detection. Serial sections were stained either HHF35, or with the monoclonal antibodies 8 and 35 against viral antigens, to confirm the SMC origin of RCMV infected cells. To control for specificity of signals, the same procedures were performed with aspecific as well as without monoclonal antibodies.

\section{Inflammatory cells}

Immunostaining, using the same three layer alkaline phosphatase technique, was performed as well with $\mathrm{ED}-1$, a monoclonal antibody reacting with rat macrophages/monocytes (Dijkstra et al. 1985) and W3/13, a monoclonal antibody reactive with rat T lymphocytes (Brown et al. 1981). Control procedures were performed with aspecific as well as without monoclonal antibodies.

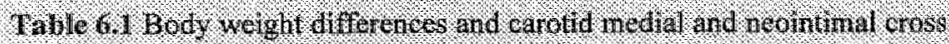

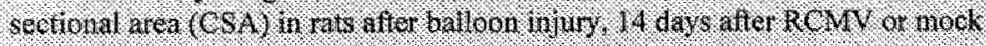
iniredion:

\begin{tabular}{lll}
\hline & RCMV+ & RCMV \\
\hline $\begin{array}{l}{ }^{2} \Delta \text { Weight }(g) \\
\text { CSA }\left(\mathrm{mm}^{2}\right)\end{array}$ & $-22 \pm 25$ & $+9.7 \pm 3.5^{1}$ \\
Lef carotid artery & & \\
- neointima & $0.06 \pm 0.01$ & $0.06 \pm 0.03$ \\
- media & $0.12 \pm 0.01$ & $0.14 \pm 0.02$ \\
- Lumen & $0.19 \pm 0.07$ & $0.12 \pm 0.07$ \\
Right carotid artery & & \\
- media & $0.11 \pm 0.01$ & $0.11 \pm 0.005$ \\
- Lumen & $0.23 \pm 0.05$ & $0.21 \pm 0.03$ \\
\hline
\end{tabular}

" $\mathrm{P}<0.05$ as compared with $\triangle$ Weight in RCMV infected rats.

${ }^{3} \mathrm{~A}$ Weight $=$ weight at time of death minus weight at RCMV or mock infection.

Expressed is the mean $\pm \mathrm{SD}$ of $\Delta$ weight for individual rats.

All values are expressed as mean $\pm \mathrm{SD}$. 
Cross sectional area

Neointimal, medial and luminal cross sectional areas of carotid arteries were measured, using a computer assisted morphometry system (Quantimet 570, Leica) on Lawson stained cross sections. The area surrounded by the external and internal elastic lamina was defined as the medial cross sectional area. The neointimal cross sectional area is defined as the area surrounded by the internal elastic lamina and the arterial lumen.

\section{Statistics}

Intimal and medial cross sectional areas at 14 days after virus administration, were compared with cross sectional areas in mock infected animals, using Student's $t$ test. The Student's $t$ test was also used for comparison of weights in the two groups.

\section{Results}

Mean body weights at the start of the experiments were $310 \mathrm{~g} \pm 12$ and $313 \pm 30 \mathrm{~g}$ (mean $\pm \mathrm{SD}$ ) for RCMV infected and noninfected animals, respectively. However, during the two weeks after infection, RCMV infected rats lost weight $(-22 \pm 25 \mathrm{~g})$, whereas mock infected rats gained weight $(+10 \pm 4 \mathrm{~g})$ weight $(\mathrm{P}<0.5)($ Tabel 6.1).

\section{Virus detection}

Generalized infection was present in all rats that had received RCMV, as shown by the presence of RCMV antigens in the spleens four days after virus administration and in the salivary glands, 14 days after the virus had been administered. Spleens were not positive for RCMV antigens at two days and at two weeks after administration, which are usual findings in systemically infected rats (Stals et al. 1990).

In carotid arteries of rats that were killed 2 and 4 days after virus administration, no RCMV antigens could be detected in the injured carotid media or intima. However in $50 \%$ of the injured carotid arteries of rats that were killed fourteen days after RCMV infection, viral antigens were detected. Isolated RCMV antigen containing cells and focal small clusters of positive cells were found sporadically in the neointima of these arteries (Figure 6.1). In haematoxilin-eosin stainings some of these cells showed a characteristic CMV infected appearance with cytoplasmic and nuclear inclusions. RCMV antigen positive cells or cytomegalic cells were never found in the media.

Control rats that had been mock infected never showed any sign of RCMV infection. Moreover, the non-injured right carotid artery in RCMV infected rats remained negative for RCMV antigens.

\section{$S M C$ - actin and inflammatory cells}

The cells of the left carotid artery that did stain positive with monoclonal antibodies against RCMV antigens, also showed immunoreactivity with HHF35 in respective stainings of serial section (Figure 6.2). This confirms the SMC origin of the infected vascular cells. The arteries that were positive for RCMV antigens, did never stain with ED1 or W3/13 (Figure 6.2). 


\section{Cross sectional areas}

At14 days after virus or mock infection, neointimal, medial and luminal cross sectional areas of injured carotid arteries in RCMV infected rats did not differ significantly from the corresponding cross sectional areas in rats that had been mock infected, (Table 6.1). No differences were found either between medial or luminal cross sectional areas of non-injured arteries in the two groups.
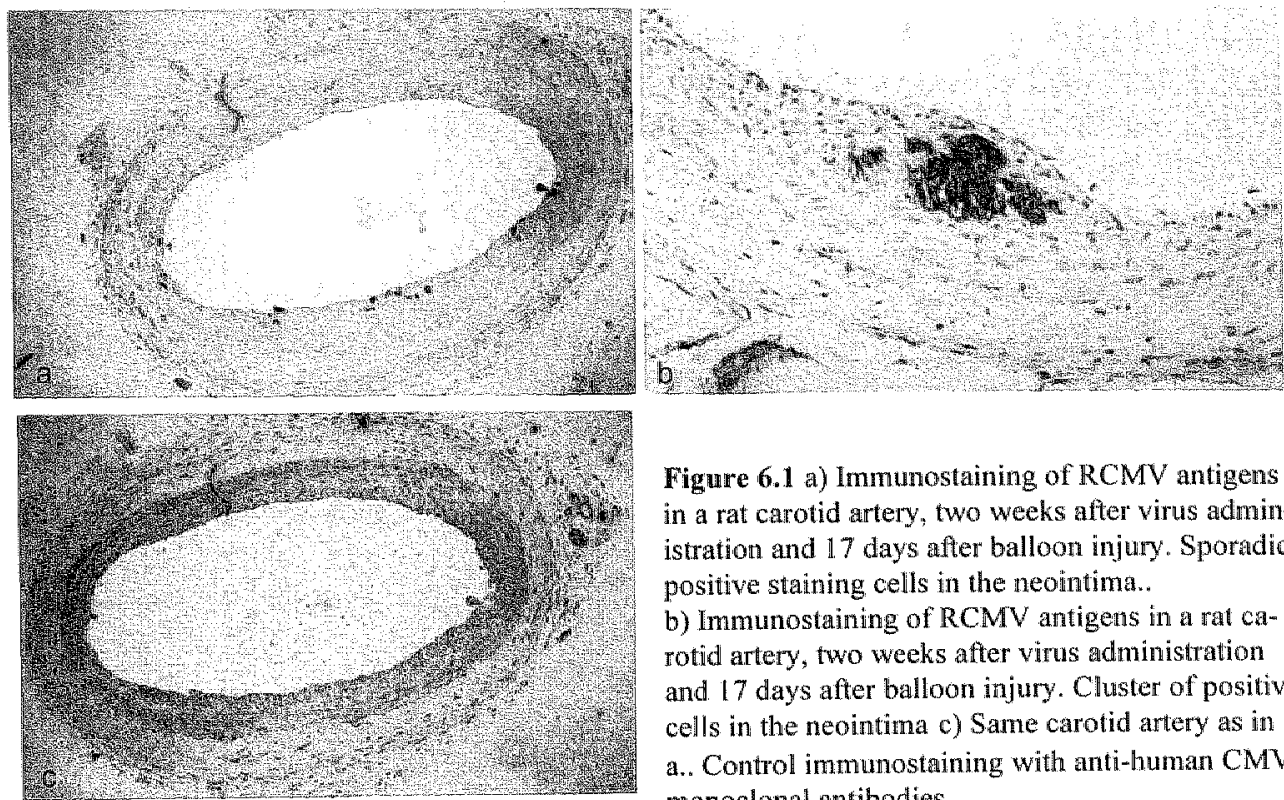

Figure 6.1 a) lmmunostaining of RCMV antigens in a rat carotid artery, two weeks after virus administration and 17 days after balloon injury. Sporadic, positive staining cells in the neointima..

b) Immunostaining of RCMV antigens in a rat carotid artery, two weeks after virus administration and 17 days after balloon injury. Cluster of positive cells in the neointima c) Same carotid artery as in

a. Control immunostaining with anti-thuman $\mathrm{CMV}$ monoclonal antibodies.

\section{Discussion}

CMV is thought to have a potential role in atherogenesis and SMCs, being present in atherosclerotic lesions, are important candidates to mediate such a CMV contribution. In previous studies we have been able to show that rat specific CMV can actively infect neointimal SMCs in vivo albeit under certain circumstances.

In this study, the in vivo susceptibility of medial SMCs to CMV is investigated in rat carotid arteries that have been injured by a balloon catheter. It is shown that medial SMCs in this model can not be infected with RCMV. Even when the virus is administered early after balloon injury, medial SMCs are not infected. This absence of medial infection indicates that medial SMCs are not, or at least far less than are neointimal SMCs, susceptible to RCMV infection.

The time of virus administration, three days after balloon injury of the left carotid artery, was chosen, since at that time proliferation and dedifferentiation of medial SMCs have reached a maximum, while migration of SMCs to the intima has not started 
(Clowes et al. 1983). In this way we were able to mimick the conditions of previous studies, in which we have shown that RCMV actively infect intimal SMCs, but only when these are in a dedifferentiated / proliferating state (Persoons et al. 1997). One possibility to explain the data in this study is that röntgen radiation may have blocked medial SMC proliferation at the time of RCMV administration. We therefore checked the effect of röntgen radiation on medial SMC DNA synthesis, as measured by immunostaining of DNA incorporation of bromodeoxyuridine. It was found that röntgen radiation, given at the third day after balloon injury, reduces cumulative levels of DNA synthesis of medial SMCs in the following two days to a certain extent. However, these levels remain significantly elevated, indicating increased rates of SMC proliferation (data not shown).

Two weeks after administration of the virus, sporadic RCMV infected neointimal SMCs were present in the neointima of $50 \%$ of the rats that had been infected, whereas no infected medial cells were seen. This finding indicates that infection had either taken place in the media at the time of administration, or that RCMV had infected intimal SMCs at later times. To investigate the first possibility, rats were killed as soon as two and four days after virus administration. The absence of RCMV early antigens in medial SMCs -as well as other signs of viral infection- at the second and fourth day after virus administration indicate that RCMV, even at time of increased medial SMC proliferation, does not infect medial SMCs. Moreover, it suggests that circulating RCMV incidentally did infected intimal SMCs, at later times.

The amount of virus that circulates at later times, is small in comparison with the virus load at the time of intravenous administration. This may be the reason that intimal infection in this study was found only very locally in the carotid arteries of $50 \%$ of the rats, which is in sharp contrast with the massive intimal infection that has been described to be present when RCMV is administered at the time of high intimal SMC proliferation (Persoons et al. 1994). A higher virus load increases the change of hitting target cells, resulting in a higher degree of infection, as has been described for CMV in vitro (Vossen et al. 1997).

There are several possible explanations for the difference in susceptibility of medial and intimal SMCs to CMV infection. Medial and intimal SMCs possess distinct properties (Majesky et al. 1992, Tumilowicz, 1990), which may include the susceptibility to CMV infection. Alternatively, the phenotypic state of the SMC may be crucial for its susceptibility to CMV; neointimal SMCs are known to reach much higher levels of proliferation in response to injury than do medial SMCs (Clowes et al. 1983, own observations), which may increase the change of CMV infection of SMCs. The fact that CMV does infect human and rat medial SMCs in vitro (Tumilowicz et al. 1985, Tumilowicz, 1990, Vossen et al. 1997), contradicts the hypothesis that intrinsic differences of SMCs could explain different susceptibilities to RCMV infection between intimal and medial SMCs. However, it coincides with the explanation that the phenotypic state of the cells, specifically dedifferentiation/proliferation, is important, since in vitro SMCs are mainly of the dedifferentiated, synthetic, phenotype. Moreover, this explanation would be compatible with our previous finding that susceptibility of neointimal SMCs to RCMV infection depends on their dedifferentiated and/or proliferating state (Persoons et al. 1997). 
The data presented here, strongly support the idea that intimal SMCs may be preferential sites for active CMV infection, since even relatively low levels of circulating RCMV in rats, that are recovering from immunosuppression, are shown to infect arterial neointimas. This is interesting, since in previous studies it has been described that a minimal dose ( $\left.10^{5} \mathrm{PFU}\right)$, administered directly after an even stronger immunosuppression than has been given in this study, is required to result in infection of different organs (Stals et al. 1990).

Thus, our study suggests that medial SMCs in vivo are not susceptible to CMV infection, which may represent the existence of a dedifferentiation/proliferation treshold for active CMV infection of SMCs. The intima, on the other hand, containing high levels of proliferating SMCs, seems to be a preferential site for CMV infection. Whether CMV persists in a latent state and by which ways CMV -in a latent or (re-)active state- possibly contributes to atherogenesis, remain topics of investigation.
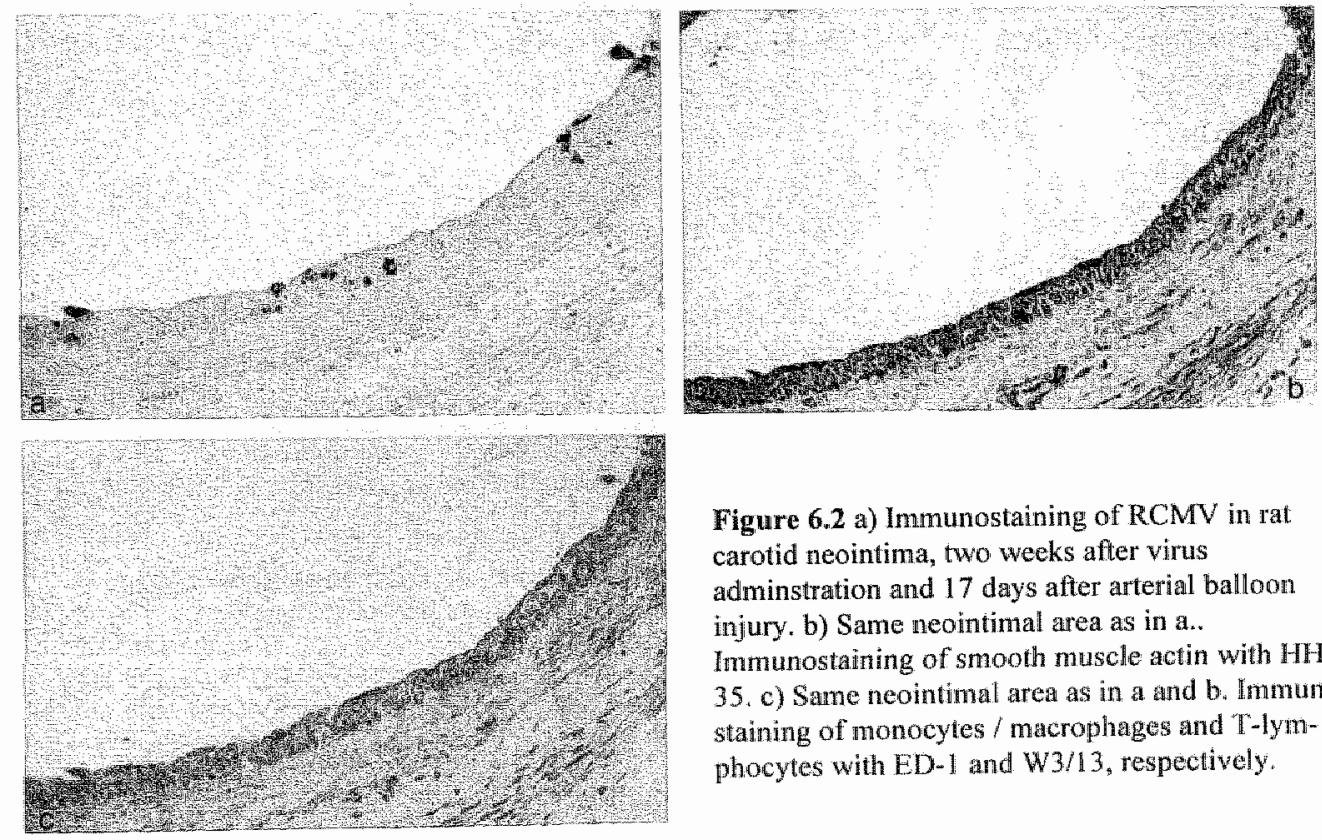

Figure 6.2 a) Immunostaining of RCMV in rat carotid neointima, two weeks after virus adminstration and 17 days after arterial balloon injury. b) Same neointimal area as in a.. Immunostaining of smooth muscle actin with $\mathrm{HHF}$. 35. c) Same neointinal area as in a and b. Immunostaining of monocytes / macrophages and T-lymphocyles with ED-1 and W $3 / 13$, respectively.

\section{References}

Adam E, Melnick JL, Probtsfield JL, Petrie BL, Burek J, Bailey KR, Mc Collum CH, DeBakey ME. High levels of cytomegalovirus antibody inpatients requiring vascular surgery for atherosclerosis. Lancet 1987;2:291-293.

Brown RA, Barclay AN, Sunderland CA, Wiliams F. Identification of a glycophorin-like molecule at the surface of rat thymocytes. Nature. $1981 ; 289: 456-460$.

Bruggeman CA, Meijer H, Bosman F, van Boven CPA. Biology of rat cytomegalovirus infection. Intervirology $1985 ; 24: 1-9$. 
Bruning $\mathrm{NH}_{3}$ Debie WHM, Dormans PH, Mejer H, Bruggeman CA. The development and characterisation of monoclonal antibodies against rat cytomegalowirus induced antigens. Arch Virol $1987994: 55-70$.

Bruning JH, Persoons MCJ, Lemstron KB, Stals FS, De Clereq E, Bruggeman CA. Enhancement of transplantation associated atherosclerosis by $\mathrm{CMV}$, which can be prevented by antiviral therapy in the form of HPMPC. Transplant Int 1994; 7(suppl 1):365-370.

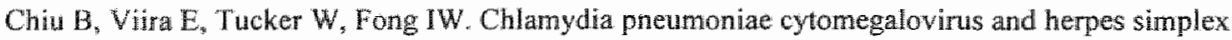
virus in atherosclerosis of the carotid artery. Circulation $1997 ; 96: 2144-2148$.

Clowes AW, Reidy MA, Clowes MM. Kinetics of cellular proliferation after arterial injury. I. Smooth muscle cell growth in the absence of endothelium. Lab Invest 1983;49:327-333.

Daemen MMAP, Lombardi DM, Bosman FT, Schwarz SM. Angiotensin II induces smooth muscle cell proliferation in the normal and injured arteriall wall. Circ Res. 1991;68:450-456.

Dijkstra CD, Döpp EA., Joling P, Kraal G. The heterogeneity of mononuclear phagocytes in lymphoid organs: distinct macrophage subpopulations in the rat recognized by monoclonal antibodies ED 1, ED2 and ED3. Inmunology. 1985; 54:589-599.

Grattan MT, Moreno-Cabrall CE, Starnes VA, Oyer PE, Stinson EB, Shumway N.E. Cytomegalovirus infection is associated with cardiac allograft rejection and atherosclerosis. JAMA 1989:261:3561-3566.

Hendrix MGR, Salimans MM, van Boven CP, Bruggeman CA. High prevalence of latently present cytomegalovirus in arterial walls of patients suffering from grade lll atherosclerosis. Am I Patholl $1990 ; 136: 23-28$.

Koskinen PK, Nieminen MS, Krogerus LA, Mattita SP, Hayry PJ, Lautenschlager IT, Cytomegalovirus infection and accelerated cardiac allograft vasculopathy in human cardiac allografts. I Heart Lung. Transplant 1993;12:724-729.

Lemsitröm KB, Bruning JH, Bruggenan CA, Lautenschlager IT, Håyry PJ.Cytomegalovirus infection enhances smooth muscle cell proliferation and intimal thickening of rat aortic allografts. I Clin Invest $1993 ; 92: 549-558$.

Lemström $\mathrm{K}$, Koskinen $\mathrm{P}$, Krogerus L, Daemen, M, Bruggeman C, Häyry. Cytomegalowirus antigen expression, endothelial cell proliferation, and intimal thickening in rat cardiac allografts after cytomegalovirus infection. Circulation 1995:92:2594-2604

Majesky MW, Giachell CM, Reidy MA, Schwartz SM. Rat carotid neointimal smooth muscle cells rexptess a developmentally regulated mRNA phenotype during repair of arterial injury. Circ Res. $1992 ; 71: 759-768.31$

McDonald K, Rector TS, Braunlin TA, Kubo SH, Olvari MT. Association of coronary artery disease in cardiac transplant recipients with cytomegalovirus infection. Am I Pathol 1989;64:359-362.

Meinick IL, Dreesman GR, McCollum CH, Petrie BL, Burek J, Debakey M.E.Cytomegalovirus antigen within thuman arterial smooth muscle cells. Lancet. 1983,$2 ; 644647$.

Persoons MCJ, Daemen MJAP, Bruning JH, Bruggeman CA. Active cytomegalovirus infection of arterial smooth muscle cells immunocompromised rats. A clue to herpesvirus associated atherogenesis? Circ Res 1994;75:214-220.

Persoons MCI, Daemen MIAP, van Kleef EM, Grauls GELM, Wijers E, Bruggeman CA. Neointimal smooth muscle cell phenotype is important in its susceptibility to cytomegalovirus (CMV) infection: a study in tat. Cardiovase Res 1997;86:282-288.

Petrie BL, Melnick JL, Adam E, Burek J, McCollum CH, DeBakey ME. Nucleic acid sequences of cytomegallovirus in cells cultured from human arterial tissue. J Infect Dis. 1987;155:158-159. 
Speir E, Modali R, Huang ES Fuang, Leon MB, Shawl F, Finkel T, Epstein S.E. Potential role of human cytomegalovirus and p53 interaction in coronary restenosis. Science 1994:265:391 -394.

Stals FS, Bosman F, van Boven CPA, Bruggeman CA. An animal model for therapeutic intervention studies of CMV infection in the immunocomprimised host. Arch Virol 1990; 114:91-107.

Tumilowicz JJ. Characteristics of human arterial smooth muscle cell cultures infected with cytomegalovirus. In Vitro Cell Dev Biol. 1990;26:1144-1150.

Tumilowicz JJ, Gawlik ME, Powell BB, Trentin JJ. Replication of cytomegalovinus in huntan arterial smooth muscle cells. J Virol 1985;56:839-845.

Vossen RCRM, Persoons MCJ, Slobbe-van Drunen MEP, Bruggeman CA, van Dam-Mieras MCE. Intracellular thiol redox status affects rat cytomegalowins infection of vascular cells. Virus Research $1997 ; 48: 173-183$.

Yamashiroya HM, Ghosh L, Yang R, Robertson AL. Herpesviridae in the coronary arteries and aorta of young trauma wictims. Am J Pathol 1988;130:71-79.

Zhou YT, Leon MB, Wlacawiw MA, Popma IJ, Yu ZX, Finkel t, Epstein SE. Association between prior cytomgalowins infection and the risk of restenosis after coronary atherectomy. New Engl I Med $1996 ; 335: 624-630$. 
Chapter 7

General discussion 
The studies that are described in this thesis, strongly support our preexistent thought that vascular involvement is of basic importance in cytomegalovirus (CMV) pathology and moreover, that the nature of such vascular involvement is diverse.

In rat, CMV was shown to actively infect different vascular cells in vivo (Figure 7.1). However, susceptibility and consequences of infection proved to largely depend on specific circumstances. These include the nature of the vascular structure which the cell is part of, cellular phenotypic properties and immunological factors, such as host immunological status and histoimmunocompatibility.

Moreover, it was shown that active infection is not always necessary for RCMV to affect vascular cell behaviour and induce vascular pathology.

That CMV can infect endothelial cells has been known for a long time. Culture studies on human CMV and endothelial infection are usually performed with endothelial cells that have been derived from human umbilical veins. However, it has become clear that these endothelial cells are far less permissive for the virus than are for instance fibroblasts or arterial SMCs. In humans the presence of CMV infected endothelial cells has been reported in CMV vasculitis of especially the gastrointestinal tract and skin. This is compatible with finding acute (this is active) rat CMV (RCMV) infection of microvascular endothelial cells in vivo, as decribed in this thesis (chapter 2). However, endothelium of medium sized and larger arteries have never been found to be actively infected by RCMV, as shown by the absence of viral antigens and CMVspecific cytopathology. In fact the presence of endothelial cells in carotid arteries that had been balloon injured, was shown to prevent infection of underlying neointimal SMCs (chapter 4). Moreover, endothelial cells of transplanted abdominal aortas did never contain RCMV antigens or showed any other sign of active RCMV infection (chapter 3).

During disseminated RCMV infection, infected microvascular endothelial cells were observed in several organs (chapter 2). This concerned primarily endothelium of venules and capillaries. In the local (subdermal) RCMV infection model, it appeared that these endothelial cells become relatively late infected; mononuclear inflammatory cells and tissue fibroblasts to be RCMV infected days before the endothelial cells. From all these findings it may be concluded that endothelial cells are not the most permissive cells or preferential sites for CMV infection, nevertheless, our studies do support a central role for endothelial cells in CMV disease. This is fully compatible with the commonly accepted concept that endothelial cells are important active participants in inflammatory processes (Pober and Cotran 1990). Endothelial disturbance and/or activation is not necessarily the result of endothelial infection, but may as well be induced by contact with CMV or CMV infected cells, or by inflammatory mediators produced by other cells.

The studies decribed in chapter 2 , indicate that microvascular endothelial activation, as manifested by morphologic changes and leucocyte adhesion, is one of the earliest events to occur after CMV infection. During generalized CMV infection diffuse microvascular endothelial activation may occur, resulting in leucocyte adhesion, increased endothelial permeability, transmigration of leucocytes, and triggering of the 


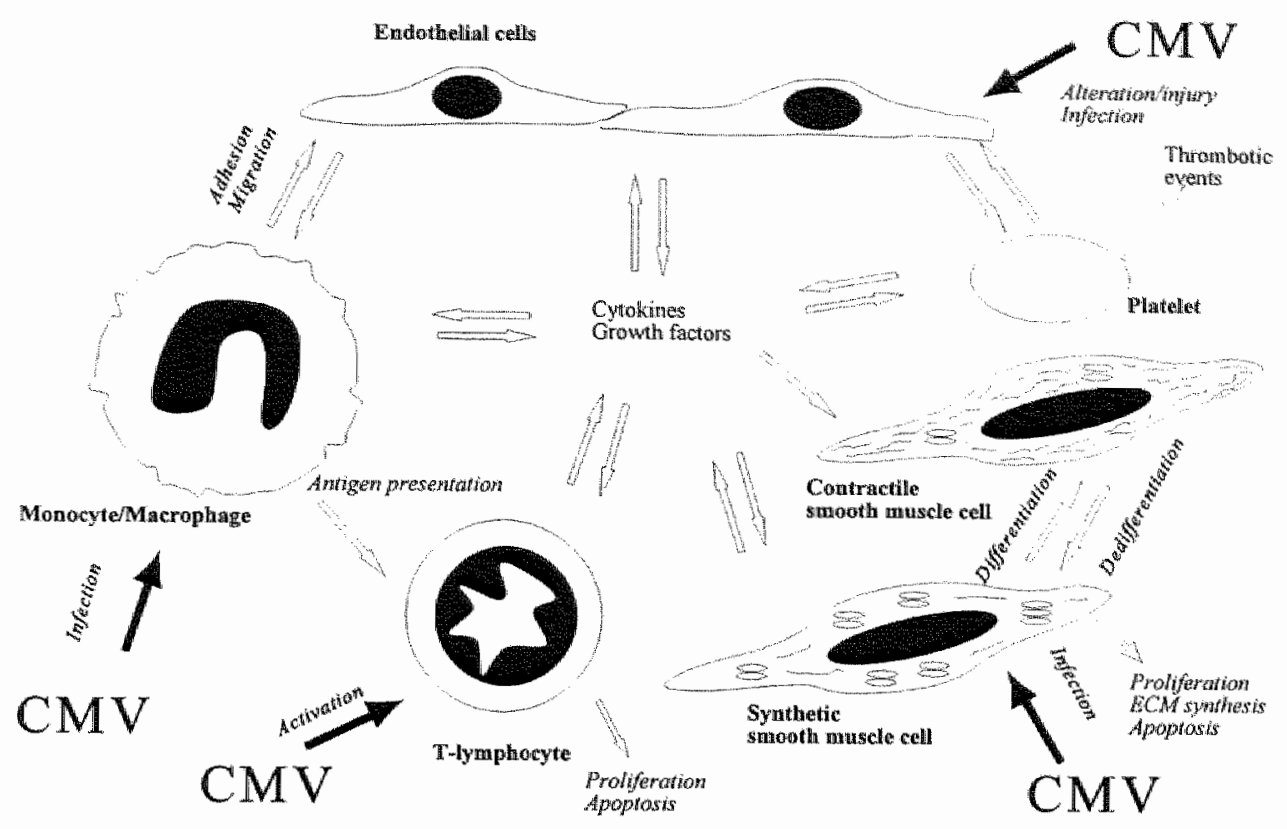

Figure 7.1 Schematic representation of (direct and indirect) CMV interactions with different vascular cells.

trombotic system by increased procoagulant activity of endothelial cells. We have not determined plasma fibrinogen degradation products, but disseminated intravascular coagulopathy as a result of such a diffuse thrombotic activation has been made very likely by the presence of intravascular fibrin, thrombotic microvascular occlusions, as well as by decreased plasma levels of coagulation factors. Macroscopically this coagulopathy is manifested by extended haemorrhages.

The -rather late- infection of endothelial cells may be the result of transmission of the virus by circulating infected mononuclear inflammatory cells as has been demonstrated in culture (Waldman et al. 1995). Endothelial infection further contributes to inflammatory and procoagulant reactions including microvascular destruction and tissue deterioration. Our combined findings in the RCMV models decribed in chapter 2 , are compatible with the pathology of disseminated CMV infection in humans and the presence of circulating infected cells of endothelial origin in such patients (Percivalle et al. 1993, Grefte et al. 1993).

The fact that infected endothelial cells of larger arteries have never been found in our rat models, nor have been described in humans, does not implicate that large artery endothelial cells have no part in CMV associated atherosclerosis. Endothelial cells are active mediators in the inflammatory proces of atherosclerosis. Altered endothelial function by CMV may be induced indirectly by inflammatory mediators (such as cytokines and growth factors that are locally secreted by other vascular cells, or circulating in the plasma), or alternatively, it may result from contact with CMV and/or 
CMV infected cells, such as intimal SMCs or monocytes. In turn, endothelial injury or disturbance of endothelial cell integrity, does, via release of cytokines and growth factors, affect the phenotype and behaviour of SMCs, which may be of importance in SMC susceptibility to CMV infection, as decribed in this thesis (chapters 5 and 6). The CMV enhanced infiltration of mononuclear cells, especially $T$-cells, in allograft aortas, which can be largely prevented by prophylaxis with HPMPC (chapter 3), is compatible with findings of others (Lemström et al. 1995, Koslinen et al. 1993, Li et al. $1996 \mathrm{a}$ andb) and indicates an alloimmune response that may be CMV specific. This is supported by Li et al. (Li et al. 1996a), who described a correlation between the extent of RCMV infection in organs, such as the spleen, and the amount of perivascular infiltration of mainly $\mathrm{T}$-cells in rat aortic allografts. Besides the fact that CMV infection has been described to initiate polyclonal $T$-cell activation and upregulation of allospecific T-cells (Via et al. 1990, Yang et al. 1989), it has been hypothesized that endothelial cells may be main targets for CMV initiated immune injury (Koskinen et al., Li et al.). However, it is remarkable that CMV infected cells are hardly present in the allograft vascular wall during CMV infection. With the exception of sporadic RCMV positive cells in the adventitia we did not find signs of active RCMV infection in allogenic aortas, which has been confirmed by others (Lemström et al. 1995, Li et al. $1996 \mathrm{a}$ and b). Waldman et al. have demonstrated that CMV infected endothelial cells in culture will activate T-cells that are derived from CMV seropositive donors, suggesting a CMV specific response (Waldman et al. 1992). This activation appeared to occur in the absence of allogeneic antigens and to be at least partly mediated by the endothelial expressed adhesion molecule ICAM-1 (Waldman et al. 1998). T-cells activated in this way were shown to induce the expression of HLA-DR antigens on surrounding noninfected endothelial cells, but not on infected cells (Waldman et al. 1993), as well as enhancement of the expression of ICAM-I and HLA class I (Waldman et al. 1996). Induction of these antigens was proven to be mediated by cytokines (IFN $\gamma$ and TNF $\alpha$ ) (Waldman et al. 1993,1996). These studies suggest that once -even very low levels of- CMV infected cells are present in the allograft endothelium, or possibly after contact of infected cells of other cell origin with this endothelium, CMV specific host T-cell activation and further triggering of inflammatory cascades can be elicited. This may continue in the absence of the virus.

Arterial SMCs are at the centre of the second part of this thesis. Main findings are that RCMV can acutely infect arterial SMCs in vivo and that neointimal SMCs after injury turned out to be the preferential sites for such an active infection, but only within a small time window.

Previously, (R)CMV has been reported to actively infect arterial SMCs in vitro (Tumilowics et al. 1985, Vossen et al. 1997) and arterial SMCs that had been derived from atherosclerotic and restenotic lesions, were shown to express CMV antigens when brought into culture (Melnick et al. 1983, Speir et all 1994). However, active CMV infection in vivo has not been described before. We, like others, have never been able to find signs of active RCMV infection in arterial SMCs of non-injured arteries, not 
even in rats that were suffering from acute infection in multiple organs. After balloon injury, however, massive acute RCMV infection of neointimal SMCs occurs in the absence of acute infection of the organs, with the exeption of a low grade infection of the salivary glands (chapter 4 ). From the experiments decribed in the chapters 4-6, it appeared that the SMC phenotype is a crucial factor in the enhanced permissiveness to CMV infection.

There are different subtypes of arterial SMCs and it is even thought that SMCs in different arteriai beds, other than is the case for endothelial cells, may be different from. each other (Ross 1994, Daemen et al. 1995). However, at least two different phenotypes of SMCs have been discriminated on basis of the myosin filaments and the extent to which secretory protein apparatus (Golgi and rough endoplasmic reticulum) is formated. SMCs in a contractile phenorype respond to agents that induce either vasoconstriction or vasodilatation, while SMCs in the synthetic phenotype are capable to express genes for a number of growth-regulatory molecules and cytokines, as well as receptors to respond to such factors, and synthesize extra-cellular matrix (Ross, 1994, review). As are most dedifferentiated cells, synthetic SMCs generally are proliferating to enhanced degrees.

From the data presented in this thesis, it may be concluded that these synthetic SMCs, being present in large amounts in the first weeks after arterial balloon injury, are the cells that are prone to acute CMV infection. This may explain why medial SMCs in vitro are highly permissive fot CMV infection and replication, since SMCs in culture are primarily of the synthetic type. Whether it is the proliferative state of the cell and/or other features of dedifferentiation the virus needs for the expression of viral proteins and viral replication, is not clear and it would probably be of interest to find this out in the future.

Our studies indicate that the degree to which synthetic SMCs are present in the intima or media, determines whether acute CMV infection will be found or not. This may reflect the existence of a treshold of the sensitivity of detection methods that are used. However, it seems likely that CMV needs a certain amount of cells that are permissive for vinus replication to maintain an active state and thus local infection. As shown in chapter 5 , a few months after massive neointimal infection bad been established, when neointimal SMCs almost completely have returned to a dedifferentiated state and proliferation levels are very low, CMV infection has faded away. Perllaps it would be interesting to confirm our data in vitro and to determine at what levels of proliferation CMV will infect intimal and medial SMCs. This might be performed with the use of a medium that will keep SMCs in a more or less non-proliferating state (Libby et al. 1983).

The high permissiveness of synthetic SMCs to CMV infection has potential clinical relevance, since these cells are present in increased numbers in atherosclerotic lesions, allograft arteries and arterial areas that have undergone angioplasty (Schwartz et al. 1986, Desmouilliere et al. 1992, O'Brien et al. 1993). CMV nucleic acids have been demonstrated in atherosclerotic arteries. (Yamashiroya et al. 1988, Hendrix et al. 1989) and are thought to represent the presence of latent CM. Active CMV infection may be low graded and fluctuating, depending on local inflammatory mediators and immunosuppressive factors, whereas the virus itself can contribute to local 
inflammation. Furthermore, it can be hypothesized that active virus infection within an atherosclerotic lesion may be one reason for plaque instability and acute vascular events.

In the rat carotid artery balloon injury model, we could not demonstrate any effect of RCMV on neointimal thickness and/or SMC proliferation. Attempts to determine proliferation of SMCs during SMC infection failed, due to the interference of enhanced viral DNA synthesis (chapter 4). The lack of any significant increase in neointimal thickness could have have been due to apoptosis of massively infected SMCs, which might have opposed a potential enhancing effect on neointimal cross sectional area by SMC proliferation and/or inflammation. This is a probability that has not been investigated in the studies of this thesis. In the allograft aorta model, in which CMV has been demonstrated to stimulate neointimal thickness and SMC proliferation (chapter 3 and Lemström et al. 1993) active RCMV infection of SMC has not been found and thus CMV induced apoptosis seems less likely. This, hypothetically, may as well be a reason for the different findings in the two models. Alternatively, it may be that endothelial cells are essential mediators in CMV induced SMC proliferation and that the absence of endothelium in the infected balloon injured arteries is responsible for different findings in the two models. Moreover, not finding evidence for a stimulatory effect of CMV on SMC proliferation in non-transplant arteries does not perse contradict the findings of Speir et al. in human restenotic coronary arteries after angioplasty. Although these authors hypothesize that the correlations they have found between CMV and the occurrence of restenosis after angioplasty, could be mediated by an inhibiting effect of the virus on p53 and thus stimulating SMC proliferation, they have never evidenced CMV induced SMC proliferation in restenotic lesions (Speir et al. 1994). Besides, it is thought that SMC proliferation may not be an important factor at all in arterial restenosis that occurs after coronary angioplasty (Lafont 1995, Mintz 1997, Kimura 1997).

In conclusion, different rat models have proved to be valuable in the study on CMV induced vascular pathology. They have provided more insight in CMV involvement at different vascular levels, the mechanisms along which this may occur and the clinical relevance of such CMV induced vascular changes.

\section{References}

Daemen MJ, De Mey JG. Regional heterogeneity of arterial structural changes. Hypertension 1995; 25:464-473.

Desmouiliere A, Gabbiani G. The cytoskeleton of arterial smooth muscle cells during human and experimental atheromatosis. Kidney Int 1992;41 Suppl 37:S-87 S-89.

Grefte, JMM, van der Giessen M, wan Son WI, The TH. Circulating human cytomegalovirus (HCMV)infected endothelial cells in patients with an active HCMV infection. J Inf Dis 1993; 167:270-277

Hendrix MGR, Dormans PHJ, Kitselaar P, Bosman F, Bruggeman CA. The presence of CMV nucleic acids in arterial walls of atherosclerotic and non-atherosclerotic patients. Am J Pathol. 1989;134:1 151 1157.

Huang $\mathbb{E H}$, Sedmak DD. Bidirectional transmission of infectious cytomegalovirus between monocytes 
ans vascular endothelial cell: an in vitro model. IInfect Dis 1995;171:263*272.

Kinura K, Kaburagi S, Tamura T, Yokoi H, Nakagawa Y, Yokoi H, Hanasaki $N_{2}$, Nosoka H. Nobuyoshi M, Mintz GS, Popma JJ. Leon MB. Remodelling of human coronary arteries urdergoing angioplasty or atherectomy. Circulation 1997:96:475-483.

Koskinen PK, Krogerus LA, Nieminen MS, Mattila SP, Hayry PJ "Lantenschlager IT. Quantitation of cytomegalovirus infection-associated histologic findings in endomyocardial biopsies of heart allografts. J Heart Lung Transplant 1993;12:343-354.

Koskinen PK, Lemström KB, Bruggeman CA, Lautenschlager T, Häyry. Acate cytomegalovirus infection induces a subendothelial inflammation (endothelialitis) in the allograft vascular wall. A possible linkage with enhanced allograft arteriosclerosis. Am J Pathol 1994;144:41-50.

Lafont A, Guzman LA, whitlow PL, Goomastic M, Cornhill JF, Chisholm GM. Restenosis after experimental angioplasty. Intimal, medial, and adventitial changes associated with constrictive remodeling. Circ Res 1995;76:996-1002.

Lemström $\mathbb{K}$, Koskinen $\mathrm{K}, \mathrm{P}$, Krogerus L, Daemen M, Bruggeman $\mathrm{C}$, Hayry P. Cytonegalovirus antigen expression, endothelial cell proliferation, and intimal thickening in rat cardise allografts after cytomegalovirus infection. Circulation 1995;92:2594-2604.

Lemström KB, Brüning JH, Bruggeman CA, Lautenschlager IT, Hayry PJ. Cytomegalowirus infection enhances smooth muscle cell proliferation and intimal thickening of rat aortic allografts. J Clin Invest $1993 ; 92: 549-558$.

Li F, Grauls G, Yin M, Bruggeman C. Correlation between the intensity of cytomegalovirus infection and the amount of perivasculitis in aortic allografts. Transpl Int 1996a;9S340-S344.

Li F, Grauls $\mathrm{G}$, Yin M, Bruggeman $\mathrm{C}$. Initial endothelial injury and cytomegalovirus infection accellerate the development of allograft arteriosclerosis. Transplantation Proceedings 19966;27:35523554.

Libby $\mathrm{P}, \mathrm{O}^{\prime} \mathrm{Brien} \mathrm{KV}$. Culture of qujescent arteial smooth muscle cells in a defined serum-free medium. J Cell Physiol 1983;115:217-223.

Melnick $\mathrm{JL}$, Dreesman GR, McCollum CH, Petrie BL, Burek J, DeBakey M.E.Cytomegalowirus antigen within human arterial smooth muscle cells. Lancet 1983;2:644-647.

Mintz GS, Kent KM, Pichard AD, Satien LF, Popma JJ, Leon MB. Contribution of inadequate anterial remodeling to the development of the focal coronary artery stenoses. An intravascular ultrsound study. Circulation 1997;95:1791-1798.

O'Brien ER, Alpers CE, Stewart DK, Fergusan N, Tran N, Gordon D, Benditt E, Hinohara T, Simpson JB, Schwartz SM. Proliferation in primary and restenotic coronary atherectomy tissue; implications for antiproliferative therapy. Circ Res 1993;73:223-231.

Percivalle E, Revello MG, Vago L, Morini F, Gerna G. Circulating endiothelial gient cells permissive for human cytomegalovirus (HCMW) are detected in disseminated HCMV infections with organ involvement. J Clin Invest 1993; 92:663-670

Pober S, Cotran RS. The rolle of endothelial cells in inflammation. Transplantaion 1990;50:537-544.

Ross R. The pathogenesis of atherosclerosis: a perspective for the 1990s. Nature 1993;362:801-809.

Scliwartz SM, Campbell GR, Campbell JH. Replication of smooth muscle cells in vascular disease. Circ Res 1986;58:427-444.

Speir E, Modali R, Huang ES, Leon, Shaw F, Finkel T, Epstein SE. Potential role of human cytomegalovirus and p53 interaction in coronary retenosis. Science 1994;265:391-394. 


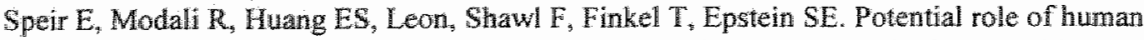
cytomegalowirus and p53 interaction in coronary retemosis. Science 1994;265:391-394.

Tumilowicz JJ, Gawlik ME, Powell BB, Trentin JJ. Replication of cytomegallovinus in human arterial smooth musicle cells. I Virol. 1985; $560839-845$.

Via CS, Shanley JD, Shearer GM. Synergistic effect of murine cytomegalowirus on the induction of acute graft-ws-host disease involving MHC Class I differences only. Analysis of in wito $T$ cell function. I inmuno: $1990 ; 145: 3283-3289$.

Vossen RCRM, Persoons MCJ, Slobbe-van Drunen MEP, Bruggeman CA, van Dam-Mieras MCE. Intracellular thiol redox status affects rat cytomegalovirus infection of vascular cells. Wirus Research $1997: 48: 173-183$.

Waldman WJ, Adams PW, Orosz $\mathrm{CG}_{*}$ Sedmak DD. T lymphocyte activation by cytomegalovirusinflected, allogeneic cultured human endothelial cells. Transplantation 1992;54:887-896.

Waldman WJ, Knight DA, Adams PW, Orosz CG, Sedmak DD. In vitro induction of endothelial HLA class II antigen expression by cytomegalovirus-activated CD4+ T-cells. Transplantation 1993;56:15041512

Walldman WJ, Knight DA, Huang EH, Sedmak DD. Bidirectional transmission of infectious cytomegalowirus between monocyts and vascular endothelial cell: an in vitro model. J Infect Dis $1995 ; 171: 263-272$.

Wallman WI, Knight DA. Cytokine mediated induction of endothelial adhesion molecule and histocompatibility leucocyte antigen expression by cytomegalovirus-activated T-cells. Am J Pathol $1996 ; 148: 105-119$.

Waldman WJ, Knight DA, Huang EH. $\mathrm{An}$ in vitro model of T cell activation by autologous cytomegalovirus (CMV)-infected human adult endothelial cells: contibution of CMV-enhanced endothelial ICAM-1. J immunol 1998;160:3143-3151.

Yamashiroya HM, Ghosh L, Yang R, Robertson AL. Herpesviridae in the coronary arteries and aorta of young trauma victims. Am J Pathol. 1988;130:71-79.

Yang $\mathrm{H}$, Dundon PL, Nahill SR, Welsh RM. Virus induced polyclonal cytotoxic T lymphocytes stimulation. J Immunol 1989;142:1710-1718. 


\section{Summary}

Cardiovascular disase has remained the main cause of mortality in the western world and atherosclerosis accounts for the majority of these deaths.

Through the years, infectious agents have been mentioned as potential causes of atherosclerotic disease and especially cytomegalovirus (CMV), being one of the herpesviruses, has been frequently associated with atherosclerotic lesions. The virus along with the bacterium Chlamydia pneumoniae- has becone the most serious infectious candidate for a causative or contributing role in atherogenesis.

CMV is a ubiquitous virus, -the prevalence of anti-CMV antibodies in the general population is as high as $50-80 \%-$, however, by far the majority of infections in immunocompetent hosts remain aymptomatic. On the other hand, CMV is a wellknown cause of severe, often fatal, disease in immunocompromised patients, especially transplant recipients and patients suffering the acquired immunodeficiency syndrome (AIDS). CMV induced pathology in these patients may be diverse and often multiple organs are involved. Vascular changes are frequently described to be part of such pathology.

Based on the preexistent hypothesis that vascular involvement may be of principal importance in CMV induced pathology, the studies in this thesis are focussed on CMV interactions with large and medium sized arteries, as well as with the microvasculature, and the clinical relevance of such interactions.

Chapter I starts with some general aspects of atherosclerotic lesions and atherogenesis. Furthermore, the possible role of infectious agents in atherosclerosis is discussed on basis of the literature. The main part of this chapter concerns a review of literature describing associations that have been established between CMV and atherosclerosis and other vascular pathologies. At the end of this chapter hypotheses and aims of this thesis are stated.

Chapter 2 describes studies in rat models of localized and generalized CMV infection, using rat-specific CMV (RCMV). Both models constituted evidence for extensive microvascular involvement in CMV associated pathology, manifested by activation and infection of microvascular endothelium, vasculitis, thrombotic occlusions and haemorrhages. Increased bleeding times and thrombocytopenia during disseminated CMV infection supported the existence of diffuse intravascular coagulopathy. The nature and chronology of RCMV induced pathologic vascullar events are shown, indicating the importance of (microvascular) endothelial activation and damage in CMV disease.

In chapter 3 the use of a rat allogeneic abdominal aorta transplantation model is 
described in a study of the effects of CMV infection on transplantation associated arteriosclerosis. RCMV administration, three weeks after the transplantation, at which time intimal smooth muscle cell (SMC) proliferation and adventitial infiltration of inflammatory cells hawe reached maximum levels, resulted in enhanced neointima thickness, as well as increased numbers of SMCs in the intima. Moreover, mononuclear cell infiltration into the adventitia was evidently enhanced in RCMVV infected recipient rats. RCMV infected cells were only sporadically present in the adventitia, however, were never seen in neointima or media.

The CMV induced effects were not found in syngeneic aorta grafts and were inhibited by prior administration of the acyclic nucleoside anallogue (S)-1-(3-hydroxy-2phosphonylmethoxypropylycytosine (HPMPC), a potent and selective inhibitor of CMV infection. The data indicate that CMV enhances alloimmune graft reactions, as manifested by augmentation of 'atherosclerotic' changes.

SMCs are important constituents of atherosclerotic processes and though they have been suggested to be potential sites of CMV infection, active infection of arterial SMCs in vivo had not been described before. Chapter 4 concerns a study after the susceptibility of medial and neointimal SMCs to acute CMV infection in vivo. Hereto a rat balloon injury model was used. In immunocompetent rats, as well as in rats that had been immunocompromised, the left carotid artery was injured with a balloon catheter. Two weeks after injury, when a neointima had developed and proliferation levels of neointimal SMCs were still high, rats were intravenously infected with RCMV. Two weeks after this RCMV administration, extensive active RCMV infection was established in the innermost layer of the neointima of inmunocompromised rats. This was evidenced by the presence of typical nuclear CMV inclusions and of early viral antigens and DNA in the cytoplasm and nucleus of intimal cells, while the virus was visualized in these cells with electron microscopy. The infected cells were almost exclusively SMCs, as could be concluded from the electron microscopic images and staining of infected cells with anti-smooth muscle actin antibodies. In the areas that had been recovered by endothelium, infection of underlying SMCs did not occur. Infected cells were never observed in the media. Moreover, in this model RCMV infection was not detected in rat organs, with the exception of the salivary glands. Neointima and media cross sectional areas were not significantly affected by RCMV infection.

The data presented in this chapter proved neointimal SMCs to be highly preferential sites for active CMV infection.

In the study described in chapter 5 it was investigated whether neointimal RCMV infection after injury results in arterial changes on the long term. Moreover it was investigated whether the phenotypic state of neointimal SMCs may influence their susceptibility to active CMV infection, since so far we had found neointimal SMCs to become infected at the time of increased neointimal proliferation, while infection of medial SMCs had never been observed.

With respect to the first question, rats received RCMV intravenously, two weeks after balloon injury of the left carotid artery. At 20 weeks after infection, no significant 
RCMV induced differences in intima or media thickness were found and intimal SMC proliferation levels, as indicated by bromodeoxyuridin incorporation, had returned to normal levels, irrespective of prior RCMV infection. Moreover, no signs of active infection were observed at that time.

With respect to the second question, RCMV was administered at 8 weeks after balloon injury. At this time neointimal SMC phenotype had changed from a synthetic (dedifferentiated) in a more contractile (redifferentiated) phenotype, which was confirmed by immunohistochemical determination of $\alpha$-actin, desmin and vimentin contents. Two weeks after virus administration no signs of infection were found in the intima nor in the media. These findings indicate that intimal SMC phenotype determines its susceptibility to active CMV infection in vivo. Since dedifferentiation of neointimal SMCs was associated with enhanced proliferation of these cells, it was concluded that dedifferentiation and/or proliferation are prerequisites for active CMV infection.

Chapter 6 describes a study after the susceptibility of medial SMCs to active CMV infection. RCMV in this study was administered early (three days) after balloon catheterisation of the left rat carotid artery, which is in a period of increased proliferation and dedifferentiation of SMCs in the media. Two and four days after infection, RCMV antigens or other signs of active RCMV infection were observed neither in the media, nor in the neointima that had just started to develop. At 14 days after infection, solitary SMCs, or small clusters of SMCs that contained RCMV specific antigens were sporadically present in the neointima of $50 \%$ of the infected rats. However RCMV antigens were not found in medial cells. Since the media had remained negative during the time of migration (3-7 days) of SMCs into the intima, it is unlikely that infected intimal SMCs represent medial SMCs that had been infected before migration (or intimal SMCs, infected by such medial SMCs). It is laypothesized that infection might have taken place by circulating infected blood cells at later times. These data strongly suggest that the arterial media, in contrast to the neointima, is not a preferential site for active CMV infection.

In essence, the studies that are presented in thesis, confirm our hypothesis that CMV induces vascular changes at different levels and of different nature and that vascular involvement is of basic importance in CMV pathology.

The most characteristic findings and their possible clinical relevances are recounted hereafter.

-Active RCMV infection of endothelial cells was found, but only of endothelial cells from microvascular origin.

-RCMV was found to enhance neointima formation and neointimal influx and/or proliferation of SMCs, as well as adventitial inflammatory infiltration, but only under allo-immune conditions.

- Neointimal SMCs of larger arteries proved to be highly preferential sites for active RCMV infection, but only when they are in a dedifferentiated/proliferating state and in the absence of intact endothelium. 
-Infection was found not to be necessarily present for RCMV to influence cellular behaviour, supporting possible mediation by factors, like cytokines and growth factors in such RCMV induced cellular effects.

With respect to microvascular involvement, it was shown that CMV induced endothelial activation and damage may initiate disseminated intra-organ vascular pathology and coagulopathy that manifest CMV disease.

Concerning RCMV enhanced events in aorta allografts, these findings are fully compatible with clinical associations that have been found between CMV infection and enhanced allograft rejection with accelerated graft arteriosclerosis. They underline the causative nature of such associations.

The clinical relevance of dedifferentiated/proliferating intimal SMCs being highly susceptible to active CMV infection, is less clear. However, the finding has a lot of potential, since SMCs in such a phenotypic state are present in the intima of vascular pathologies, such as atheromatous plaques, post-angioplasty arteries, as well as in arterial grafts. In which way(s) active CMV infection of these cells, or reactivation of latently present CMV under certain local conditions, may contribute to the pathogenesis of such lesions, needs to be further elucidated. 


\section{Samenvatting}

Hart- en vaatziekten vormen nog steeds de voornaamste doodsoorzaak in de westerse wereld en atherosclerose neemt hierbij verreweg de belangrijkste plaats in. Door de jaren heen zijn verschillende infectieuze agentia genoemd als potentiële causale factoren in het ontstaan van atherosclerose. Met name cytomegalovirus (CMV), een herpesvirus, is frequent geassocieerd met atherosclerotische lesies en samen met de bacterie Chlamydia pneumoniae- is dit virus de meest serieuze kandidaat gebleken voor een causale of bijdragende rol van infectie aan het chronische proces dat atherosclerose is. CMV is wereldwijd een veel voorkomende verwekker van infecties $50-80 \%$ van de mensen in de algemene populatie heeft specifieke antistoffen tegen CMV-, echter, bij mensen met een normale immunologische weerstand verlopen deze infecties over het algemeen asymptomatisch. Anders ligt het in geval er sprake is van een verminderde immunologische afweer. In AIDS patiënten en ontvangers van orgaantransplantaten is CMV een beruchte, oorzaak van ernstige en dikwijls fataal verlopende infecties. CMV geinduceerde pathologie in deze patiënten is uiteenlopend van aard en betreft vaak meerdere organen. Vasculaire veranderingen zijn herhaaldelijk beschreven onderdeel uit te maken van dergelijke pathologie. Gebaseerd op onze hypothese dat vasculaire betrokkenheid van wezenlijk belang is in CMV geïnduceerde pathologie, zijn de studies die in dit proefschrift beschreven worden gericht op mogelijke interacties van CMV met grote en middelgrote arteriën en met de microvasculatuur, alsmede op de klinische relevantie van clergelijke interacties.

Hoofdstuk I begint met enige algemene aspecten van atherosclerotische lesies en het ontstaan hiervan. Vervolgens wordt de mogelijke rol die infectieuze agenta hierbij kunnen spelen, bediscussieerd. Het belangrijkste deel van dit hoofdstuk betreft een overzicht van de bestaande literatuur waarin gevonden associaties worden beschreven van CMV met atherosclerose en andere vasculaire pathologische veranderingen. Tot slot worden hypotheses en daaruit resulterende doelstellingen van de onderzoeken die beschreven worden in dit proefschrift, uiteengezet.

Hoofdstuk 2 beschrijft de onderzoeken in rattenmodellen van gelocaliseerde en gegeneraliseerde CMV infectie, waarbij gebruik gemaakt werd van een rat-specifiek CMV (RCMV). Beide modellen leverden bewijzen voor uitgebreide microvasculaire betrokkenheid in CMV geassocieerde pathologie, welke gemanifesteerd wordt door activatie en infectie van microvasculair endotheel, vasculitis, thrombotische afsluitingen en bloedingen. Verlengde bloedingstijden en lage concentraties van stollingsfactoren en thrombocyten tijdens gegeneraliseerde CMV infectie ondersteunen het bestaan van diffuus intravasculaire stolling. De aard en chronologie van RCMV 
geinduceerde vasculaire pathologische veranderingen worden getoond, en indiceren het belang van (microvasculaire) endotheelactivatie en schade tijdens gegeneraliseerde CMV infectie.

In hoofdstuk 3 wordt het gebruik van een model van allogene (abdominale) aortatransplantatie in ratten beschreven, in een studie naar de effecten van CMV op transplantatie geassocieerde arteriosclerose. Toediening van RCMV, drie weken na de transplantatie, wanneer proliferatie van gladde spiercellen in de zich vormende neointìma en infiltratie van ontstekingscellen in de adventitia maximaal zijn, resulteerde zowel in een toename van neointimadikte, als in een toegenomen aantal neointimale gladde spiercellen. Bovendien was er in de met RCMV geïnfecteerde ratten sprake van een duidelijk toegenomen infiltratie van mononucleaire cellen in de adventitia. Met uitzondering van een sporadisch RCMV geïnfecteerde cel in de adventitia, werd actieve infectie nooit waargenomen in de neointima of media. De door RCMV geïnduceerde effecten werden niet gezien in syngene aortatransplantaten en werden in de allogene transplantaten volledig voorkomen door het vooraf toedienen van (S)-1-(3-hydroxy-2-phosphonylmethoxypropyl)cytosine (HPMPC), een acyclisch nucleoside analoog met een zeer effectieve en selectieve activiteit tegen CMV. De resultaten van deze studie wijzen erop dat CMV alloimmunologische reacties in het transplantaat stimuleert, wat zich manifesteert in een toename van 'atherosclerotische' veranderingen.

Gladde spiercellen zijn belangrijke deelnemers aan atherosclerotische processen en hoewel bij herhaling genoemd als potentiële 'target'cellen woor CMV infectie, is actieve CMV infectie van gladde spiercellen in vivo nog niet eerder beschreven. Hoofdstuk 4 betreft een studie die gedaan is naar de gevoeligheid van mediale en neointimale gladde spiercellen in vivo, voor acute CMV infectie. Hierbij werd gebruik gemaakt van een balloncatheterisatiemodel in ratten (een bekend model in onderzoek naar aspecten van neointimavorming). In zowel immunocompetente als immunogecompromiteerde ratten werd de linker arteria carotis communis gecatheteriseerd, waarbij over een traject van de vaatwand, endotheel 'gestript' werd.. Twee weken nadien, wanneer zich in respons op deze mechanische beschadiging een neointima had gevormd en het niveau van proliferatie van intimale gladde spiercellen nog steeds sterk verhoogd was, werden ratten intraveneus geïnfecteerd met RCMV. Twee weken na infectie werd in de immunogecompromiteerde ratten een massale actieve RCMV infectie gezien van de binnenste (aan het lumen grenzende) laag van de neointima. Deze infectie manifesteerde zich in de aanwezigheid van voor CMV typische kerninsluitsels, alsmede van virale (vroege) antigenen en viraal DNA in kern en cytoplasma van intimale cellen, terwijl bovendien het virus zelf met behulp van electronenmicroscopie in deze cellen zichtbaar gemaakt kon worden. De geïnfecteerde cellen betroffen vrijwel allemaal gladde spiercellen, zoals aangetoond met antilichamen tegen gladde spiercel $\alpha$-actine en met electronenmicroscopie. Daar waar reëndothelialisatie had plaats gevonden, werd geen infectie van de onderliggende gladde spiercellen gezien en geünfecteerde cellen werden eveneens nooit waargenomen in de media. Verder bleek er, met uitzondering van de speekselklieren, geen actieve 
RCMV infectie aanwezig in de organen. RCMV had geen significant effect op neointima- en mediaoppervlakte. De bevindingen in deze studie laten zien dat neointimale gladde spiercellen in vivo in hoge mate gevoelig zijn voor actieve infectie door CMV.

In de studie die wordt beschreven in hoofdstuk 5, werd onderzocht of neointimale RCMV infectie, welke optreedt na beschadiging van de arteriële vaatwand, in arteriële veranderingen op de lange termijn resulteert. Bovendien werd onderzocht of het fenotype van de intimale gladde spiercel mogelijk van invloed is op diens gevoeligheid voor actieve CMV infectie, daar er tot op dat moment slechts infectie van intimale gladde spiercellen gevonden was, ten tijde van verhoogde proliferatie, terwijl infectie van mediale gladde spiercellen nog nooit was aangetoond.

Met betrekking tot de eerste vraag, ontvingen ratten RCMV weer twee weken na het toebrengen van schade aan de vaarwand van de a. carotis. $\mathrm{Na} 20$ weken werden geen significante door RCMV geïnduceerde verschillen in dikte van neointima en media gevonden en was het niveau van gladde spiercelproliferatie in de neointima genormaliseerd, zoals kon worden afgeleid uit DNA incorporatie van toegediend bromodeoxyuridine. Bovendien werden er geen tekenen van actieve infectie meer gezien.

Met betrekking tot de tweede onderzoekswraag, werd RCMV acht weken na de ballonschade toegediend. Op dat tijdstip is het fenotype van gladde spiercellen in de neointima veranderd van een overwegend 'synthetisch' (gededifferentieerd) fenotype in een meer 'contractiel' (ge(re-)differentieerd) fenotype, wat bevestigd werd door immunohistochemische kleuring van $\alpha$-actine, desmine en vimentine in de neointima. Twee weken na RCMV toediening werden geen tekenen van actieve infectie gezien in de intima of media. Deze bevindingen suggereren dat het fenotype van de intimale gladde spiercel bepalend is voor diens gevoeligheid voor actieve infectie door CMV. Omdat dedifferentiatie geassocieerd is met verhoogde proliferatie van intimale gladde spiercellen, is de conclusie dat dedifferentiatie en/of proliferatie voorwaarde(n) zijn voor actieve CMV infectie.

Hoofdstuk 6 beschrijft een studie naar de gevoeligheid van mediale gladde spiercellen voor actieve CMV infectie. RCMV werd in deze studie in een vroeg stadium (drie dagen) na balloncathererisatie van de a. carotis toegediend, in de periode van verhoogde dedifferentiatie en proliferatie van gladde spiercellen in de media. Twee en vier dagen na infectie werden er in de media, noch in de neointima welke zich op dat moment juist begon te ontwikkelen, RCMV antigenen of andere bewijzen van actieve infectie gezien. Twee weken na infectie werden in de neointima van $50 \%$ van de ratten sporadisch solitaire cellen en/of kleine clusters van cellen waargenomen die RCMV antigenen bleken te bevatten. In de media echter werden nooit geïnfecteerde cellen gedetecteerd. Omdat de media gedurende de periode van migratie (3-7 dagen na balloncatheterisatie) RCMV negatief is gebleven, is het zeer onwaarschijnlijk dat de RCMV positieve cellen in de intima, mediale gladde spiercellen betreffen, welke vóór migratie naar de intima geüfecteerd zijn (of intimale gladde spiercellen die door zulke mediale cellen geïnfecteerd zijn). De hypothese is dat infectie van intimale gladde 
spiercellen heeft plaats gevonden via circulerende geïnfecteerde cellen, in een later stadium na infectie. Deze data suggereren sterk dat de arteriële media, in tegenstelling tot de neointima, geen voorkeursplaats is voor actieve CMV infectie.

In essentie bevestigen de studies die in dit proefschrift gepresenteerd worden, onze vooraf bestaande hypothese dat CMV vasculaire veranderingen induceert op verschillende niveaus en van verschillende aard en dat dergelijke veranderingen van fundamentele betekenis zijn in CMV geînduceerde pathologie.

De meest karakteristieke bevindingen, alsmede de mogelijke klinische relevanties ervan, worden hierna nog eens op een rij gezet.

- Actieve RCMV infectie van endotheliale cellen is aangetoond, doch alleen van microvasculair endotheel.

- RCMV stimuleert zowel de vorming van een neointima en intima-influx en/of proliferatie van intimale gladde spiercellen, als infiltratie van inflammatoire cellen in de adventitia, doch alleen onder allo-immune condities.

- Neointimale gladde spiercellen zijn gebleken voorkeurscellen te zijn voor actieve RCMV infectie, doch alleen indien zij in een gededifferentieerde en/of prolifererende staat verkeren en in de afwezigheid van intact endotheel.

- Infectie bleek niet persé noodzakelijk voor RCMV om het gedrag van cellen te beinvloeden, wat een mogelijke rol voor cytokines en groeifactoren ondersteunt.

Wat betreft de microvasculaire veranderingen, is het aannemelijk gemaakt dat door CMV geïnduceerde endotheliale activatie en schade, vasculaire pathologie in organen en stollingsstoornissen initiëren, welke symptomatische CMV infecties kenmerken. De door RCMV gestimuleerde reacties in allogene aortatransplantaten passen bij de gevonden correlaties tussen CMV infectie en toegenomen transplantaatafstoting met versnelde arteriosclerose in ontvangers van allogene transplantaten. Zij onderstrepen een waarschijnlijk causaal karakter van dergelijke correlaties.

De klinische betekenis van het in hoge mate gevoelig zijn van gededifferentieerde / prolifererende intimale gladde spiercellen voor actieve CMV infectie is minder eenduidig, hoewel het een in dit opzicht mogelijk zeer interessante bevinding betreft. Gladde spiercellen met een dergelijk fenotype zijn immers aanwezig in de intima van arteriële lesies, zoals atheromateuze plaques, 'gedotterde' arteriële gebieden en getransplanteerde arteriën. Op welke wijze(n) actieve CMV infectie van deze cellen, en/of reactivatie van latent aanwezig CMV onder bepaalde locale condities, kan bijdragen aan de pathogenese van dergelijke lesies, verdient vervolgonderzoek. 


\section{Nawoord}

Mij er -uit eigen ervaring-van bewust zijnde dat het nawoord, voor vele mensen die dit boekje zullen ontvangen, tot de weinige bladzijden behoort die werkelijk gelezen zullen worden, begin ik aan één van de laatste 'klusjes' voor dit proefschrift dat na een periode van negen jaar dan toch eindelijk tot stand (b)lijkt te komen. Vooral juist het feit dat dit alles negen jaar geleden een aanvang kende, maakt dat ik me realiseer niet bepaald voor een simpel klusje te staan. Zóveel mensen die op meerdere plaatsen, verschillende momenten en verschillende wijze in de betreffende tijdspanne iets voor mij hebben betekend met betrekking tot dit boekje en/of het werk dat er in beschreven staat. Een aantal namen wil ik hier noemen, waarbij ik een zekere chronologie zal trachten te handhaven.

De vacature. Nancy, wanneer jij geen Volkskrant gehad zou hebben in dat bewuste paasweekend dat ik bij je verbleef in Schimmert, zou ik -bezig met een keuze co-schap en me juist beginnende af te vragen wat ik zou willen met mijn toekomst- het lezen van de bestaande vacatures in de gezondheidszorg in de betreffende krant een weekje hebben overgeslagen. Bedankt dus hiervoor, want ik ben "best aardig" terecht gekomen. Bedanken wil ik je hier dan ook maar meteen voor de vele gezamenlijke loopuurtjes door het Limburgse heuvelland, "s avonds -een enkele keer zelfs tussen de middag- vanaf het BMC, of in het weekend vanaf je boerderij. Heel karakteristiek voor met name die eerste AIO jaren, lopen was zonder twijfel een belangrijke factor in mijn geestelijk welbevinden en werkplezier. Goede herinneringen bewaar ik ook aan de vele gesprekken over werk en andere 'zaken des levens' die wij plachten te voeren tijdens onze duurlopen.

De aansielling. Prof. dr. CPA van Boven, Cees, jij hebt mij indertijd aangenomen en hoewel jij nooit de degene bent geweest die richting gaf aan mijn onderzoek en naar Leiden vertrok op het moment dat ik in opleiding ging (geen causale relatie!), schept dat toch een blijvende band. Wij zijn elkaar natuurlijk nog regelmatig tegen gekonen. en daarbij durfde je het altijd aan naar de voortgang van mijn boekje te informeren. Jouw zitting in de beoordelingscommissie was voor mij iets vanzelfsprekends en ik ben dan ook blij dat je dit hebt willen doen.

Het onderzoek. Prof. dr CA Bruggeman, Cathrien, natuurlijk had jij alles met die aanstelling te maken, als 'baas' van al het CMV onderzoek dat binnen de vakgroep plaats vindt. $\mathrm{Jij}$ bent echter in deze hoedanigheid voor mij vooral degene die in belangrijke mate bepalend is geweest voor de inhoud en het verloop van het onderzoek dat de basis vormt voor dit proefschrift. Hoewel, inherent aan het werken met proefdieren, resultaten vaak lang of voorgoed uitbleven en ideeên dikwijls bijgesteld dienden te worden, denk ik dat we er uiteindelijk toch in geslaagd zijn er een erg leuk geheel van te maken. Ik kan je er alleen maar dankbaar voor zijn tijdens mijn opleiding druk te zijn blijven zetten achter de voortgang en mij, toen er zo'n $300 \mathrm{~km}$ en een full- 
time baan tussen ons in kwam, in telefoongesprekken en tijdens mijn spaarzame bezoekjes, wist te stimuleren en ervan te owertuigen alles tot een goed einde te kunnem brengen.

Analiste van het eerste uur is Selma Herngreen. Selma, hoeveel uren hebben we niet coupes gesneden, ratten geinfecteerd, geperfuseerd, bestraald, coupes gekleurd, gehybridiseerd? Je thebt zelfs een "inteme" spoedopleiding EM genoten bij Paul. Jouw werk en wriendschap vommen een wezenlijk onderdeel van mijn tijd Maastricht. Analiste van het tweede wur is Martine Hulscher. Martine, jij was mijn grote toeverlaat op het moment dat ik reeds in opleiding was en niet langer mijn volledige dagen op het virologielab steet. Coupes van gedenudeerde rattencarotiden, maar vooral van. rattenpootjes, ik weet zeker dat er een tijd geweest is dat je ze niet meer wenste te zien.... De herinnering aan jouw inzet, zakelijk organisatievermogen en (ont-) yuchter(end) kijk op dingen zijn mij dierbaar.

Analiste tenslotte van het laatste uur, Gert Grauls. Gert. jij had "de eer" mij bij mijn sollicitatie door de proefdierstallen (toen nog BMC) rond te mogen leiden en ja, ik dacht werkelijk dat alle ratten naar jou vernoemd waren.

Omdat je pas terugkeerde op het research virologielab tegen het einde van mijn verblijf in Maastricht, raakte je relatief laat betrokken bij mijn werk. De "afrondingsfase" is echter de langste fase gebleken en betreft de fase waarin jij heel belangrijk voor mij geweest bent. Jouw ervaring, werkvermogen en overzicht over alles wat er op de afdeling gaande is, is van onschatbare waarde geweest. Met een kopie van de administratie van mijn experimenten in jouw bezit en alle paraffineblokjes en coupes systematisch opgeborgen en gedocumenteerd, heb je nog de nodige metingen en kleuringen verricht en foto's gemaakt, wanneer ik je daar vanuit Emmen om vroeg. Helaas een tulpenjurkje zit er, denk ik, eind oktober niet meer in (?), maar jij zult met mij blij zijn dat het eind dan toch bereikt is.

Prof. dr. MJAP Daemen. Mat, waar jou in deze min of meer chronologische terugblik te plaatsen? Al in een vrij vroeg stadium lowam ik via jou tot de zogenaamde denudatie-experimenten, welke mij uiteindelijk drie van de wijf artikelen hebben opgeleverd. Hoewel je mij persoonlijk de beginselen wan deze arteriêle balloncatheterisatie in ratten hebt eigen gemaakt, zijn de grote series denudaties verricht door Carolien Eerdmans-Thijssen, Edwin Beukers, Ellen van Kleef -die ik hiervoor bij deze allemaal nog eens wil bedanken-, alsmede door jou. Jouw onderzoekservaring, scherpe kijk op dingen en 'no-nonsense' attitude hebben de experimenten in belangrijke mate mede gevormd. Je windt me (soms) eigenwijs, ik jou ook, het heeft denk ik tot een goede samenwerking geleid. Misschien nog wel het meest in je gewardeerd heb ik je nuttige, kritische commentaar bij het schrijven van mijn artikelen en met name, in een later stadium, van dit proefschrift. Op een uiterst. heldere wijze weet je een ander tot de kem(en) van de zaak te laten doordringen. Jouw nuchtere "Je bent eigenlijk al zo goed als klaar" heeft mij eigenlijk het licht doen zien en het schrijven in een 'stroomversnelling' gebracht, al zul jij waarschijnlijk vinden dat het alletmaal nog veel sneller gekund had.

In de context van mijn onderzoeken (en ook daarbuiten) heb ik altijd veel gastvrijheid genoten bij andere vakgroepen. Bij de pathologie was ik kind aan huis. Snijden van wries- en paraffine coupes (zelfs toen we over eigen microtomen beschikten) en het 
doorvoeren en inbedden van orgaanbiopten, waren bijna dagelijks terugkerende werkzaamheden. Het 'lab van Edith" (van der Linden), werd door mij dan ook veelvuldig bezocht en ik ben door Edith, doch ook door de andere mensen van de pathologie altijd vriendschappelijk en zeer behulpzaam bejegend met nane in het verkrijgen van mono-/polyclonalen en informatie omtrent kleuringen.

Thuis was ik ook bij de anatomie. Van de uitsnijruimte, inclusief apparatuur, aldaar heb ik zeer vaak gebruik gemaakt. De $-80^{\circ} \mathrm{C}$ was voor een groot deel gevuld met mijn materiaal (ik kan nu eenmaal niets weggooien). Nooit deed ik tevergeefs beroep op de gastvrijheid of behulpzaamheid van Johan, Els en met name van Paul (van Dijk). Paul, je leerde me via het hart (in de rat) perfusies uit te voeren, popliteale lymfekliertjes opzoeken, je hebt zelfs rattenpootjes voor mij ontkalkt in mierenzuur en daar röntgenfoto's van gemaakt. Bovendien betreft mijn mooiste foto -en in leder geval één van de mooiste foto's van onze vakgroep-een bij jullie in plastic ingebedde en met toluiddine blauw gekleurde geïnfecteerde venule (zie omslag van dit proefschrift). Tenslotte, je verhalen -en dia's- van je belevenissen in de oerwouden van Frans Guinea (en Costa Rica!) waren fantastisch.

Wanneer experimenten 'liepen', was er mijn vrijwel dagelijkse gang naar de centrale proefdiervoorziening (CPV), onder leiding van Ton van den Bogaard.. Met 'de jongens' aldaar kon ik lezen en schrijven. Frans, Peter, Eep, bedankt voor jullie medewerking wanneer ik weer eens met hopeloze bestellingen aan kwam zetten en voor jullie huip wanneer nodig. Bedankt ook alle andere medewerkers voor de prettige samenwerking en de goede zorgen voor "mijn dieren".

Een apart verhaal, want wel heel letterlijk een stukje thuis geworden, is natuurlijk de EM (electronen microscopie). Mijn bezoekjes aan deze afdeling hebben zeer verstrekkende gevolgen gekregen.... Met mijn kennismaking met elektronenmicroscopie ontvouwde zich werkelijk een andere wereld voor mij. Peter, Paul, Jos en natuurlijk Marc, maar jij komt elders nog uitgebreid aan bod, jullie ontvangst was altijd warm, de behulpzaamheid zonder grenzen. Zonder grenzen leek ook de koelkast, heb ik je ooit laten weten dat je alles wat er van mij nog rest in de koelkast kunt weggooien, Paul? Ik zal wel niet meer komen inbedden, maar wie weet nog wel eens plaats nemen achter de CMlo.

Bedanken wil ik ook Ad Duyvenstein en (in een later stadium) Jan Damoiseaux van de vakgroep immunologie voor het regelmatig verstrekken van EDI en W3/13.

Terug bij mijn eigen (toenmalige) vakgroep. Een aantal mensen daarbinnen behoren hier nog zeker genoemd te worden. Wil Mullers, altijd bescheiden ('sorry'), van grote waarde bij het maken van grafieken en statistische verwerking van experimentele gegevens en altijd wel open voor een roddeltje, toch? Wil, je bent voor mij een van de boegbeelden van de afdeling en ik heb onze momenten van samenwerking als heel plezierig ervaren. Peter Dormans, ook jou beschouwde ik als een soort nestor binnen de research van de afdeling en volgens mij voelde jij je ook zo, wanneer er zich weer zo'n nieuwe (arts-)onderzoeker aanmeldde die jou op je ervaring aansprak en je wat inhoudsdeskundige informatie omtrent bepaalde technieken probeerde te ontfutselen. Frans Stals, zeker ook een markante figuur op de afdeling. Toen ik in Maastricht kwam, was je in je laatste jaar van de opleiding en juist gestart met het onderzoek dat uiteindelijk resulteerde in je proefschrift. Mijn eerste weken (of waren het maanden?) 
heb ik wat met je mee "gehuppeld" om de eerste beginselen van het proefdierwerk af te kijken. Je was altijd heel enthousiast en vol nieuwe ideeën. Jouw optimisme was aanstekelijk en gaf dikwijls enig nieuw vertrouwen in lopende en komende zaken. Het heeft ook tot de opzet van het tweede artikel in dit proefschrift geleid.

Ron Hendrix en 'Yvette Kraat, mijn 'kompanen' in de opleiding en ook bezig met (CMV!) promotieonderzoek. Wij hebben verschillende kamers gedeeld in de loop der jaren. Ron, je was een beetje onze 'grote broer' en effenaar wan meerdere paden binnen onderzoek en opleiding. Moet niet altijd makkelijk ('understatement?') geweest zijn, twee van die giechelende meiden om je heen. Yvette, hoewel onze onderzoeken totaal verschillend van elkaar waren, gingen onze wegen (in onderzoek en opleiding) grotendeels gelijk op en waren we dikwijls op elkaar aangewezen. Het nodige lief en leed werd gedeeld. Dat schept een band. Ik ben blij dat we beiden ook straks het onderzoeksgedeelte met een promotie bekroond zullen zien.

Het secretariaat. Tijdens mijn tijd in Maastricht waren daar Fia, Lidwine en Rési, die mede de sfeer op de afdeling (in positieve zin) bepaalden, mij altijd aclequaat en goedgemutst ter wille waren en regelmatig bezocht werden voor een praatje, zeker in de tijd dat we directe buren waren. Na mijn vertrek was daar nog steeds Fia en bovendien José, Angèle en Patricia, waarmee een regelmatig telefoon-, fax- en, niet te vergeten, $\mathrm{E}$ - mail verkeer in stand gehouden werd.

Frank van Tiel, mijn opleider. Frank, je kreeg ons plotsklaps in je schoot geworpen en diende er (van ons dus) maar het beste van te maken. Dat moet je de nodige grijze haren bezorgd hebben, want je hebt dit vanaf het begin zeer serieus genomen en als een grote verantwoordelijkheid gezien. Je was altijd geïnteresseerd en motiveerde ons ook zeker in het afronden van ons onderzoek.

Alle overige medewerkers van de vakgroep, de virologische diagnostiek en, niet te vergeten, het baclab wil ik hier bedanken voor de fijne samenwerking en voor de gezelligheid en de vriendschap die ik heb mogen ondervinden.

Vóór ik de Maastrichtse periode verlaat, moet ik andere belangrijke medewerkers memoreren; de ratten die aan de onderzoeken meegedaan hebben. Het viel mij aanvankelijk zeer hard met proefdieren te moeten werken en vervolgens viel het me van mezelf tegen deze weerstand zo snel onderdrukt te hebben. Hoe dan ook, ik ben het aan hen toch ook wel verplicht geweest het tot een promotie te laten komen.

Het boekje. Van mijn na-Maastrichtse tijd wil ik me in de eerste plaats richten tot mijn naaste collega, mijn 'maatje', Ton van $Z$ wet. Ton, vanaf het allereerste begin heb jij me te kennen gegeven het erg belangrijk te vinden een 'doctor' in Drenthe naast je te hebben. Jouw enthousiasme en gedrevenheid in je werk, werkte echter synergistisch met vergelijkbare eigenschappen in mij en maakte dat mijn proefschrift vaak naar de achtergrond geschoven werd. Toch heb ik regelmatig de gelegenheid die jij me gaf om thuis te werken terwijl jij de honneurs waarnam, benut. Jouw motivatie alles door te zetten is, denk ik, belangrijker geweest dan jij vermoedt.

Ook René (Benne) wil ik bedanken voor zijn hulp, door waarneming, in de allerlaatste fase.

De meisjes en -inmiddels ook- jongens van 'mijn' labs wil ik bedanken voor de flexibiliteit waarmee altijd op mijn dikwijls instant gewijzigde plannen voor de dag 
gereageerd werd. Heleen (Feikens), omdat ik bij jou altijd alles in goede handen wist, ervan overtuigd was dat alle -mogelijk- belangrijke zaken mij zouden bereiken en omdat je me soms letterlijk weg stuurde, heb ik uiteindelijk toch menig extra uurtje aan dit proefschrift kunnen werken.

Onze oppassen in Maastricht (Yvonne) en Emmen (Hennie), zijn met hun flexibiliteit in de opvang van onze jongens, in deze ook van groot belang geweest.

Collega's in mijn beide ziekenhuizen, alsmede binnen het Streeklaboratorium hebben altijd interesse en waardering getoond voor een 'op handen zijnde' promotie. Ook dit werkte stimulerend (niet in de laatste plaats in verband met geloofwaardigheid....).

Een woord tenslotte tot de mensen die me het meest na staan en dus ook alles te maken hebben met dit boekje.

Mijn ouders. Het valt niet te beschrijven wat jullie voor mij hebben betekend en betekenen. Jullie hebben ons altijd alle kansen gegeven, op alle fronten gestimuleerd en jezelf op het tweede plan gesteld. Ik wil jullie laten weten dit absoluut niet als vanzelfsprekend te hebben beschouwd. Ik weet dat jullie trots op me zijn. Ik ben trots op mijn ouders en dit boekje is daar een symbool voor.

Marc. Wat moet ik zeggen? Twee boekjes, eindelijk dan toch. De druk tot afronding te komen is voor jou nog groter geweest dan voor mij, de opluchting, hoop ik, navenant. Ik voel trots en bewondering voor de wijze waarop je dit voor elkaar gekregen hebt. Het was hectisch, maar 'rustig' zal ons leven toch niet worden en dat is prima. (Hoewel een beetje meer slaap wel wenselijk is). De laatste maanden hebben we elkaar beurtelings moeten oppeppen, maar vooral het samenzijn met de kinderen werkte meestal heerlijk ontnuchterend. We hebben onze jongens, vind ik, deze jaren toch heel. veel aandacht kunnen geven en volop van hen genoten. Daarover hoeven we dus nooit spijt te hebben. Dank voor alles, je liefde, je zorgen, de lay-out van dit proefschrift. Tijmen en Merijn, een onweerstaanbaar koppel, jullie maken het ons steeds makkelijk het belang van een groot aantal zaken te kunnen relativeren.

Het jonge leventje in mij. Hoewel fysiek niet altijd even comfortabel, ervaar ik het als heel bijzonder met jou bij mij dit boekje te hebben afgerond en straks samen in de aula te staan. Hierna kunnen wij ons echt op jouw komst gaan richten.

Aan het einde van dit nawoord gekomen -dat inmiddels zo lang geworden is dat het wellicht toch door weinigen gelezen gaat worden-, wil ik de leden van de beoordelingscommissie bedanken voor het lezen van dit proefschrift en hun positieve beoordeling ervan. 



\section{Curriculum vitae}

Maike Persoons werd geboren op 24 juli 1963 te Utrecht. Na het behalen van het VWO diploma aan het Ashram College in Alphen aan de Rijn en een jaar studie psychologie aan de Rijksuniversiteit Leiden, begon zij in augustus 1982 met de studie geneeskunde aan deze universiteit. In april 1989 verkreeg zij haar arts-diploma, waarna ze in oktober van dat jaar in dienst trad van de Rijksuniversiteit Limburg in verband met een gecombineerde assistent in opleiding/assistent geneeskunde in opleiding (AIO/AGIO) aanstelling bij de vakgroep medische microbiologie (prof. dr CPA van Boven). Onder leiding van dr. CA Bruggeman (vanaf 1994 hoogleraar virologie) werd begonnen met onderzoek dat de basis vormt voor dit proefschrift. In 1991 startte de schrijfster van dit proefschrift met de opleiding tot arts-microbioloog, in het academisch ziekenhuis Maastricht (opleider dr. FW van Tiel). In augustus 1995 werd deze opleiding voltooid en in november van dat jaar trad zij in dienst van het Streeklaboratorium voor de Volksgezondheid voor Groningen en Drenthe. Vanaf die tijd is zij als artsmicrobioloog werkzaam in het Scheper ziekenhuis te Emmen en het Streekziekenhuis Coevorden/Hardenberg te Hardenberg. Maike Persoons is getrouwd en moeder van twee zoontjes en verwacht begin december de geboorte van haar derde kindje. 



\section{List of publications}

Neyts J, Stals FS, Atherton S, Persoons MCJ, Bruggeman CA, De Clercq E. Efficacy of HPMPC in the treatment of CMV infections in various animal models. In; multidisciplinary approach to understanding cytomegalovirus disease. 1993;279-285. Michelson S, Plotkin SA, eds. Elsevier Science Publishers B.V., Amsterdam, New York.

Lemstrom K, Persaons M, Bruggeman C, Ustinov J, Lautenschlager I, Hayry P. Cytomegalovirus infection enhances allograft arteriosclerosis in the rat. Transplant Proc. 1993;25:1406-1407.

Persoons MCJ, Daemen MJAP, Bruning JH, Bruggeman CA. Active cytomegalovirus infection of arterial smooth muscle cells in immunocompromised rats. A clue to herpesvirusassociated atherogenesis? Circ Res. 1994;75:214-220.

Bruning JH, Persoons MCJ, Lemström K, Stalls FS, de Clerq E, Bruggeman CA. Enhancement of transplantation-associated atherosclerosis by $\mathrm{CMV}$, which can be prevented by antiviral therapy in the form of HPMPC. Transplant International 1994;7 [Suppl.1]: S365-S370.

Kellens J, Persoons M CJ, Vaneechoutte M, van Tiel F, Stobberingh E. Evidence of lectinmediated adherence of Moraxella catarrhalis. Infection. 1995;23:37-41.

Eerdmans PH, Persoons MCJ, Debets SJ, Struijker Boudier HA, Smits JF, Bruggeman CA, De Mey JG. Impaired arterial reactivity following cytomegalovirus infection in the immunosuppressed rat. Br J Pharmacol. 1996;1 19:637-646.

Vossen RCRM, Persoons MCJ, Slobbe-van Drunen MEP, Bruggeman CA, van Dam-Mieras MCE. Intracellular thiol redox status affects rat cytomegalovirus infection of vascular cells. Virus Res. 1997;48:173-183.

Persoons MCJ, Daemen MJAP, van Kleef EM, Grauls GELM, Wijers E, Bruggeman CA. Neointimal smooth muscle cell phenotype is important in its susceptibility to cytomegalovirus (CMV) infection: a study in rat. Cardiovasc Res. 1997;36:282-288.

Persoons MC, J Stals FS, van dam Mieras MCE, Bruggeman CA. Multiple organ involvement during experimental cytomegalovirus infection is associated with disseminated vascular pathology. J Pathol 1998;184:103-109.

MCJ Persoons, MJAP Daemen, EM van Kleef, GELM Grauls, CA Bruggeman. Rat medial smooth muscle cells in vivo are not susceptible to active cytomegalovirus infection. (Submitted for publication). 